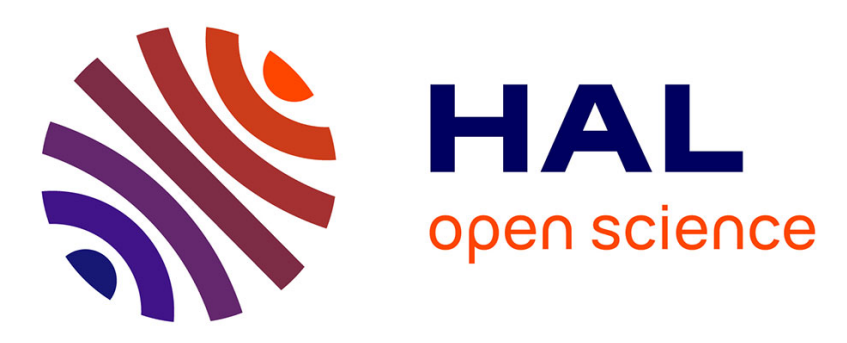

\title{
Recent advances in the understanding of Ni-based catalysts for the oxidation of hydrogen-containing fuels in alkaline media
}

Alexandr G Oshchepkov, Guillaume Braesch, Antoine Bonnefont, Elena R Savinova, Marian Chatenet

\section{To cite this version:}

Alexandr G Oshchepkov, Guillaume Braesch, Antoine Bonnefont, Elena R Savinova, Marian Chatenet. Recent advances in the understanding of Ni-based catalysts for the oxidation of hydrogen-containing fuels in alkaline media. ACS Catalysis, 2020, 10 (13), pp.7043-7068. 10.1021/acscatal.0c00101. hal-02953312

\section{HAL Id: hal-02953312 \\ https://hal.univ-grenoble-alpes.fr/hal-02953312}

Submitted on 30 Sep 2020

HAL is a multi-disciplinary open access archive for the deposit and dissemination of scientific research documents, whether they are published or not. The documents may come from teaching and research institutions in France or abroad, or from public or private research centers.
L'archive ouverte pluridisciplinaire HAL, est destinée au dépôt et à la diffusion de documents scientifiques de niveau recherche, publiés ou non, émanant des établissements d'enseignement et de recherche français ou étrangers, des laboratoires publics ou privés. 


\section{Recent advances in the understanding of Ni-based}

\section{catalysts for the oxidation of hydrogen-containing fuels}

\section{in alkaline media}

Alexandr G. Oshchepkov ${ }^{\dagger, *}$, Guillaume Braesch ${ }^{\dagger} \S$, Antoine Bonnefont ${ }^{\#}$, Elena R. Savinova ${ }^{\dagger}$, Marian Chatenet $^{\S, *}$

† Boreskov Institute of Catalysis SB RAS, 5 Lavrentiev Ave. 630090 Novosibirsk, Russia

$\ddagger$ Institut de Chimie et Procédés pour l’Energie, l’Environnement et la Santé, UMR 7515 CNRS-

University of Strasbourg, 25 rue Becquerel 67087 Strasbourg Cedex, France

$\S$ University Grenoble Alpes, University Savoie Mont Blanc, CNRS, Grenoble INP (Institute of engineering, University Grenoble Alpes), LEPMI, 38000 Grenoble, France

" Institut de Chimie de Strasbourg, UMR 7177 CNRS-University of Strasbourg, 4 rue Blaise Pascal 67070 Strasbourg, France 
KEYWORDS. Nickel, Hydrogen oxidation reaction (HOR), Borohydride Oxidation Reaction (BOR), Ammonia Borane Oxidation Reaction (ABOR), Hydrazine hydrate oxidation reaction (HHOR)

ABSTRACT.

Nickel is a very abundant transition metal in the Earth crust, and finds numerous applications in electrochemical processes where metallic $\mathrm{Ni}$ or its oxides are thermodynamically stable, particularly in alkaline environments. This contribution addresses electrocatalytic properties of Ni-based catalysts in reactions of fuel oxidation in alkaline media. It firstly details the electrochemical behavior of $\mathrm{Ni}$ in alkaline media and approaches to determine the active surface area of Ni electrodes. Secondly, the electrocatalytic activities of Ni-based electrocatalysts for the alkaline hydrogen oxidation reaction are described (an endeavor for the development of anion exchange membrane fuel cells), along with a detailed analysis of the strategies put forward to improve them. It is notably shown that the state of Ni surface (oxidized or reduced) largely determines its electrocatalytic activity. This state of the surface also conveys a pivotal importance regarding the activity of $\mathrm{Ni}$ for the oxidation of complex fuels (borohydride, boranes and hydrazine). Finally, emphasis is made on the durability of Ni-based catalysts in alkaline environments. It is shown that in such media, the materials durability of Ni-based electrodes can be high, but this does not necessarily warrant stable electrocatalytic activity, owing to possible deactivation following surface oxide or bulk hydride formation in operation. 


\section{Contents}

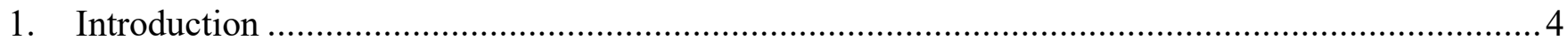

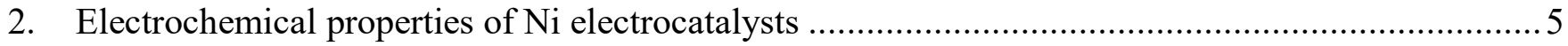

2.1. Electrochemical behavior of $\mathrm{Ni}$ in alkaline media ...............................................................

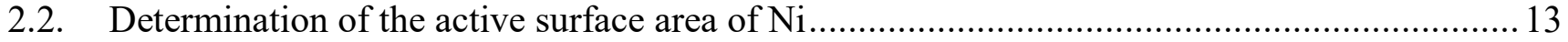

3. Electrocatalytic properties of Ni-based electrocatalysts in the HOR in alkaline media .................... 17

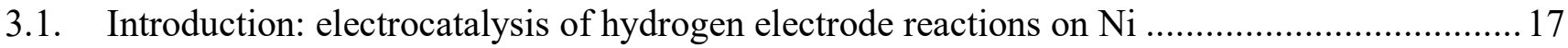

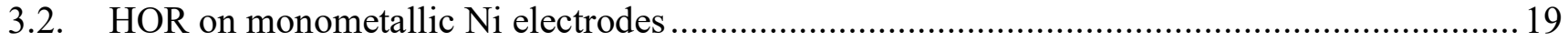

3.3. Strategies for improving the activity of $\mathrm{Ni}$ electrocatalysts in the HOR ...................................22

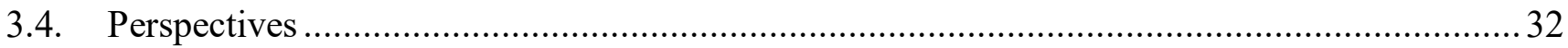

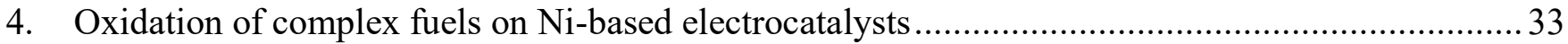

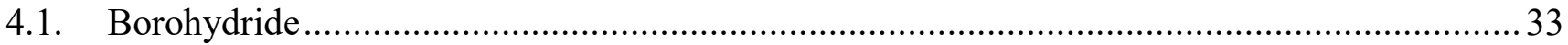

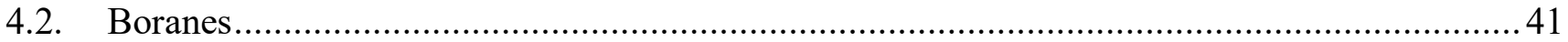

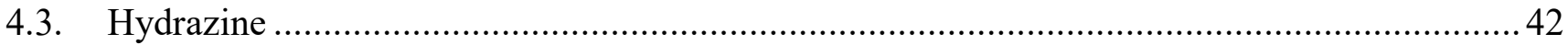

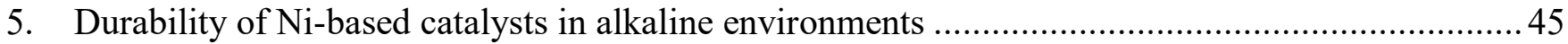

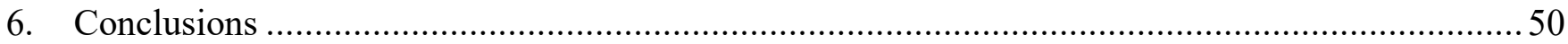




\section{Introduction}

Recent years have witnessed tremendous increase in the interest towards electrocatalysis in alkaline medium. This is largely due to the success in the development of more potent anion exchange membranes, but also to the desire to replace scarce and expensive noble metals by more abundant platinum group metal (PGM)-free materials in fuel and electrolysis cells. ${ }^{1-4} \mathrm{Ni}$ is a ubiquitous element widely applied in both heterogeneous catalysis and electrocatalysis due to its low cost, high abundance and high corrosion stability in alkaline media. ${ }^{5}$ In heterogeneous catalysis $\mathrm{Ni}$ is mostly used for hydrogenation and reforming of hydrocarbons, largely owing to its ability to dissociatively adsorb (similar to Pd and Pt) hydrogen providing $\mathrm{M}-\mathrm{H}_{\mathrm{ad}}$ active species, while being a much cheaper alternative. ${ }^{6} \mathrm{Ni}$ is indispensable in energy storage/conversion systems, such as batteries and electrochemical capacitors, ${ }^{7-9}$ Li-ion batteries, ${ }^{10,11}$ solar cells ${ }^{12}$ where it is used in the form of (oxy)hydroxides, simple and complex oxides. In electrocatalysis, Ni-based materials are used for catalyzing oxygen ${ }^{13-16}$ and hydrogen evolution ${ }^{17-19}$ reactions. Ni is also widely encountered as a current collector/substrate for catalyst' deposition (see e.g. Refs. ${ }^{20-22}$ ).

This review considers electrocatalytic properties of $\mathrm{Ni}$ as a promising anode material for fuel cells fed either with hydrogen or complex fuels (borohydride, boranes and hydrazine) in alkaline medium. We start by discussing electrochemical properties of $\mathrm{Ni}$ in alkaline medium. Under ambient conditions, $\mathrm{Ni}$ is prone to oxidation resulting in the formation of ca. 1-2 nm thick surface oxide layer composed of $\mathrm{NiO}$ and $\mathrm{Ni}(\mathrm{OH})_{2} \cdot{ }^{23-25}$ The presence of oxides on the Ni surface can greatly affect its catalytic properties, especially in low-temperature electrocatalysis, where, contrary to high temperature heterogeneous catalysis, their reduction may not be facile. Section 2.1. is devoted to the electrochemical oxidation of Ni in different potential intervals as well as hydrogen adsorption/absorption. Section 2.2. discusses the determination of the surface area of Ni electrocatalysts. This issue is of paramount importance for heterogeneous catalysis and electrocatalysis, since it forms the basis for benchmarking Ni-based electrocatalysts. Section 3 of the 
review summarizes recent advances in the understanding of electrocatalysis of the hydrogen oxidation reaction (HOR) on $\mathrm{Ni}$, with a specific emphasis on how it is affected by the surface state of $\mathrm{Ni}$. It considers the development of Ni and Ni-based electrocatalysts for the HOR and strategies used to prepare highly active materials for the anodes of alkaline fuel cells (AFC) and anion exchange membrane fuel cells (AEMFCs). Meanwhile, the hydrogen evolution reaction (HER) on Ni-based electrodes, which has been widely discussed and reviewed in the past ${ }^{17,18,26-28}$, is only briefly discussed, primarily in the potential region in the vicinity of the equilibrium potential of the hydrogen electrode, when it enters in competition with the oxidation of complex fuels. Section 4 is devoted to the oxidation of complex fuels, such as borohydride, boranes and hydrazine, which can be used in direct liquid fuel cells (DLFC). Finally, the stability issues of Ni-based electrocatalysts are briefly presented in Section 5.

\section{Electrochemical properties of Ni electrocatalysts}

\subsection{Electrochemical behavior of $\mathrm{Ni}$ in alkaline media}

Electrochemical properties of $\mathrm{Ni}$ electrodes have been widely studied since the beginning of the $\mathrm{XX}^{\text {th }}$ century, starting from the works of Emelianova, ${ }^{29}$ Frumkin et al., ${ }^{30,31}$ Conway et al., ${ }^{32-39}$ Breiter et al., ${ }^{40,41}$ Bockris and Potter ${ }^{42}$ as well as some others. The behavior of Ni in alkaline media has been recently summarized by the groups of MacDougall ${ }^{43,44}$ and Jerkiewicz, ${ }^{45-47}$ who discussed in detail various potential-dependent processes taking place on the surface of Ni electrodes. In addition, Oshchepkov et al. have recently pointed out to the influence of the surface state of Ni electrodes on their HOR/HER activity

in the potential interval $-0.2<E<0.5 \mathrm{~V} v s$ RHE. ${ }^{48-52}$ Below the most relevant information regarding electrochemistry of Ni electrodes in alkaline media is briefly summarized.

In order to facilitate the discussion about characteristic features of cyclic voltammograms (CVs) of a $\mathrm{Ni}$ electrode (Figure 1a) as well as its electrocatalytic properties in a number of oxidation reactions, it is 
convenient to mark out two potential intervals, depending on the reversibility of the Ni oxidation. The latter include the "low-potential region" at $-0.2<E \leq 0.5 \mathrm{~V} v$ S RHE, where the surface of a Ni electrode can be reversibly oxidized and reduced, and the "high-potential region" at $0.5<E<1.6 \mathrm{~V} v \mathrm{RHE}$, in which the formation of irreversible, passivating, Ni oxides occurs, the degree of irreversibility depending on the anodic potential limit. The high-potential region can be additionally split into two sub-regions, namely $0.5<E<1.2 \mathrm{~V} v s \mathrm{RHE}$ and $1.2<E<1.6 \mathrm{~V} v s$ RHE depending on the degree of Ni oxidation, as discussed further in the text. Below $E=0 \mathrm{~V} v s$ RHE and above ca. $E=1.5 \mathrm{~V} v s$ RHE the evolution of hydrogen and oxygen take place, respectively. In what follows, the processes taking place on Ni electrodes in the low- and the high-potential regions will be briefly discussed, mainly focusing on the former one, due to controversies existing in the literature.
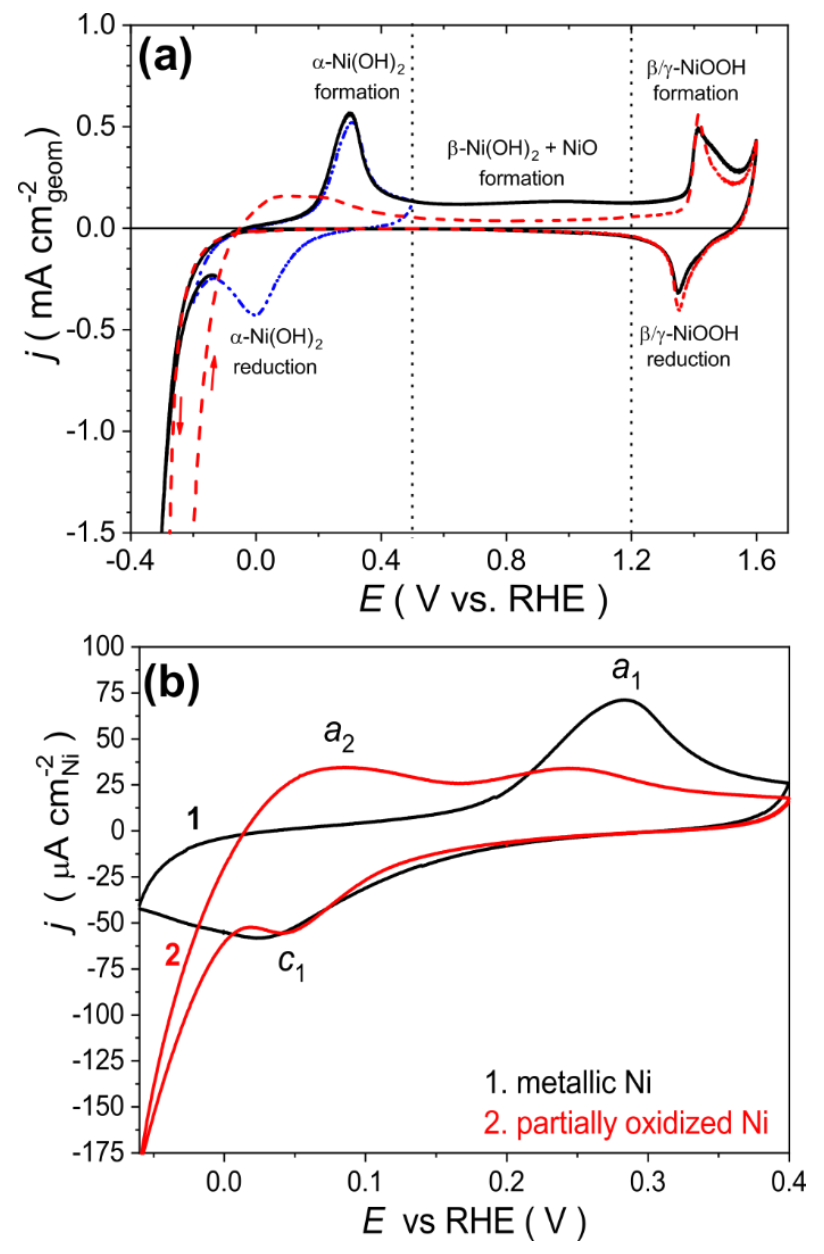
Figure 1. (a) CVs of a polycrystalline Ni electrode in $\mathrm{N}_{2}$-saturated $0.1 \mathrm{~mol} \mathrm{~L}^{-1} \mathrm{NaOH}$ at a sweep rate $v$ $=50 \mathrm{mV} \mathrm{s}^{-1}$ and $T=25^{\circ} \mathrm{C}$. The first $\mathrm{CV}$ in panel a (dash-dotted blue curve) covers the potential range from $E=-0.2$ to $0.5 V$ vs RHE, while two other CVs (first scan - solid black curve and second scan dashed red curve) cover the potential range from $E=-0.3$ to $1.6 \mathrm{~V} v \mathrm{~s} R \mathrm{E}$. The figure is inspired by some previous works ${ }^{47,53-56}$ (b) CVs obtained for metallic and partially oxidized polycrystalline Ni electrodes in $\mathrm{N}_{2}$-saturated $0.1 \mathrm{~mol} \mathrm{~L} \mathrm{~L}^{-1} \mathrm{NaOH}$ at a sweep rate $\mathrm{v}=20 \mathrm{mV} \mathrm{s}^{-1}$ and $\mathrm{T}=25^{\circ} \mathrm{C}$. Adapted from Ref. ${ }^{48}$ with permission from Springer.

\section{$\underline{\alpha-\mathrm{Ni}(\mathrm{OH})_{2} \text { formation }}$}

It is generally accepted that the main process occurring in the low-potential region is the reversible oxidation of $\mathrm{Ni}$ with the formation of surface $\alpha-\mathrm{Ni}(\mathrm{OH})_{2}$ during the anodic sweep, followed by its reduction in the cathodic sweep. ${ }^{43,45,53,55,57}$ The common use of the term ' $\alpha-\mathrm{Ni}(\mathrm{OH})_{2}$ ' (suggesting formation of a 3D structure with $\mathrm{H}_{2} \mathrm{O}$ molecules incorporated between $\mathrm{Ni}(\mathrm{OH})_{2}$ layers $\left.{ }^{43}\right)$ is explained by the fact that it likely grows on the $\mathrm{Ni}$ surface through formation of 3D islands of $\alpha-\mathrm{Ni}(\mathrm{OH})_{2}$. This has been evidenced by the use of in situ scanning tunneling microscopy ${ }^{58,59}$ as well as by the analysis of CVs at low $(<263 \mathrm{~K})$ temperatures. ${ }^{55}$ According to the place-exchange model proposed by Conway et al. ${ }^{60}$ and later adapted by Alsabet et al., ${ }^{45}$ the formation of $\alpha-\mathrm{Ni}(\mathrm{OH})_{2}$ proceeds through three consecutive steps: firstly, the discharge of $\mathrm{OH}^{-}$anions at the $\mathrm{Ni}$ surface and formation of adsorbed $\mathrm{OH}$ species $\left(\mathrm{Ni}-\mathrm{OH}_{\mathrm{ad}}\right)$, secondly, the incorporation of $\mathrm{OH}$ into subsurface between the first and the second layer of $\mathrm{Ni}$ atoms $\left((\mathrm{OH}-\mathrm{Ni})_{\text {quasi-3D lattice }}\right)$ and thirdly, chemisorption of the second monolayer of $\mathrm{OH}$ groups on the $(\mathrm{OH}-$ $\mathrm{Ni})_{\text {quasi-3D lattice: }}$

$$
\begin{aligned}
& \mathrm{Ni}+\mathrm{OH}^{-} \rightleftarrows \mathrm{Ni}^{-} \mathrm{OH}_{\mathrm{ad}}+\mathrm{e}^{-} \\
& \mathrm{Ni}-\mathrm{OH}_{\text {ad }} \rightleftarrows(\mathrm{OH}-\mathrm{Ni})_{\text {quasi-3D lattice }}
\end{aligned}
$$

(2.2, rate determining step) 


$$
(\mathrm{OH}-\mathrm{Ni})_{\text {quasi-3D lattice }}+\mathrm{OH}^{-} \rightleftarrows \mathrm{Ni}(\mathrm{OH})_{2, \text { ad }}+\mathrm{e}^{-}
$$

The existence of intermediate $\mathrm{Ni}-\mathrm{OH}_{\mathrm{ad}}$ species was suggested on the basis of electrochemical (mainly cyclic voltammetry) ${ }^{41,61}$ and in situ scanning tunneling microscopy ${ }^{59}$ measurements.

The influence of crystallographic orientation of the Ni surface on its electrochemical behavior has been studied in several works, both in acid and in alkaline media 40,41,54,59,62-65. While early studies ${ }^{40,54,64}$ did not find noticeable differences in the $\alpha-\mathrm{Ni}(\mathrm{OH})_{2}$ formation for low-index Ni planes (111), (110), (100), recent work of Esau et al. clearly demonstrates the differences in the CV profile depending on the crystallographic orientation of the $\mathrm{Ni}$ surface. ${ }^{65}$ In particular, the anodic peak potential of $\alpha-\mathrm{Ni}(\mathrm{OH})_{2}$ formation shifts positive following the order $(100)<(110)<(111)$, and an additional (pre-)peak at lower potential values shows up in the case of $\mathrm{Ni}(100)$ and $\mathrm{Ni}(110)$ planes (with a less intense pre-peak in the latter case). This observation agrees with DFT calculations, ${ }^{66,67}$ which point to structure-sensitive adsorption of $\mathrm{OH}$ and other species on the $\mathrm{Ni}$ surface (vide infra). Meanwhile, the potential of the cathodic peak is very similar for the three Ni single crystal planes.

In addition to $\alpha-\mathrm{Ni}(\mathrm{OH})_{2}$ discussed above, some works mention possible formation of $\mathrm{NiO}$ species sandwiched between the metal and the outer layer of $\alpha-\mathrm{Ni}(\mathrm{OH})_{2} \cdot{ }^{23,68,69}$ The amount of $\mathrm{NiO}$ formed during potential cycling in the low-potential region can be considered insignificant, as evidenced by in situ Raman ${ }^{57}$ and IR spectroscopy ${ }^{70}$ as well as ex situ X-ray photoelectron spectroscopy (XPS). ${ }^{71}$ Note however, that $\mathrm{NiO}$ might be also formed on the surface of $\mathrm{Ni}$ electrode upon contact with oxygen species, followed by partial transformation of this $\mathrm{NiO}$ layer into $\alpha-\mathrm{Ni}(\mathrm{OH})_{2}$ after either contact with humid air or immersion in an aqueous alkaline electrolyte, thus resulting in a three-layer structure $\mathrm{Ni}|\mathrm{NiO}| \alpha-$ $\mathrm{Ni}(\mathrm{OH})_{2} \cdot{ }^{23}$ Finally, it is worth mentioning that, contrary to acidic medium, anodic dissolution and cathodic redeposition of $\mathrm{Ni}$, which might be expected from Pourbaix diagram, ${ }^{72}$ have not been observed in alkaline electrolytes in the low-potential interval. ${ }^{55,69}$ 
It is remarkable that for a $\mathrm{Ni}$ electrode, whose surface is partially covered by stable $\mathrm{Ni}$ oxides (e.g. $\mathrm{NiO}$ or $\beta-\mathrm{Ni}(\mathrm{OH})_{2}$ ), the latter formed either through oxidation of $\mathrm{Ni}$ in air (i.e. chemical oxidation) or via excursions to high anodic potentials (i.e. electrochemical oxidation), the shape of $\mathrm{CV}$ changes substantially, an additional anodic peak showing up for $0.05<E<0.15 \mathrm{~V} v s$ RHE (Figures 1a and 1b). Such changes are reproducible and have been reported in several publications. ${ }^{41,64,68,73-79}$ The peak potential and the corresponding current density significantly depend on the surface state of the electrode, as well as on the cathodic potential limit of the CV. ${ }^{50,76,79}$ The origin of that second anodic peak is still debated, some authors attributing it to the formation of $\mathrm{Ni}-\mathrm{OH}_{\mathrm{ad},}{ }^{48,64}$ the other - to the oxidation of adsorbed/absorbed hydrogen, ${ }^{41,73,74,80}$ as discussed below.

\section{$\underline{\text { Hydrogen adsorption }}$}

Hydrogen adsorption is of paramount importance for the HOR/HER on metal electrodes (vide infra), and thus has widely been discussed in the literature (see Refs. ${ }^{81-83}$ and references therein). On Pt and other PGM electrodes, there has been convincing evidence for the existence of two types of phenomena, usually addressed as "under-potential" deposition of hydrogen $\left(\mathrm{H}_{\text {upd }}\right)$ at potentials above $E=0 \mathrm{~V} v s$ RHE and “over-potential" deposition of hydrogen $\left(\mathrm{H}_{\mathrm{opd}}\right)$ at potentials below $E=0 \mathrm{~V} v s$ RHE. ${ }^{81,82}$ While the presence of $\mathrm{H}_{\mathrm{opd}}$ on $\mathrm{Ni}$ is commonly accepted, there are significant controversies in the literature regarding the existence of $\mathrm{H}_{\text {upd }}$ on Ni electrodes. Some researchers insist that, above $E=0 \mathrm{~V} v s \mathrm{RHE}$, a Ni electrode is covered by adsorbed oxygenated species $\left(\mathrm{OH}_{\mathrm{ad}} / \mathrm{OH}^{-} \mathrm{ad} / \mathrm{H}_{2} \mathrm{O}_{\mathrm{ad}}\right)$ which prevent adsorption of $\mathrm{H}_{\text {ad. }}{ }^{45,69,81,84,85}$ Other publications present evidence for the existence of $\mathrm{H}_{\text {upd }}$ on the surface of Ni electrodes (even if it is still being debated). More specifically, $\mathrm{Hu}$ and $\mathrm{Wen}^{73}$ investigated electrocatalytic hydrogenation of p-nitroaniline in alkaline medium, and found out that the reaction occurs on $\mathrm{Ni}$ and on

Pt electrodes roughly in the same potential interval, that is below ca. $E=0.2 \mathrm{~V} v s$ RHE. Considering formation of $\mathrm{H}_{\text {upd }}$ on $\mathrm{Pt}$ in this potential interval, they inferred the existence of adsorbed hydrogen on the 
surface of Ni under these conditions as well. Note that the authors of Ref. ${ }^{73}$ demonstrated that prior oxidation of the Ni electrode surface at $T=400^{\circ} \mathrm{C}$ leads to complete suppression of p-nitroaniline hydrogenation, and attributed this to the blocking of hydrogen adsorption by the formed passive layer of $\mathrm{NiO}$, which cannot be electrochemically reduced due to likely insufficient electronic conductivity. In addition, several authors documented intersection (named "isopotential") points in the forward and backward scans of CVs recorded until different positive potential limits [for example, Hu and Wen, ${ }^{73}$ Katic et al. $\left.{ }^{86}\right]$, which they attributed to $\alpha-\mathrm{Ni}(\mathrm{OH})_{2}$ formation and hydrogen adsorption/desorption occurring in the same potential interval (above $E=0 \mathrm{~V} v s$ RHE) and competing for the Ni surface sites. This is in agreement with the adsorption isotherms calculated by Pshenichnikov for the hydrogen and oxygen adsorption from the gas phase. ${ }^{74}$ Finally, some of us ${ }^{48-51}$ studied the HOR on Ni by combining electrochemical measurements with microkinetic modeling, and concluded that assuming the existence of $\mathrm{H}_{\text {upd }}$ on Ni allows the most consistent explanation of a large amount of experimental data for the HOR on Ni electrodes subjected to various surface treatments (reductive $v s$ oxidative), as discussed in more detail in section 3 of this review.

Along with experimental works, there has been significant number of computational studies devoted to the adsorption of $\mathrm{H}, \mathrm{OH}, \mathrm{O}$ and other species on $\mathrm{Ni}$. The binding energy values computed using density functional theory (DFT) and reported by different research groups, vary depending on the density functional used for the calculations. However, some general trends can be identified. Firstly, it is widely accepted that oxygen atoms $\left(\mathrm{O}_{\text {ads }}\right)$ adsorb much stronger that the hydrogen atoms ${ }^{66,87,88}$ In the meantime, comparison of $\mathrm{H}$ and $\mathrm{OH}$ binding energies is less straightforward, some studies reporting stronger adsorption of $\mathrm{OH}$ compared to $\mathrm{H}$, while the other presenting similar binding energy values. For example, Bai et al. ${ }^{88}$ computed the following binding energy values (in $\mathrm{eV}$ ) for $\mathrm{H}$ and $\mathrm{OH}$ on different sites on $\mathrm{Ni}(111)$ using self-consistent GGAPW91 functional (at a $1 \frac{1}{4}$ monolayer coverage): $\mathrm{H}$ ( -2.89 (fcc); -2.88 
(hcp)); $\mathrm{OH}$ ( -2.47 (top); -2.92 (bridge); -3.01 (fcc); -2.91 (hcp)). Thus, one may see that the binding energy strongly depends on the type of surface site, and that the $\mathrm{H}$ and $\mathrm{OH}$ adsorption energy is comparable. Taylor at al. ${ }^{89}$ performed $a b$ initio calculations in order to probe influence of water and surface charge on the hydrogen adsorption on $\mathrm{Ni}(111)$. Based on calculated Gibbs energies of adsorption, the authors constructed a hydrogen over $\mathrm{Ni}(111)$ potential-pH diagram, which corroborates hydrogen adsorption on Ni above $E=0 \mathrm{~V} v s$ RHE (hence, $\mathrm{H}_{\text {upd }}$ ), and suggests that equilibrium potential of the $\mathrm{H}_{\mathrm{ad}} / \mathrm{H}^{+}$couple shifts positive with $\mathrm{pH}$. Besides, it is worth noting that according to theoretical calculations, adsorption energies for $\mathrm{H}_{\mathrm{ad}}$ and $\mathrm{OH}_{\mathrm{ad}}$ demonstrate different coverage dependence. Indeed, according to Greeley and Mavrikakis, the strength of $\mathrm{H}_{\text {ad }}$ to $\mathrm{Ni}(111)$ only slightly decreases from 0 to 1 monolayer coverage. ${ }^{90}$ Meanwhile, Juares et al. ${ }^{87}$ found that because of their high negative charge, $\mathrm{OH}_{\mathrm{ad}}$ on $\mathrm{Ni}$ strongly repel each other, leading to a significant decrease of the adsorption strength with the coverage. As a result, under certain conditions, adsorption of hydrogen may become more favorable compared to that of $\mathrm{OH}_{\mathrm{ad}}$ species. Note also that, according to the DFT calculations, ${ }^{91,92}$ the state of the Ni surface (namely the presence of adsorbed oxygen in the vicinity of $\mathrm{Ni}^{0}$ sites) largely affects the adsorption energy of the $\mathrm{H}_{\mathrm{ad}}$. This conclusion is also supported by microkinetic modeling ${ }^{48-50}$ of the HOR on Ni electrodes as discussed in the following sections.

In the end, if one acknowledges the existence of $\mathrm{H}_{\text {upd }}$ on $\mathrm{Ni}$ in the potential interval from $E=0$ to $0.2 \mathrm{~V}$ vs RHE, the anodic CV peak at ca. $E=0.3 \mathrm{~V} v$ s RHE in Figure 1a should not be interpreted as $\alpha-\mathrm{Ni}(\mathrm{OH})_{2}$ formation on free Ni surface sites but rather as $\mathrm{H}_{\text {upd }}$ replacement by $\mathrm{OH}_{\text {ad }}$ followed by the conversion of the latter into a surface $\alpha-\mathrm{Ni}(\mathrm{OH})_{2}$ layer (Eqs. 2.2 and 2.3). In this context, it is instructive to recall hydrogen UPD on Pt, which until recently had been considered as a well-understood phenomenon. Meanwhile, new evidence provided by electrochemical experiments, DFT calculations and surface science studies (see Janik et al. ${ }^{93}$ and references therein) confirms that certain peaks observed in the 
potential interval of hydrogen UPD in fact do not correspond to $\mathrm{H}_{\text {upd }}$, but rather to the replacement of adsorbed $\mathrm{H}$ atoms by $\mathrm{OH}$ on low-co-ordinated Pt sites.

\section{Hydrogen absorption}

There are numerous evidence of hydrogen absorption in the Ni lattice, which occurs at potentials significantly below $E=0 \mathrm{~V} v s$ RHE, especially upon prolonged water electrolysis conditions. ${ }^{43,69,75,77,78,94-}$

${ }^{96}$ Since hydrogen diffusion in the Ni lattice under ambient conditions is slow, in a transient (e.g. fast CV) experiment the release of these hydrogen species from the Ni lattice may be detected as an anodic current at potentials above $E=0 \mathrm{~V} v s$ RHE, ${ }^{43,95,97}$ that is in the potential interval of $\alpha-\mathrm{Ni}(\mathrm{OH})_{2}$ formation, further complicating interpretation of the CVs. Such a release of absorbed hydrogen at positive potentials has been evidenced by electrochemical quartz crystal microbalance measurements ${ }^{69}$ and in situ measurement of surface stress of a thin $\mathrm{Ni}$ film. ${ }^{97}$ It has also been noticed that oxidation of the Ni surface facilitates hydrogen absorption and related formation of Ni hydrides ${ }^{41,64,75,77,78}$ (in essence Ni-oxides are more disordered and thus less dense than Ni-metal, and therefore facilitate hydrogen insertion). However, in most cases, the contribution of absorbed hydrogen to the anodic currents at potential above $E=0 \mathrm{~V} v \mathrm{~s}$ RHE is negligible, especially when the cathodic limit of CVs lies above $E=-0.2 \mathrm{~V} v s$ RHE.

Hydrogen absorption in Ni lattice has also been studied in surface science and heterogeneous catalysis. For example, surface science studies of Comsa et al. provided a convincing evidence for the absorption and bulk diffusion of hydrogen (deuterium) into the Ni lattice. ${ }^{98}$ More recently, Ceyer's group performed high precision surface science experiments in order to imbed hydrogen atoms in the Ni lattice, detect their formation, and study their reactivity ${ }^{99}$ An excellent overview of the literature, published before 2001 and related to the hydrogen absorption in metals was performed by Ceyer. ${ }^{100}$ In addition, Greeley and Mavrikakis performed first-principles study and calculated the phase diagram of the hydrogen/Ni system, which suggest the formation of one monolayer of subsurface hydrogen at high $\mathrm{H}_{2}$ gas pressure. ${ }^{90}$ 
Considering this phase diagram and by using the Nernst equation, it is possible to estimate an equilibrium potential for the conversion of hydrogen from the adsorbed into a sub-surface state. At $300 \mathrm{~K}$ this potential lies around $E=-0.15 \mathrm{~V} v s$ RHE. This estimation is in agreement with the electrochemical studies evidencing hydrogen absorption in the Ni lattice at high cathodic polarization.

\section{$\underline{\alpha-/ \beta-\mathrm{Ni}(\mathrm{OH})_{2} \text { and } \mathrm{Ni}(\mathrm{OH})_{2} / \mathrm{NiOOH} \text { transition }}$}

In the high-potential region, increase of the potential from $E=0.5$ to $1.2 \mathrm{~V} v s$ RHE leads to dehydration of $\alpha-\mathrm{Ni}(\mathrm{OH})_{2}$ and its irreversible transformation into $\beta-\mathrm{Ni}(\mathrm{OH})_{2}$, along with the formation and/or thickening of the $\mathrm{NiO}{ }^{23,43,44,46,47,57,59,101}$ Formation of a stable $\beta-\mathrm{Ni}(\mathrm{OH})_{2}$ layer leads to an attenuation of the cathodic peak in the low-potential region (Figure 1a), firstly followed by its shift towards more negative values, ${ }^{45,61,102}$ and finally, once $\beta-\mathrm{Ni}(\mathrm{OH})_{2}$ fully covers the electrode surface (red curve on Figure 1a), complete disappearance of the peak in the low-potential region. ${ }^{43,77,79}$ Above $E=1.2 \mathrm{~V} v s$ RHE, $\alpha / \beta-$ $\mathrm{Ni}(\mathrm{OH})_{2}$ undergoes further transformation into $\gamma / \beta-\mathrm{NiOOH}$, resulting in an emergence of the anodic peak around $E=1.4 \mathrm{~V} v s$ RHE (Figure 1a). The corresponding cathodic peak appears around $E=1.3 \mathrm{~V} v s$ RHE and at low sweep rates is often split into two components supposedly due to the presence of two distinct ( $\beta$ and $\gamma$ ) phases of the surface $\mathrm{NiOOH}$ oxyhydroxide ${ }^{103-105}$. At potentials above $E=1.5 \mathrm{~V} v$ s $\mathrm{RHE}$, the surface of the $\mathrm{Ni}$ electrode is covered by $\mathrm{NiOOH}$ and $\mathrm{NiO}$ as evidenced by in situ Raman spectroscopy 101,106-109 and XPS measurements (both ex situ and in situ) ${ }^{71,110,111}$. The crystal plane-orientation dependence of Ni oxidation in the high-potential region has not been observed, likely because of the fast structure disordering at high potentials. ${ }^{65}$

\subsection{Determination of the active surface area of $\mathrm{Ni}$}

Correct determination of the electrochemical surface area (ECSA) of an electrode is of paramount importance for evaluation of its intrinsic electrocatalytic activity and comparison between various materials. However, facile oxidation of $\mathrm{Ni}$ and possible presence of various oxides (reversible or 
irreversible, vide supra) on its surface complicate its ECSA determination. Thus, there is still no generally accepted way to determine the ECSA, the latter depending on several factors discussed below. For electrocatalytic reactions occurring in the low-potential region (for example, the HOR), the adsorption of reagents typically takes place at metallic Ni sites, whose number is thus essential for determination of the specific electrocatalytic activity. As a consequence, the surface fraction covered by stable oxide species (such as $\beta-\mathrm{Ni}(\mathrm{OH})_{2}$ or $\mathrm{NiO}$ ) may be discarded for the determination of the ECSA value. In contrast, for reactions occurring in the high-potential region (for example oxidation of various organic molecules as well as the oxygen evolution reaction), the active sites generally comprise oxidized $\mathrm{Ni}$. In this case, utilization of the $\mathrm{Ni} / \alpha-\mathrm{Ni}(\mathrm{OH})_{2}$ potential region for the ECSA determination (as it is frequently done in the literature) may result in its significant underestimation, if the electrode surface has been (at least partially) covered by stable Ni oxides. This is evident from the comparison of CVs of a Ni disk (Figure. 1a): after partial oxidation of the $\mathrm{Ni}$ electrode, the charge under the anodic peak of $\alpha-\mathrm{Ni}(\mathrm{OH})_{2}$ formation as well as the double layer capacitance between $E=0.5$ and $1.2 \mathrm{~V} v s$ RHE significantly decrease, while the charge under the peaks corresponding to the $\mathrm{Ni}(\mathrm{OH})_{2} / \mathrm{NiOOH}$ transition changes only slightly, due to a small modification of the $\mathrm{Ni}$ surface roughness caused by cycling in a wide potential range ${ }^{43,112}$.

At present, one of the most suitable approaches developed to estimate the ECSA of metallic Ni is based on the use of the full anodic charge under the peak of $\alpha-\mathrm{Ni}(\mathrm{OH})_{2}$ formation ${ }^{45,75}$ and the corresponding specific charge of $514 \mu \mathrm{C} \mathrm{cm}^{-2}$ experimentally determined with the aid of low index single crystal Ni(hkl) electrodes $^{54}$. This value assumes transfer of $2 \mathrm{e}^{-}$per $\mathrm{Ni}$ surface site and hence corresponds to the formation of a monolayer of $\alpha-\mathrm{Ni}(\mathrm{OH})_{2}$. The cathodic charge of $\alpha-\mathrm{Ni}(\mathrm{OH})_{2}$ reduction may also be considered to determine the ECSA ${ }^{113-115}$, but this requires correct subtraction of currents corresponding to the HER (which is not an easy task). In order to minimize the influence of side processes on the estimation of ECSA, it is recommended to record CVs with a cathodic potential limit between $E=-0.06$ and $-0.12 \mathrm{~V} v s$ 
RHE (to minimize the formation of Ni hydrides) and anodic potential limit between $E=0.40$ and $0.50 \mathrm{~V}$ $v s$ RHE (to avoid formation of irreducible $\beta-\mathrm{Ni}(\mathrm{OH})_{2}$ ), at sweep rates between $v=10$ and $50 \mathrm{mV} \mathrm{s}^{-1}$. Note however that the described procedure has some inherent uncertainties. Firstly, the $\alpha-\mathrm{Ni}(\mathrm{OH})_{2}$ layer may grow beyond a monolayer thickness, and its growth depends on the experimental conditions (sweep rate, upper potential limit, temperature, etc.), which affects the accuracy of the surface area determination ${ }^{45}$. Furthermore, assuming that formation of surface $\alpha-\mathrm{Ni}(\mathrm{OH})_{2}$ occurs via replacement of $\mathrm{H}_{\text {upd }}$ (see Section 2.1), the charge under the anodic peak in the low-potential region must also involve hydrogen desorption, further questioning the accuracy of the described procedure of the Ni surface area determination.

Another way to estimate the ECSA of metallic Ni is based on the measurement of the electrochemical double layer capacitance $\left(C_{\mathrm{DL}}\right)$, either by electrochemical impedance spectroscopy (EIS) or by $\mathrm{CV}$ in a narrow potential interval $(<100 \mathrm{mV})$ slightly positive of $E=0 \mathrm{~V} v s$ RHE. Specific capacitance values of metallic Ni electrodes range from 20 to $25 \mu \mathrm{F} \mathrm{cm}{ }^{-2}{ }^{41,80,114,116-118}$ Once the surface of a Ni electrode is (partially) oxidized, the $C_{\mathrm{DL}}$ value changes. Thus, Grden et al. estimated the $C_{\mathrm{DL}}$ value of a fully-oxidized Ni surface to be around $8 \mu \mathrm{F} \mathrm{cm}{ }^{-2} 114$ in the potential interval between $E=-0.2$ and $-0.25 \mathrm{~V} v s$ RHE. However much higher values of 40 to $60 \mu \mathrm{F} \mathrm{cm} ~_{-2}$ have been reported at positive potentials $(0.8<E<1.2$ V vs RHE). ${ }^{15,119-121}$ Such significant uncertainties in the specific capacitance values raise a question regarding the applicability of the estimated $C_{\mathrm{DL}}$ values to measure the ECSA. ${ }^{15,122}$

In order to determine the total surface area of a $\mathrm{Ni}$ electrode (i.e. including contribution both from metallic and from oxidized Ni sites), Grden et al. have suggested to complement CV (or CV plus EIS) measurements with XPS experiments. ${ }^{114}$ In their approach the XPS data are used to determine the ratio between the surface areas of oxidized and metallic $\mathrm{Ni}\left(r=A_{\mathrm{ox}} / A_{\mathrm{m}}\right)$, which is then applied to calculate the entire surface area of Ni. Note however that ex situ XPS data might not necessarily reflect the surface state of a Ni electrode established in situ after conditioning in a specific potential region. Besides, to the 
best of the authors' knowledge, XPS does not allow to differentiate between $\alpha-\mathrm{Ni}(\mathrm{OH})_{2}$ and $\beta-\mathrm{Ni}(\mathrm{OH})_{2}$, the former species being reducible in the low-potential region, while the latter - not.

When Ni electrocatalysts are used for reactions occurring in the high-potential region (organics oxidation or oxygen evolution reaction), the active sites consist of $\mathrm{Ni}(\mathrm{II}) / \mathrm{Ni}(\mathrm{III})$ species. In this case, the most straightforward way to estimate the ECSA of a Ni electrode could be the determination of the charge associated with the $\mathrm{Ni}(\mathrm{OH})_{2} / \mathrm{NiOOH}$ transition. The difficulty, however, lies in the $\mathrm{NiOOH}$ layer growth beyond a monolayer, its thickness depending on the growth conditions. ${ }^{47}$ To overcome this complication, Hall et al., ${ }^{123}$ suggested to use oxalate salt (acting as a stabilizing agent due to the formation of an oxalate ad-layer) and sufficiently high sweep rate $v \geq 150 \mathrm{mV} \mathrm{s}^{-1}$ to limit the thickness of surface $\mathrm{Ni}(\mathrm{OH})_{2}$ and $\mathrm{NiOOH}$ to a single layer. This approach was later adopted to measure the ECSA of a Ni foam. ${ }^{12}$ In this case sharp and narrow peaks for the $\mathrm{Ni}(\mathrm{OH})_{2} / \mathrm{NiOOH}$ oxidation-reduction processes were observed in the CVs, resulting in higher precision of the determined ECSA value of Ni assuming a specific charge of 195 $\mu \mathrm{C} \mathrm{cm}^{-2}$. However, the latter method can only be applied either after measuring the catalytic activity of an electrode, or in a separate experiment, since the presence of the oxalate salt in the electrolyte will most likely affect the electrocatalytic properties of Ni. Alternatively, Ho and Piron ${ }^{95}$ and later Lyons and Brandon ${ }^{94}$ suggested to galvanostatically charge a $\mathrm{Ni}$ electrode in the potential interval of the oxygen evolution reaction (occurring on the $\mathrm{NiOOH}-$ covered surface) and then calculate charge passing during a cathodic current-time transient. This method assumes a specific charge of $420 \mu \mathrm{C} \mathrm{cm}$, although, as mentioned by the authors, the exact charge passing during the desorption of a full monolayer of the oxygen evolution reaction intermediates is uncertain, and may vary, in particular, depending on the type of the $\mathrm{NiOOH}$ surface phase $(\beta$ or $\gamma$ ) at stake, which present somewhat different unit cell parameters and symmetries ${ }^{44,124}$ (not to mention that the nature of active oxygen evolution intermediates is still debated). Recently, Watzele et al. ${ }^{125}$ proposed a yet another strategy to determine the ECSA of metal oxide catalysts 
(including $\mathrm{Ni}$ ) by measuring the so-called adsorption pseudocapacitance at the onset of the oxygen evolution reaction.

Finally, chemical methods to measure the surface area, while not giving the exact information about the ECSA, are still useful as they allow to calculate the full surface area of Ni. Among various techniques described by Trasatti and Petrii, ${ }^{126} \mathrm{CO}$ and $\mathrm{H}_{2}$ chemisorption measurements for metallic $\mathrm{Ni}$, or $\mathrm{N}_{2}$ physisorption measurements for Ni oxides can be mentioned. ${ }^{122,127-129}$

\section{Electrocatalytic properties of Ni-based electrocatalysts in the HOR in alkaline media}

\subsection{Introduction: electrocatalysis of hydrogen electrode reactions on $\mathrm{Ni}$}

The HOR/HER are among the most widely studied electrode processes. The mechanism of the hydrogen electrode reactions on metal electrodes ("M" in the Eqs. below stands for a metal surface site)

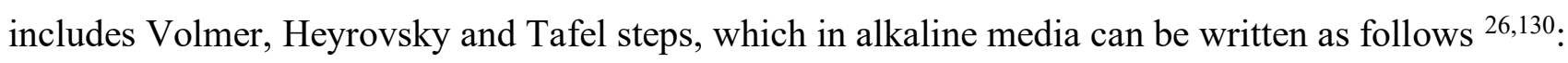

$$
\begin{aligned}
& \mathrm{H}_{2}+2 \mathrm{M} \rightleftarrows 2 \mathrm{M}-\mathrm{H}_{\mathrm{ad}} \\
& \mathrm{H}_{2}+\mathrm{OH}^{-}+\mathrm{M} \rightleftarrows \mathrm{M}-\mathrm{H}_{\mathrm{ad}}+\mathrm{H}_{2} \mathrm{O}+\mathrm{e}^{-} \\
& \mathrm{M}-\mathrm{H}_{\mathrm{ad}}+\mathrm{OH}^{-} \rightleftarrows \mathrm{H}_{2} \mathrm{O}+\mathrm{e}^{-}+\mathrm{M}
\end{aligned}
$$

Since atomically adsorbed hydrogen $\left(\mathrm{H}_{\mathrm{ad}}\right)$ acts as a reaction intermediate, the electrocatalytic activity in hydrogen electrode reactions is closely related to its strength of adsorption. ${ }^{131-134}$ There has been convincing evidence that on Pt and other PGM electrodes, $\mathrm{H}_{\text {upd, }}$, which is adsorbed in multi-fold hollow sites, cannot act as the HOR/HER intermediate due to its strong binding to the surface, and that it is rather weakly adsorbed hydrogen $\left(\mathrm{H}_{\mathrm{opd}}\right)$, likely adsorbed on-top, which participates in hydrogen electrocatalysis. ${ }^{81-83}$ For the most catalytically-active metals like Pt and Pd, the Gibbs energy of adsorption of this weakly-adsorbed hydrogen is close to zero. ${ }^{131,135,136} \mathrm{On} \mathrm{Ni}$, hydrogen in multi-fold 
hollow sites is adsorbed stronger than either on Pt or Pd. ${ }^{131,135,136}$ Santos et al., using DFT, compared strongly- and weakly-adsorbed hydrogen on $\mathrm{Ni}$, Pt and some other surfaces. ${ }^{133}$ According to these calculations, and in agreement with other studies, strongly-adsorbed hydrogen binds to Ni(111) stronger than to $\mathrm{Pt}(111)$. In the meantime, for weakly-adsorbed hydrogen on $\mathrm{Ni}(111)$, adsorbed on top of a monolayer of the strongly-adsorbed hydrogen, $\Delta G_{\mathrm{H}} \approx 0.9 \mathrm{eV}$, which makes its participation in the HOR rather unlikely. In what follows, when discussing the HOR on $\mathrm{Ni}$, it will be assumed that it is stronglyadsorbed hydrogen, which acts as a reaction intermediate on $\mathrm{Ni}$, and it will simply be denoted as $\mathrm{H}_{\mathrm{ad}}$. While this conjecture requires additional confirmation, it agrees with an increase of the HOR on Ni-based electrodes with the decrease of the strength of hydrogen adsorption, the fact widely acknowledged in the literature. ${ }^{48,50,137-142}$

Besides, experimental data (collected for PGM-based electrodes) evidence much slower hydrogen electrode kinetics in alkaline media than in acid. ${ }^{143-145}$ To explain this experimental observation, the so called 'bifunctional' mechanism has been proposed, ${ }^{18,146}$ which postulates that in order to be active in the HOR/HER in alkaline media, an electrode must provide two types of sites: one for $\mathrm{H}_{\mathrm{ad}}$ adsorption and another one for water dissociative adsorption to form $\mathrm{H}_{\mathrm{ad}}$ and $\mathrm{OH}_{\mathrm{ad}}$. We will come back to the feasibility of this 'bifunctional' mechanism on Ni.

Owing to the use of alkaline water electrolysis at the industrial level, studies of Ni-based electrocatalysts have been primarily carried out in the potential interval of the HER, while, until recently, the interest in the HOR on Ni has been rather limited. HER starts with the Volmer step, which provides hydroxyl ion and an adsorbed $\mathrm{H}_{\mathrm{ad}}$. Then, hydrogen molecule is produced via either recombination of two $\mathrm{H}_{\mathrm{ad}}$ atoms (Tafel step) or interaction of $\mathrm{H}_{\mathrm{ad}}$ and a water molecule (Heyrovsky step). The contribution of individual steps $(3.1-3.3)$ to the overall reaction mechanism depends on many factors such as the $\mathrm{Ni}$ surface state, the presence of a second element (metal or nonmetal) as well as the applied overpotential. 
In particular, the HER on polycrystalline Ni follows Volmer-Heyrovsky mechanism if the electrode surface is dominated by metallic Ni sites ${ }^{30,56,75,118}$, while the Volmer-Tafel mechanism was proposed in some publications where Ni electrodes were used likely in a partially-oxidized state of the surface. ${ }^{85,147,148}$ The latest progress in the field of the HER on $\mathrm{Ni}$ and Ni-based electrocatalysts, including the reaction mechanism, is summarized in several reviews ${ }^{17,18,26,27}$ and is beyond the scope of this paper. In this review we are primarily interested in the HOR and will mention the HER only when relevant (e.g. when it enters in competition with reactions of interest for this work). The HOR comprises the same elementary steps as the HER but in the reverse direction, the $\mathrm{H}_{2}$ molecule first dissociating with the formation of surface $\mathrm{H}_{\mathrm{ad}}$ (through the Heyrovsky and/or Tafel step), the latter undergoing electrochemical oxidation with the formation of $\mathrm{H}_{2} \mathrm{O}$ (Volmer step). It should be noted however that the nature of the rate-determining step depends on the electrode potential, thus resulting in differences in the detailed reaction mechanisms for the HOR and the HER if considered at high anodic or cathodic potentials, correspondingly.

\subsection{HOR on monometallic Ni electrodes}

Literature data regarding the kinetics of the HOR on $\mathrm{Ni}$ (and HER at low cathodic overpotentials) are very contradictory, ${ }^{41,42,64,85,118,147,149-151}$ which may be attributed to the strong influence of the electrode pre-treatment and thus the state of the surface on the reaction kinetics. ${ }^{4-50,146,152}$ In the vicinity of the equilibrium potential, a purposely-reduced metallic Ni electrode (see black solid trace in Figure $2 \mathrm{~b}$ ) shows a very small HOR current, which then increases peaking at ca. $E=0.25 \mathrm{~V} v$ s $\mathrm{RHE}$ (i.e. close to the anodic peak position observed under $\mathrm{N}_{2}$ atmosphere), and then decays again. Oshchepkov et al. attributed this low activity of metallic Ni to the slow kinetics of the Volmer step likely due to the strong adsorption of $\mathrm{H}_{\mathrm{ad}}$ species already mentioned above. ${ }^{48,49,131,132}$ Indeed, according to the results of kinetic modeling, surface coverage of metallic $\mathrm{Ni}$ with $\mathrm{H}_{\mathrm{ad}}\left(\theta_{\mathrm{H}}\right)$ is high under $\mathrm{N}_{2}$ atmosphere, and further increases in the presence of $\mathrm{H}_{2}$, adsorbed hydrogen atoms dominating on the surface until ca. $E=0.2 \mathrm{~V}$ vs RHE (Figures 
$2 \mathrm{a}$ and $2 \mathrm{~b}$, for details a reader is referred to Ref. ${ }^{49}$ ). Note that the obtained data are in a good agreement with hydrogen adsorption isotherm (from the gas phase) reported by Pshenichnikov. ${ }^{74}$ Besides, according to Taylor et al. at $\mathrm{pH}=13$ the equilibrium potential for $\mathrm{H}_{\mathrm{ad}} / \mathrm{H}^{+}$is similar to $0.2 \mathrm{~V}$, which is in agreement with the data of Figure 2a. ${ }^{89}$ At higher potential values, formation of $\alpha-\mathrm{Ni}(\mathrm{OH})_{2}$, which proceeds through the $\mathrm{OH}$ adsorption (see $\theta_{\mathrm{OH}}$ and $\theta_{(\mathrm{OH}) 2}$ traces in Figures 2), results in blocking of the Ni active sites. ${ }^{45,48,66,92}$ Thus, considering the kinetics of the HOR on Ni electrocatalysts also requires accounting for the processes of the Ni surface hydroxide formation and reduction, since they occur in the same potential range as the HOR. Besides, the coexistence of both $\mathrm{Ni}-\mathrm{H}_{\mathrm{ad}}$ and $\mathrm{Ni}-\mathrm{OH}_{\mathrm{ad}}$ species on the electrode surface might result in their recombination with the formation of water through the following reaction ('bifunctional' mechanism) $)^{146}$ :

$$
\mathrm{Ni}-\mathrm{H}_{\mathrm{ad}}+\mathrm{Ni}-\mathrm{OH}_{\mathrm{ad}} \rightleftarrows \mathrm{H}_{2} \mathrm{O}+2 \mathrm{Ni}
$$

However, contribution of the latter step to the mechanism of the HOR has been shown to be unlikely on a pure metallic Ni surface because of the very strong adsorption of $\mathrm{H}_{\mathrm{ad}}$ on $\mathrm{Ni}$ and thus the high activation barrier for the recombination reaction. ${ }^{51}$ Nevertheless, the recombination step might contribute to the HOR on bimetallic NiM electrocatalysts and/or partially oxidized Ni electrodes, when the adsorption energies of $\mathrm{H}_{\mathrm{ad}}$ and $\mathrm{OH}_{\mathrm{ad}}$ are weakened. ${ }^{50,51}$ 

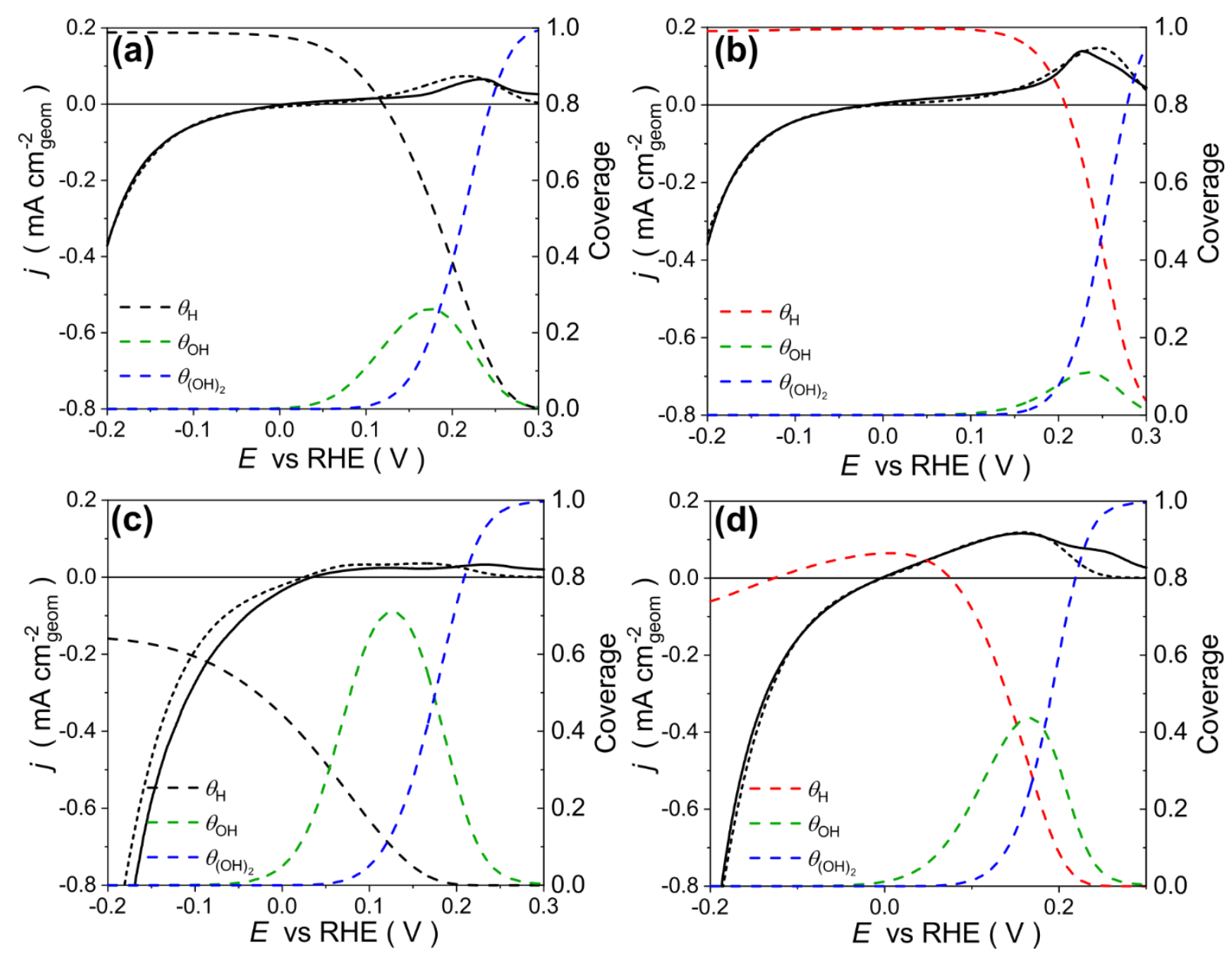

Figure 2. Experimental anodic scans of CVs (black solid curves) for (a, b) metallic and (c, d) partially oxidized polycrystalline Ni rod in $(a, c) N_{2}$ and $(b, d) H_{2}$-saturated $0.1 \mathrm{~mol} \mathrm{~L}^{-1} \mathrm{NaOH}$ at $v=5 \mathrm{mV} \mathrm{s}^{-1}$ and $T=25^{\circ} \mathrm{C}$. Dashed curves represent the simulated data of either CVs or coverage of the electrode surface by various adsorbates. Note that only Ni metal sites free from stable oxide species $\left(\mathrm{NiO}_{x}\right.$ surface coverage is estimated to be ca. $14 \%$ ) were considered for calculations. Data are replotted from Ref. ${ }^{49}$ with permission from Elsevier.

The catalytic activity of metallic ('reduced') Ni electrodes being rather low, several approaches are currently proposed to improve the performance of $\mathrm{Ni}$ and Ni-based electrocatalysts in the HOR. They target either (i) decreasing the $\mathrm{Ni}-\mathrm{H}_{\mathrm{ad}}$ binding energy and hence increasing the Volmer step kinetics, or 
(ii) increasing the kinetics of the recombination step, or (iii) making Ni less sensitive to the oxide blocking thus extending the operating potential window of an AEMFC with a Ni anode. In section 3.3 of the review, we summarize recent advances in the development of nanoparticulated $\mathrm{Ni}$ and Ni-based electrocatalysts for the HOR and outline three main strategies, which have been put forward to achieve high catalytic activity of Ni.

\subsection{Strategies for improving the activity of Ni electrocatalysts in the HOR}

\section{Effect of the surface state of Ni and heteroatom doping}

As highlighted in section 2 of this review, $\mathrm{Ni}$ is prone to oxidation already at ambient conditions resulting in the formation of surface Ni oxides, some of them (addressed as 'stable' surface oxides) surviving in the potential intervals of the HOR/HER and coexisting with metallic Ni sites at the electrode surface. It has been shown that the presence of surface $\mathrm{NiO}_{x}$ species (presumably serving as water adsorption sites) along with metallic $\mathrm{Ni}$ sites (serving as $\mathrm{H}_{\mathrm{ad}}$ adsorption sites) results in a synergistic effect leading to significant enhancement of the HOR currents on partially-oxidized Ni electrodes. ${ }^{48-50}$ The HOR activity depends on the $\mathrm{NiO}_{x}$ surface coverage, with an optimum observed at ca. 30 to $50 \%$ of $\mathrm{NiO}_{x}$ depending on the type of $\mathrm{Ni}$ electrodes (e.g. polycrystalline $\mathrm{Ni}{ }^{50}$ or $\mathrm{Ni} / \mathrm{C}$ nanoparticles ${ }^{153}$ ). On the basis of DFT calculations as well as microkinetic modeling, it has been concluded that $\mathrm{NiO}_{x}$ species weaken the strength of adsorption of $\mathrm{H}_{\mathrm{ad}}$ at nearby-located $\mathrm{Ni}$ sites and likely increase the strength of $\mathrm{H}_{2} \mathrm{O}$ adsorption at the surface, both leading to an enhancement of the kinetics of the Volmer step (Figure 2). ${ }^{50,91}$ As a result, the HOR starts at lower overpotential, as evidenced by an emergence of the second anodic peak (labeled as $a_{2}$ in Figure 3a) in CVs in $\mathrm{H}_{2}$ atmosphere. This peak shifts towards $E=0 \mathrm{~V} v s$ RHE with the $\mathrm{NiO}_{x}$ coverage and an ensuing decrease of $\mathrm{Ni}-\mathrm{H}_{\text {ad }}$ binding energy (Figure 3). It is instructive to 
compare $\theta_{\mathrm{H}}$ for a metallic and partially oxidized Ni surface (Figure 2). Indeed, $\theta_{\mathrm{H}}$ significantly decreases in the latter case $\left(\mathrm{NiO}_{x}\right.$ surface coverage is estimated to be ca. $14 \%$ based on the data presented in $\left.\mathrm{Ref}^{49}\right)$, which goes along with the increase of the HOR current. While further (preferably in situ spectroscopic) studies are required to unveil the surface state of $\mathrm{Ni}$ electrodes during the HOR and thus unambiguously confirm its influence on the reaction kinetics, it should be emphasized that the model proposed by Oshchepkov et al. currently presents the most consistent explanation of the available literature data. ${ }^{48-52}$

Armed with this knowledge, Oshchepkov et al. have recently reported a partially oxidized Ni$\mathrm{NiO}_{x} / \mathrm{XC}-72$ electrocatalyst prepared by electrodeposition technique, which possesses HOR specific activity at the level of a commercial $\mathrm{Pd} / \mathrm{C}$ electrocatalyst (Table 1). ${ }^{137}$ It has been demonstrated that the existence of surface $\mathrm{NiO}_{x}$ species (their estimated coverage varies between 48 and 58\%) enhances the surface- and mass-normalized HOR exchange current densities from 6.2 to $56 \mu \mathrm{A} \mathrm{cm} \mathrm{Ni}^{-2}$ and from 5.7 to 22.4 $\mathrm{A} \mathrm{g}_{\mathrm{Ni}^{-1}}{ }^{-1}$, respectively, compared to a reduced $\mathrm{Ni} / \mathrm{C}$ electrocatalyst. The HOR kinetic current density

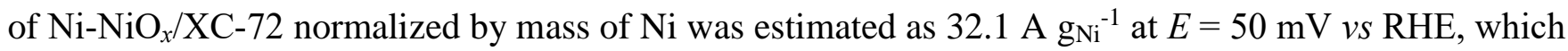
makes it the current state-of-the-art in the field of PGM-free electrocatalysts for the HOR. An improved HOR specific activity was also reported for $\mathrm{Ni} / \mathrm{NiO} / \mathrm{C}$ composites derived from the Ni-based metalorganic frameworks and ascribed by the authors to the optimal binding energies of both $\mathrm{H}_{\mathrm{ad}}$ and $\mathrm{OH}_{\mathrm{ad}}$ at the $\mathrm{Ni} / \mathrm{NiO}$ interface as well as to the high level of carbon graphitization, the latter resulting in high conductivity. ${ }^{141}$ It has also been demonstrated, that the $\mathrm{Ni} / \mathrm{NiO} / \mathrm{C}$ composite possesses much better $\mathrm{CO}$ tolerance than a $20 \mathrm{wt} . \% \mathrm{Pt} / \mathrm{C}$ catalyst, the HOR activity of the latter in the presence of CO decaying below that of $\mathrm{Ni} / \mathrm{NiO} / \mathrm{C}$ within a couple of hours. Since most of hydrogen is currently produced through natural gas reforming, the presence of $\mathrm{CO}$ in the fuel stream cannot be fully avoided, not to mention that the carbon support itself can lead to CO-like species adsorption at the metal nanoparticles (see Section 5), 
hence to their "poisoning" at low potentials. Therefore, synthesis of CO-tolerant electrocatalysts is an important task in the development of AEMFCs.
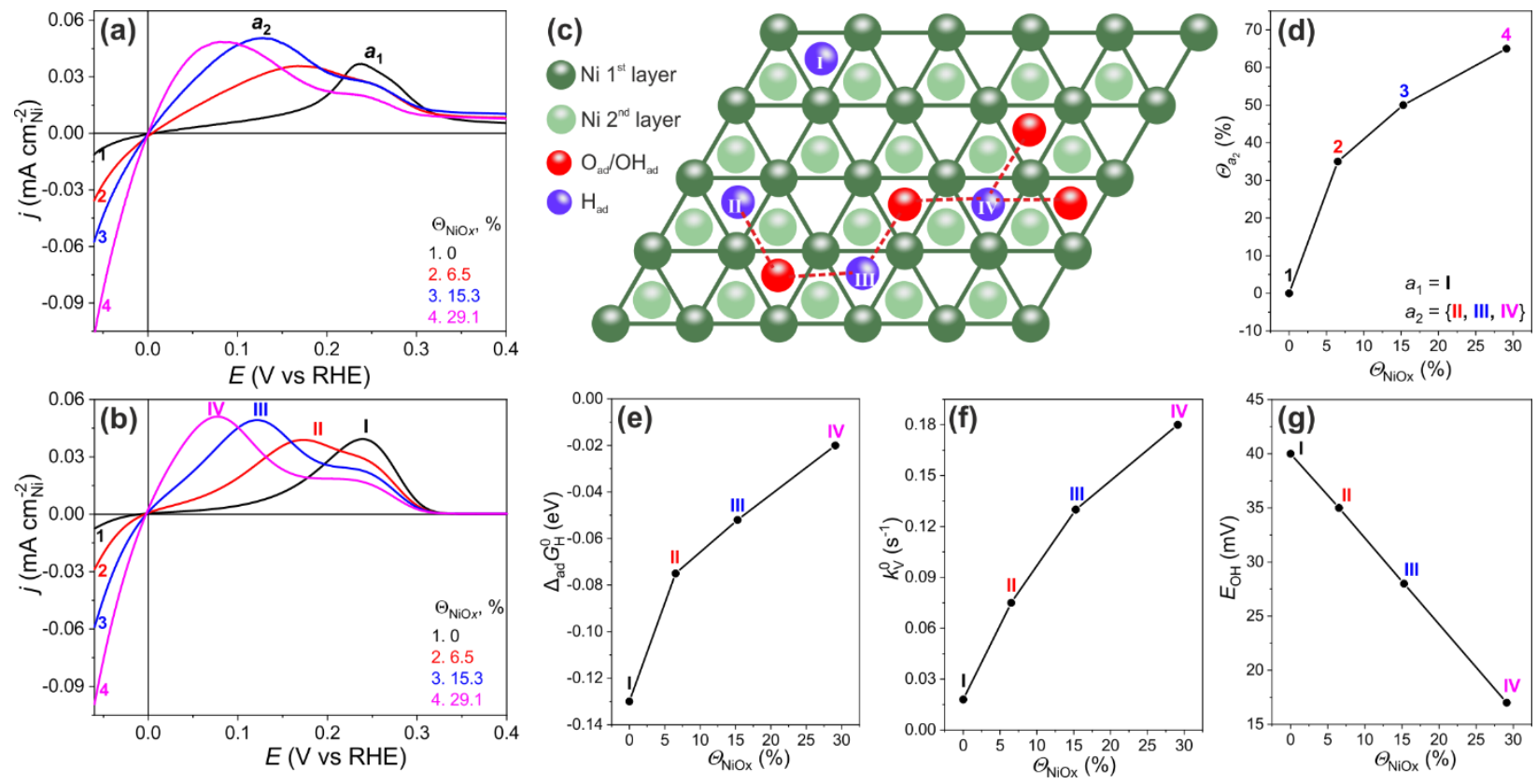

Figure 3. Comparison of the anodic scans of (a) experimental and (b) simulated $\mathrm{CVs}$ for $\mathrm{Ni} / \mathrm{NiO} \mathrm{O}_{x}$ electrodes with different degree of oxidation of their surfaces (characterized by the corresponding $\mathrm{NiO}_{x}$ coverage) in $\mathrm{H}_{2}$-saturated $0.10 \mathrm{~mol} \mathrm{L^{-1 }} \mathrm{NaOH}$ at $v=5 \mathrm{mV} \mathrm{s}^{-1}$. (c) Schematic illustration of the Ni active sites with various adsorption energies depending on the number of closely located oxide species. Influence of the $\mathrm{NiO}_{x}$ coverage on $(d)$ the percentage of $\mathrm{Ni}$ active sites affected by oxygen species (peak $\left.a_{2}\right),(e)$ the Gibbs energy of the adsorbed $H_{\text {ad }}$ intermediate, $(f)$ the Volmer rate constant $k_{V}{ }^{0}$, and $(g)$ the potential of $\mathrm{Ni}$-OH $\mathrm{H}_{\text {ad }}$ formation. Reproduced from Ref. ${ }^{50}$ with permission from Springer.

Besides modification of the Ni surface state, several authors reported successful examples of introducing heteroatoms in the structure of Ni nanoparticles. It has been demonstrated that formation of a $\mathrm{Ni}_{3} \mathrm{~N}$ phase provides significant enhancement of the activity in the HOR with respect to a pure $\mathrm{Ni}$ 
electrocatalyst (Table 1). ${ }^{139,140,142}$ DFT calculations suggest that in the presence of an interstitial $\mathrm{N}$ dopant, the absolute value of $\Delta G_{\mathrm{H}}$ decreases, hence approaching zero (i.e. an optimal value for the HOR). ${ }^{139,142}$ In addition, it was proposed that the activation energy for both water formation and water dissociation decrease at the interface between $\mathrm{Ni}_{3} \mathrm{~N}$ and $\mathrm{Ni}{ }^{139,142}$. As a result, the reported carbon-supported $\mathrm{Ni}_{3} \mathrm{~N}$ electrocatalysts provide very high mass-normalized HOR kinetic current densities at $E=50 \mathrm{mV} v s \mathrm{RHE}$ (24.38 and 29.75 ${\mathrm{A} \mathrm{g} \mathrm{Ni}^{-1}}^{-1}$, respectively from the Refs. ${ }^{140}$ and ${ }^{139}$ ), thus being close to the state-of-the-art Ni-NiO $x /$ XC-72 electrocatalyst (32.1 A $\left.\mathrm{gNi}^{-1}\right) \cdot{ }^{137}$ Notably, the $\mathrm{Ni}_{3} \mathrm{~N}$ nanoparticles supported on either carbon or on $\mathrm{Ni}$ foam demonstrated very high resistance towards CO poisoning (Figure 4) ${ }^{139,142 .}$ Moreover, the $\mathrm{Ni}_{3} \mathrm{~N} / \mathrm{C}$ shows a limiting HOR current densities up to $E=0.26 \mathrm{~V} v s \mathrm{RHE}$, which is ca. 0.1 V higher the values typically observed with Ni-based electrocatalysts. ${ }^{137-142,154}$ On the basis of ultraviolet photoemission spectroscopic measurements, this was attributed to a weaker oxygen adsorption on $\mathrm{Ni}_{3} \mathrm{~N}$ as compared to pure $\mathrm{Ni}^{1}{ }^{140} \mathrm{~A}$ decrease of the propensity of $\mathrm{Ni}$ towards oxidation was also reported by Gao et al. for a $\mathrm{Ni}$ core-hexagonal boron nitride (h-BN) shell $\left(\mathrm{Ni} / \mathrm{h}-\mathrm{BN} / \mathrm{KB}\right.$ electrocatalyst). ${ }^{129}$ This was achieved via formation of a few layers of a defective hexagonal BN shell, which protected the Ni core from an excessive oxidation in air, yet allowing $\mathrm{H}, \mathrm{OH}$, and $\mathrm{H}_{2} \mathrm{O}$ to interact with the $\mathrm{Ni}$ surface. In addition, it was suggested that the $\mathrm{h}-\mathrm{BN}$ shell weakened $\mathrm{H}_{\mathrm{ad}}$ adsorption on the Ni surface, resulting in a six times higher HOR exchange current density measured for $\mathrm{Ni} / \mathrm{h}-\mathrm{BN} / \mathrm{KB}$ as compared to pure $\mathrm{Ni} / \mathrm{KB}$ sample (Table 1). 

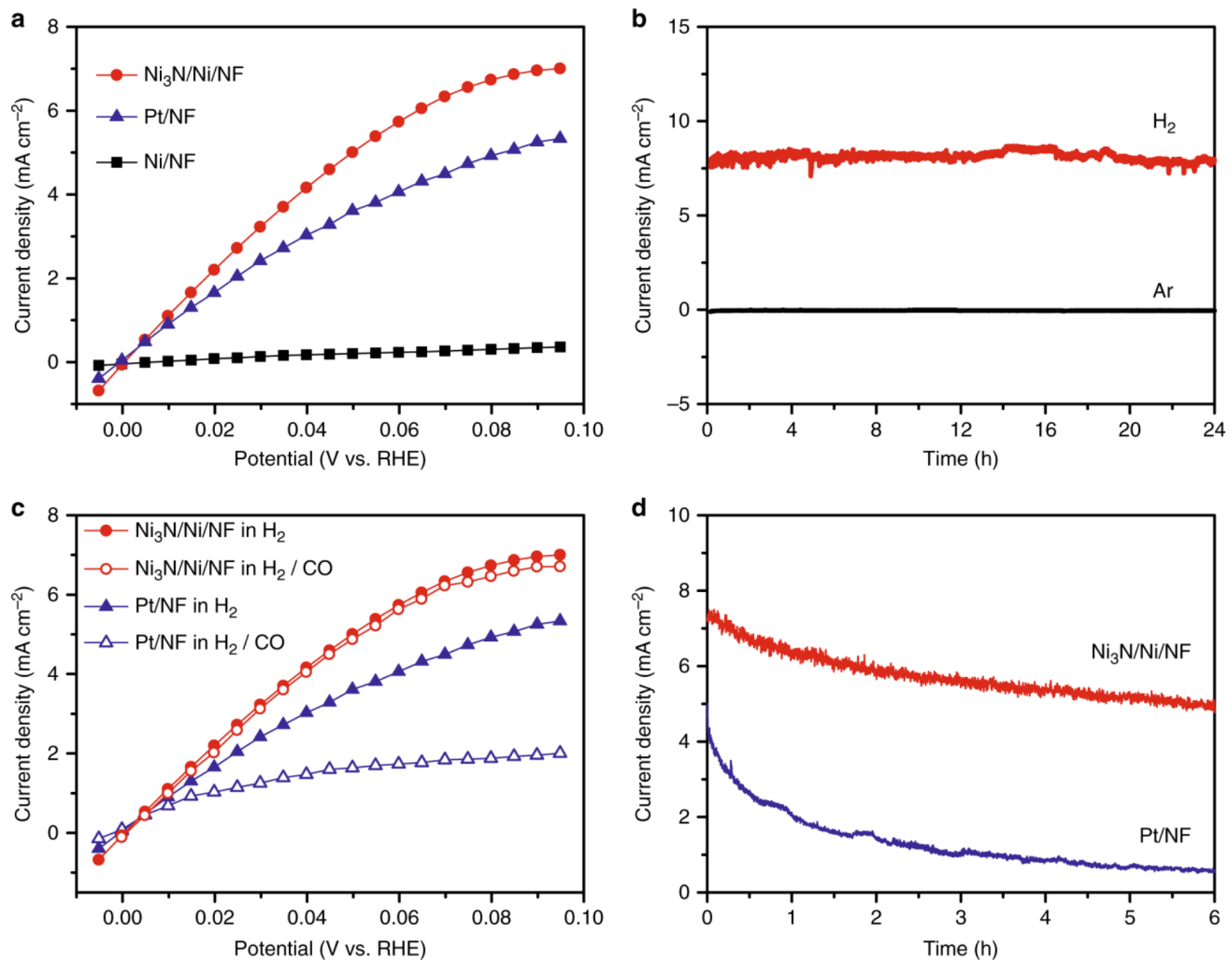

Figure 4. Electrocatalytic performance of $\mathrm{Ni} 3 \mathrm{~N} / \mathrm{Ni} / \mathrm{NF}, \mathrm{Ni} / \mathrm{NF}$, and Pt/NF (NF is a Ni foam) catalysts in the HOR. (a) Steady-state polarization curves of $\mathrm{Ni}_{3} \mathrm{~N} / \mathrm{Ni} / \mathrm{NF}, \mathrm{Ni} / \mathrm{NF}$, and Pt/NF in $\mathrm{H}_{2}$-saturated 0.1 mol L $L^{-1} \mathrm{KOH}$. (b) Chronoamperometry curves of $\mathrm{Ni}_{3} \mathrm{~N} / \mathrm{Ni} / \mathrm{NF}$ in $\mathrm{H}_{2^{-}}$or Ar-saturated $0.1 \mathrm{~mol} \mathrm{~L}^{-1} \mathrm{KOH}$ measured at $E=0.09 \mathrm{~V} v \mathrm{~s}$. RHE. (c) Comparison of the HOR polarization curves of $\mathrm{Ni}_{3} \mathrm{~N} / \mathrm{Ni} / \mathrm{NF}$ and Pt/NF in $0.1 \mathrm{~mol} \mathrm{~L}^{-1} \mathrm{KOH}$ saturated with $\mathrm{H}_{2}$ or a mixture of $\mathrm{H}_{2}$ and $2 \% \mathrm{CO}(v / v)$. (d) Chronoamperometry curves of $\mathrm{Ni}_{3} \mathrm{~N} / \mathrm{Ni} / \mathrm{NF}$ and $\mathrm{Pt} / \mathrm{NF}$ in $0.1 \mathrm{~mol} \mathrm{~L}^{-1} \mathrm{KOH}$ saturated with a mixture of $\mathrm{H}_{2}$ and $2 \% \mathrm{CO}(\mathrm{v} / \mathrm{v})$ measured at $E=0.09 \mathrm{Vvs}$. RHE. All results were collected without iR compensation. The current densities were calculated on the basis of the geometric electrode areas. Reproduced from Ref. ${ }^{142}$ with permission from Springer Nature 


\section{$\underline{\text { Bimetallic NiM electrocatalysts }}$}

Another (and the most popular) approach to modify the catalytic properties of materials and, in particular, Ni nanoparticles is based on alloying them with other metals. In order to take full advantage of the AEMFC concept, noble metal additives to Ni electrocatalysts should be avoided. Besides, alloying Ni with metals like Pt, Pd and Ir does not allow to decipher the influence of the noble metal (being more active than Ni) on its activity in the HOR. Instead, Ni serves as an additive helping to further improve the activity of noble metals in the HOR, presumably by providing surface sites for adsorbing hydroxyl species ${ }^{155-157}$ or by tuning the hydrogen binding energy. ${ }^{134}$ Considering the above-mentioned reasons, in what follows, we will only discuss NiM systems with a non-precious second component (Table 1).

Oshchepkov et al. have studied $\mathrm{NiCu} / \mathrm{XC}-72$ electrocatalysts with a $\mathrm{Cu}$ fraction from 0.05 to 0.50 prepared by the incipient wetness impregnation. In this series, samples containing $5 \mathrm{wt} . \%$ of $\mathrm{Cu}$ showed the highest specific and mass activities in the HOR, which was at least 3 times higher compared to a pure $\mathrm{Ni} / \mathrm{C}$ electrocatalyst prepared by the same method. ${ }^{127}$ By using freeze-drying, the same group prepared more homogeneous alloyed $\mathrm{NiCu} / \mathrm{XC}-72$ electrocatalysts with relatively narrow particle size distribution, in which the highest activity was again observed for the $\mathrm{Ni}_{0.95} \mathrm{Cu}_{0.05} / \mathrm{XC}-72$ sample. ${ }^{158}$ The specific activity of $\mathrm{Ni}_{0.95} \mathrm{Cu}_{0.05} / \mathrm{XC}-72$ was found to be the same in both series (ca. $14 \mu \mathrm{A} \mathrm{cm} \mathrm{Ni}^{-2}$ ), while the mass activity of the sample prepared using freeze-drying increased by a factor of 1.5 (up to $2.5 \mathrm{~A} \mathrm{~g}^{-1}$ ) due to a smaller average particle size. Similar electrocatalyst composition was also explored by Roy et al. ${ }^{159}$, who reported two times higher exchange current density $\left(25 \mu \mathrm{A} \mathrm{cm} \mathrm{Ni}^{-2}\right)$ for their $\mathrm{Ni}_{95} \mathrm{Cu}_{5} / \mathrm{Ketjenblack}$ electrocatalyst at however 2.5 times lower mass-normalized activity (Table 1). The latter is likely arising from the low ECSA of NiCu nanoparticles in Ref. ${ }^{159}$ The authors also evaluated the performance of an AEMFC 
consisting of a $\mathrm{Ni}_{95} \mathrm{Cu}_{5} / \mathrm{Ketjenblack}$ anode and a Pd/XC-72R cathode separated by a Tokuyama A201 membrane, possessing the power density of ca. 160 and $350 \mathrm{~mW} \mathrm{~cm}{ }^{-2}$ at 70 and $80^{\circ} \mathrm{C}$, respectively, and $100 \%$ relative humidity. ${ }^{159}$ In addition, Wang et al. have studied $\mathrm{Ni}-\mathrm{Cu}$ alloy films with different composition prepared using a combinatorial magnetron co-sputtering method. ${ }^{160}$ The authors have found that the highest (4 times higher compared to a pure Ni sample) exchange current density in the HOR (34 $\mu \mathrm{A} \mathrm{cm}_{\mathrm{Ni}^{-}}{ }^{-2}$ ) is reached for $\mathrm{NiCu}$ alloys with ca. $40 \% \mathrm{Cu}$ content. ${ }^{160}$ The large difference in the optimum composition of $\mathrm{NiCu}$ nanoparticles and $\mathrm{NiCu}$ alloy films towards the HOR may be related to the particlesize dependent segregation of $\mathrm{Cu}$ atoms to the surface. ${ }^{127,161}$ Indeed, Monte Carlo simulations revealed massive segregation of $\mathrm{Cu}$ to the surface of $\mathrm{NiCu}$ nanoparticles.$^{51}$ For example, for ca. $18 \mathrm{~nm}$ diameter $\mathrm{NiCu}$ nanoparticles with the $0.04 \mathrm{Cu}$ fraction in the bulk, $\mathrm{Cu}$ surface fraction was as high as 0.5 .

Another additive used to tailor Ni activity in the HOR is molybdenum. Roy et al. reported a $50 \%$ $\mathrm{Ni}_{9} \mathrm{Mo}_{1} /$ Ketjenblack electrocatalyst, which demonstrated high activity in the HOR in terms of both surface- $\left(27 \mu \mathrm{A} \mathrm{cm} \mathrm{Ni}^{-2}\right)$ and mass-normalized $\left(4.5 \mathrm{~A} \mathrm{~g} \mathrm{~g}^{-1}\right)$ exchange current densities. ${ }^{162}$ The authors assigned the high activity to the decrease of the binding energy of the hydrogen intermediate to the NiMo surface as compared to that of metallic Ni. In addition, they reported power density of $120 \mathrm{~mW} \mathrm{~cm}^{-2}$ for an AEMFC with the $\mathrm{Ni}_{9} \mathrm{Mo}_{1} /$ Ketjenblack anode and $30 \mathrm{wt} . \% \mathrm{Pd} / \mathrm{XC}-72 \mathrm{R}$ cathode separated by Tokuyama A201 membrane at $70{ }^{\circ} \mathrm{C}$ and $70 \%$ relative humidity. Note however that post-mortem XPS analysis revealed almost total disappearance of Mo (initially dominating the electrocatalyst surface) from the surface of a membrane electrode assembly after the AEMFC test. The fact that Mo leaching did not result in a noticeable decrease in the fuel cell performance raises doubts regarding the role of Mo in the electrocatalyst and the actual nature of active sites. Leaching Mo from NiMo samples has been also observed by Schalenbach et al. ${ }^{163}$, who studied NiMo alloys with different composition prepared by arc melting (more emphasis on the durability of Ni-based catalysts will be given in Section 5). Sheng et al. 
reported a ternary $\mathrm{Co}_{0.17} \mathrm{Ni}_{4.49} \mathrm{Mo}_{1}$ alloy prepared by electrodeposition with the HOR exchange current density of $15 \mu \mathrm{A} \mathrm{cm} \mathrm{Ni}^{-2} .{ }^{164}$ The much higher activity of the latter compared to pure Ni electrocatalyst has been attributed to a favorable Ni- $\mathrm{H}_{a d}$ binding energy, while the effect of $\mathrm{OH}_{\text {ad }}$ species on the HOR was considered as insignificant. It has also been proposed that $\mathrm{MoO}_{2}$ species (if surviving at the surface of a $\mathrm{Ni} / \mathrm{MoO}_{2}$ electrocatalyst) should accelerate the Volmer step of the HOR by promoting the $\mathrm{OH}_{\mathrm{ad}}$ formation, while the nearby Ni sites serve for the hydrogen adsorption. ${ }^{165}$

Tang et al. reported Ni-Ag alloys with various compositions prepared by electron-beam vapor codeposition. ${ }^{166}$ DFT calculations predict a decrease of the $\mathrm{H}_{\mathrm{ad}}$ binding energy on $\mathrm{Ni}_{3} \mathrm{Ag}$ hollow sites as compared to pure $\mathrm{Ni}$, which should result in an enhanced kinetics of the hydrogen electrode reactions. The latter was indeed observed by the authors for the $\mathrm{Ni}_{0.75} \mathrm{Ag}_{0.25}$ sample in the HER, while the HOR current densities of NiAg alloys were found to be either similar (for Ni-rich samples) or inferior (for Agrich samples) to the pure Ni sample. Finally, by using $\mathrm{CeO}_{2}(\mathrm{r})-\mathrm{Ni} / \mathrm{XC}-72$ electrocatalyst prepared through decoration of $\mathrm{Ni}$ particles with partially reduced $\mathrm{CeO}_{2}$ during hydrothermal synthesis, Yang et al. investigated the influence of the oxygen vacancies in $\mathrm{CeO}_{2}$ on the kinetics of the HOR on $\mathrm{Ni}^{115}$ The $\mathrm{CeO}_{2}(\mathrm{r})-\mathrm{Ni} / \mathrm{XC}-72$ electrocatalyst demonstrated an improved activity in the HOR with the values of exchange current density $\left(38 \mu \mathrm{A} \mathrm{cm} \mathrm{Ni}^{-2}\right)$ and mass-normalized kinetic HOR current at $E=50 \mathrm{mV} v s \mathrm{RHE}$ (12.8 $\mathrm{A} \mathrm{g} \mathrm{gi}^{-1}$ ) being at least 2 times higher than the ones obtained for the reference $\mathrm{Ni} / \mathrm{C}$ sample (Table 1). On the basis of DFT calculations the authors attributed the enhanced $\mathrm{HOR}$ performance of the $\mathrm{CeO}_{2}(\mathrm{r})-$ $\mathrm{Ni} / \mathrm{XC}-72$ electrocatalyst to a bifunctional mechanism at the interface between $\mathrm{Ni}$ and $\mathrm{CeO}_{2}$ (Figure 5). It was suggested that $\mathrm{CeO}_{2}$ moieties on the surface serve as active sites for $\mathrm{OH}_{\mathrm{ad}}$ adsorption (due to the presence of oxygen vacancies), while the nearby Ni sites are characterized by a weaker adsorption of $\mathrm{H}_{\mathrm{ad}}$ as compared to pure Ni. Both of these factors should facilitate the HOR kinetics. ${ }^{115}$ 

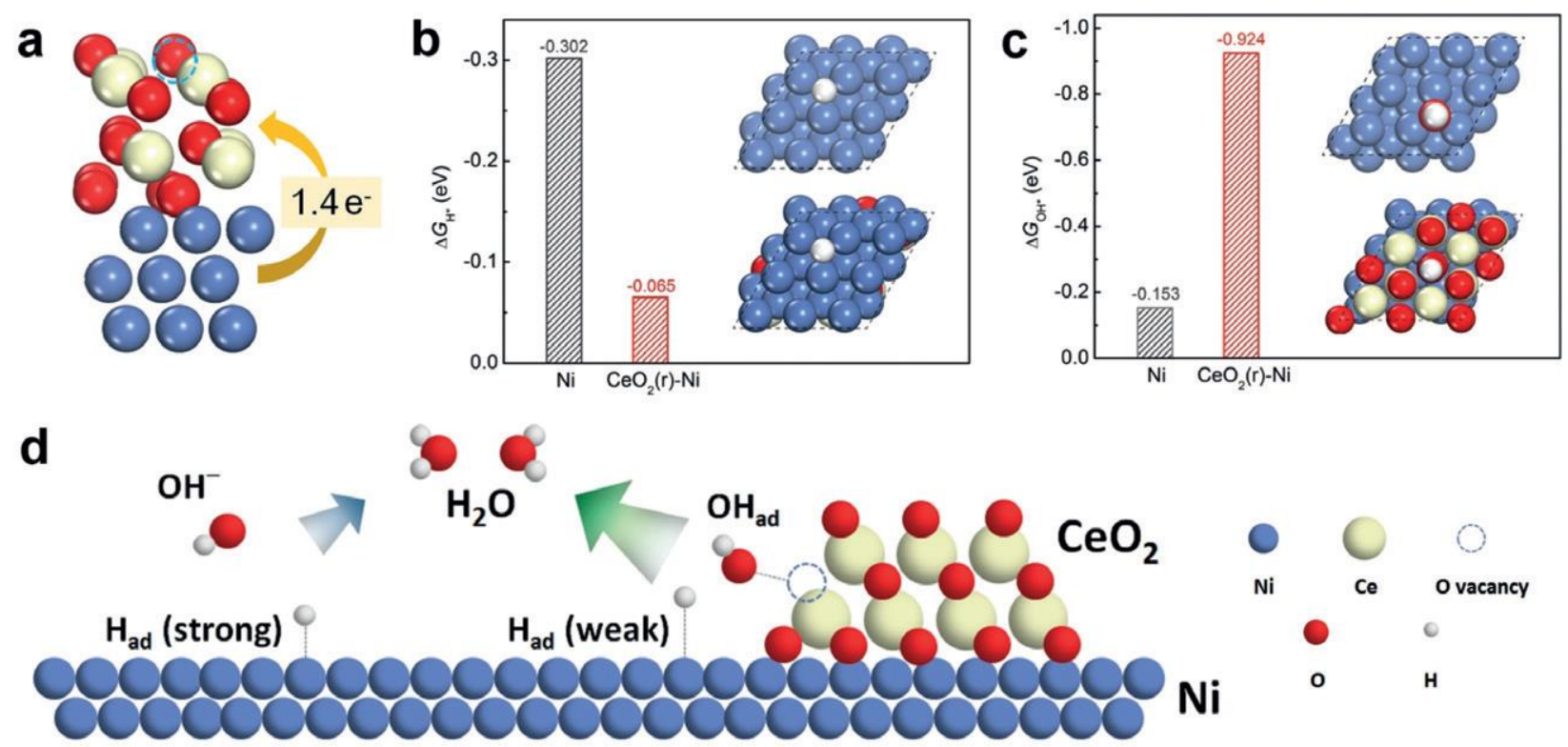

Figure 5. Schematic representation of the $\mathrm{CeO}_{2}(r)$-Ni hydrogen oxidation catalyst (the symbol ' $r$ ' points on a partial reduction of $\mathrm{CeO}_{2}$ during the catalyst preparation). (a) Representation of electron transfer between $\mathrm{CeO}_{2}(r)$ and $\mathrm{Ni}$ in the layered $\mathrm{CeO}(\mathrm{r})$-Ni hybrid. The calculated (b) $\triangle G_{\mathrm{H}}$ and (c) $\triangle G_{\mathrm{OH}}$ adsorption energies on $\mathrm{Ni}$ and $\mathrm{CeO}_{2}(r)$-Ni hybrid. (d) Schematic illustration of role of the oxygenvacancy-containing $\mathrm{CeO}_{2}$ during the HOR. Reproduced from Ref. ${ }^{115}$ with permission from Willey.

\section{Effect of support}

Modification of support rather than Ni nanoparticles opens up a new route for preparing Ni-based electrocatalysts with an improved activity in the HOR. Zhuang et al. have shown that Ni nanoparticles supported on N-doped carbon nanotubes (N-CNT) possess high surface- $\left(28 \mu \mathrm{A} \mathrm{cm} \mathrm{Ni}^{-2}\right)$ and massnormalized $\left(9 \mathrm{~A} \mathrm{~g}_{\mathrm{Ni}}{ }^{-1}\right)$ exchange currents, which are at least 20 and 3 times higher than the values obtained for unsupported and CNT-supported Ni nanoparticles, respectively. ${ }^{113}$ Using DFT calculations, the authors suggested that the $\mathrm{N}$-doped carbon support stabilizes Ni nanoparticles against reconstruction and 
affects d-orbitals of Ni leading to weakening of the $\mathrm{Ni}-\mathrm{H}_{\text {ad }}$ binding energy. Similar enhancement of the HOR activity of Ni through metal-support interaction was observed by Yang et al., who systematically evaluated performance of Ni nanoparticles supported on N-, B- and S-doped XC-72 carbon. ${ }^{167}$ The activity trend was found to follow the sequence of $\mathrm{Ni} / \mathrm{SC}>\mathrm{Ni} / \mathrm{NC}>\mathrm{Ni} / \mathrm{BC}>\mathrm{Ni} / \mathrm{C}$ (Table 1) and was ascribed by the authors to two main effects caused by heteroatom-doping: (i) formation of Ni nanoparticles with a smaller and more uniform particle size; (ii) metal-support interaction which weakens $\mathrm{Ni}-\mathrm{H}_{\mathrm{ad}}$ bonding resulting in an enhanced specific activity in the HOR.

Table 1. Comparison of the HOR activity of PGM-free $\mathrm{Ni}$-based electrocatalysts in alkaline media reported between 2014 and 2019. Notations: $d_{\mathrm{NiM}}$ (TEM) is the mean size of $\mathrm{Ni}(\mathrm{M})$ nanoparticles determined by TEM, $T$ is the temperature (RT means room temperature), ECSA is the electrochemically active surface area normalized by the mass of $\mathrm{Ni}, j_{0}$ and $i_{0}$ are the surface- and massnormalized exchange currents, $j_{\mathrm{k}}^{50 \mathrm{mV}}$ and $i_{\mathrm{k}}^{50 \mathrm{mV}}$ are the surface- and mass-normalized HOR kinetic currents at $E=50 \mathrm{mV} v s \mathrm{RHE}$

\begin{tabular}{|c|c|c|c|c|c|c|c|c|c|c|c|}
\hline & $\begin{array}{l}\text { Electro- } \\
\text { catalyst }\end{array}$ & $\begin{array}{c}\text { Loading, } \\
\text { mg }_{\text {NiM }} \\
\text { cm }_{\text {geom }}{ }^{-2} \\
\end{array}$ & $\begin{array}{c}d_{\mathrm{NiM}} \\
(\mathrm{TEM}), \\
\mathbf{n m} \\
\end{array}$ & Electrolyte & $\begin{array}{l}\mathrm{T}, \\
{ }^{\circ} \mathrm{C}\end{array}$ & $\begin{array}{l}\text { ECSA, } \\
\mathrm{m}^{2} \mathrm{gNi}^{-1}\end{array}$ & $\begin{array}{c}j_{0}, \\
\mu \mathrm{A} \text { cm }_{\mathrm{Ni}}{ }^{-2}\end{array}$ & $\begin{array}{c}i_{0}, \\
\mathbf{A} \mathbf{g}_{M}^{-1}\end{array}$ & $\begin{array}{l}i_{\mathrm{k}}{ }^{50 \mathrm{mV}} \\
\mathrm{A} \cdot \mathrm{g}_{\mathrm{Ni}}{ }^{-1}\end{array}$ & $\begin{array}{c}j_{\mathrm{k}}{ }^{50 \mathrm{mV}}, \\
\mu \mathrm{A} \cdot \mathrm{cm}_{\mathrm{Ni}}{ }^{-2}\end{array}$ & Ref. \\
\hline \multirow{6}{*}{ 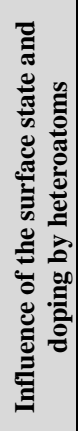 } & $42 \% \mathrm{Ni} / \mathrm{XC}-72$ & $0.07 \pm 0.01$ & 10 & $\begin{array}{c}0.1 \mathrm{~mol} \mathrm{~L}^{-1} \\
\mathrm{NaOH}\end{array}$ & 25 & $92.4 \pm 6.3$ & $6.2 \pm 0.6$ & $5.7 \pm 0.2$ & - & - & \multirow{2}{*}{137} \\
\hline & $\begin{array}{c}42 \% \mathrm{Ni}^{-} \\
\mathrm{NiO}_{x} / \mathrm{XC}-72\end{array}$ & $0.07 \pm 0.01$ & 10 & $\begin{array}{c}0.1 \mathrm{~mol} \mathrm{~L}^{-1} \\
\mathrm{NaOH}\end{array}$ & 25 & $46.7 \pm 8.6$ & $56 \pm 10$ & $22.4 \pm 4.3$ & $32.1 \pm 4.8$ & $83 \pm 12$ & \\
\hline & $\begin{array}{c}63.2 \% \\
\mathrm{Ni} / \mathrm{NiO} / \mathrm{C}\end{array}$ & 0.32 & $0-60$ & $\begin{array}{c}0.1 \mathrm{~mol} \mathrm{~L}^{-1} \\
\mathrm{KOH}\end{array}$ & - & - & 26 & - & 5 & - & 141 \\
\hline & $\mathrm{Ni}_{3} \mathrm{~N}$ & 0.28 & - & $\begin{array}{c}0.1 \mathrm{~mol} \mathrm{~L}^{-1} \\
\mathrm{KOH}\end{array}$ & - & - & 1.73 & - & - & - & \multirow{2}{*}{140} \\
\hline & $\begin{array}{c}51.4 \% \\
\mathrm{Ni}_{3} \mathrm{~N} / \mathrm{XC}-72 \mathrm{R}\end{array}$ & 0.16 & $4.6 \pm 1$ & $\begin{array}{c}0.1 \mathrm{~mol} \mathrm{~L}^{-1} \\
\mathrm{KOH}\end{array}$ & - & - & 14 & 12 & 24.38 & - & \\
\hline & $\begin{array}{c}71.7 \% \mathrm{np}- \\
\mathrm{Ni}_{3} \mathrm{~N} / \mathrm{C}\end{array}$ & 0.16 & $5-20$ & $\begin{array}{c}0.1 \mathrm{~mol} \mathrm{~L}^{-1} \\
\mathrm{KOH}\end{array}$ & RT & - & - & 10.3 & 29.75 & - & 139 \\
\hline \multirow{3}{*}{ 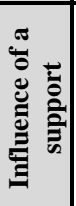 } & $\mathrm{Ni} N P s$ & 0.25 & - & $\begin{array}{c}0.1 \mathrm{~mol} \mathrm{~L}^{-1} \\
\mathrm{KOH}\end{array}$ & RT & - & 1.3 & 0.15 & 0.28 & 2.4 & \multirow{3}{*}{113} \\
\hline & $70 \% \mathrm{Ni} / \mathrm{CNT}$ & 0.25 & - & $\begin{array}{c}0.1 \mathrm{~mol} \mathrm{~L}^{-1} \\
\mathrm{KOH}\end{array}$ & RT & 10.4 & 9 & 1 & 1.9 & 18 & \\
\hline & $70 \% \mathrm{Ni} / \mathrm{N}-\mathrm{CNT}$ & 0.25 & 20 & $\begin{array}{l}0.1 \mathrm{~mol} \mathrm{~L}^{-} \\
{ }^{1} \mathrm{KOH}\end{array}$ & RT & 12.4 & 28 & 3.5 & 9.3 & 75 & \\
\hline
\end{tabular}




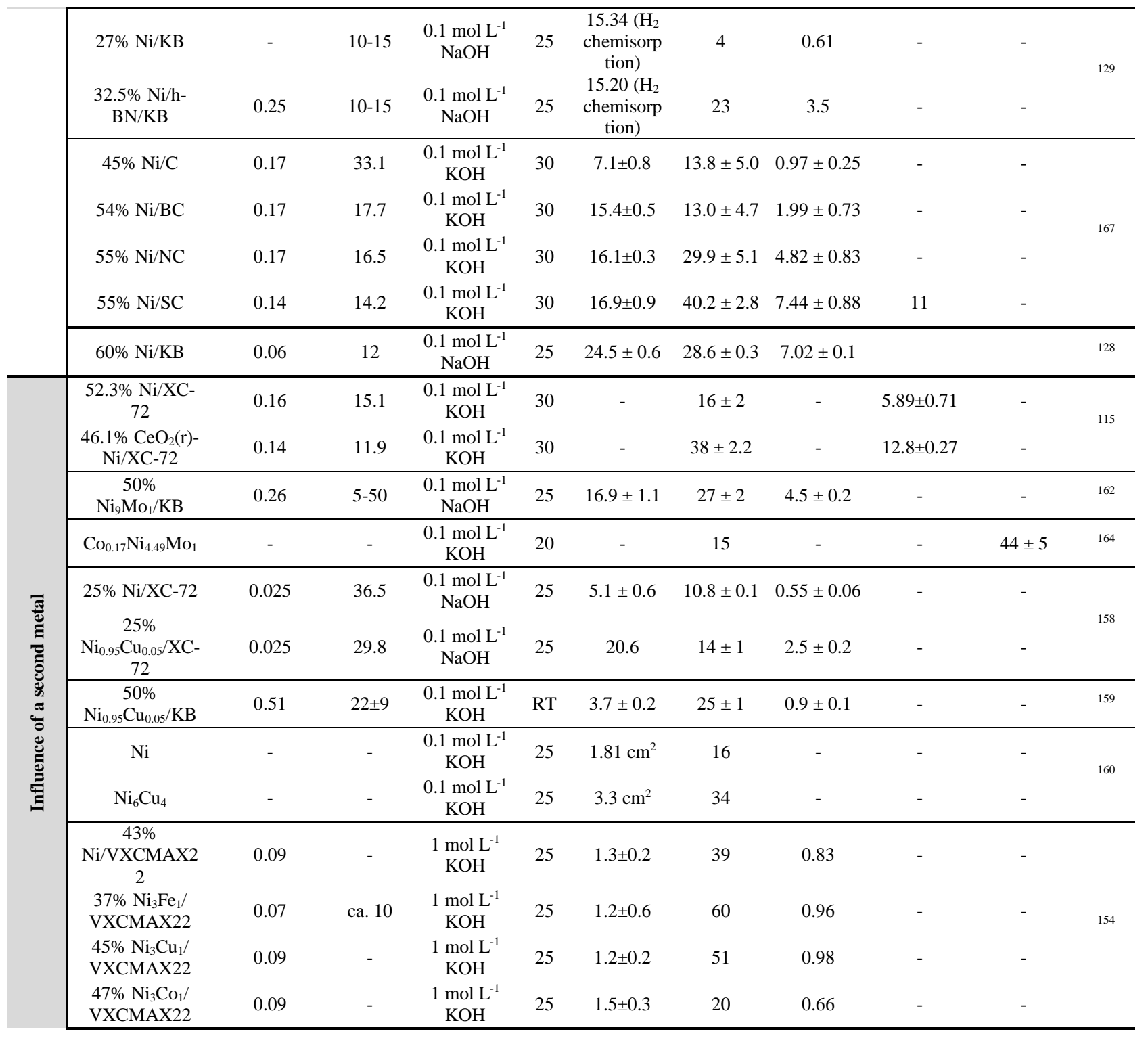

\subsection{Perspectives}

Data presented in section 3.3 revealed significant progress in the development of PGM-free Ni-based electrocatalysts for the HOR in alkaline media within the last 5 years. The activities of the best materials approach those reported for much more expensive $\mathrm{Pd} / \mathrm{C}$ electrocatalysts, while being only 10 times lower compared to those of Pt/C electrocatalysts. The most popular strategies used to enhance the performance of $\mathrm{Ni}$ in the HOR are based on its alloying with a second metal or incorporation of heteroatoms in either the Ni structure or in the carbon support. In both strategies the electronic effect of the additives on $\mathrm{Ni}$ is 
proposed as the key factor, which leads to the enhanced HOR activity due to weakening of the Ni-Had bond. At the same time, the values of the surface- and especially mass-normalized HOR activities of these alloyed and/or heteroatom-doped materials are inferior to those of the $\mathrm{Ni}-\mathrm{NiO}_{x} / \mathrm{XC}-72$ electrocatalyst with an optimized surface state of the Ni electrode. ${ }^{137}$ This suggests that addition of a second metal and/or dopant, along with a possible electronic effect, might indirectly affect the energy of hydrogen and oxygen bonding to the surface through stabilization of a particular $\mathrm{Ni}^{-N_{i O}}$ surface state, which possesses high activity in the HOR. In order to better distinguish between these two possibilities, in situ studies for monitoring the Ni surface state along with the measurement of the HOR activity are highly desirable.

\section{Oxidation of complex fuels on Ni-based electrocatalysts}

Section 3 of this review made it clear that $\mathrm{Ni}$ (and its alloys/composites) is a very popular electrocatalyst in hydrogen oxidation and evolution reactions, and that its activity greatly depends on the state of the Ni surface. Considering this, one may expect similar behavior of $\mathrm{Ni}$ in other electrocatalytic reactions occurring on the surface of metallic Ni sites and/or involving adsorbed $\mathrm{H}_{\mathrm{ad}}$ species in the reaction mechanism. In the current section we discuss more "exotic" oxidation reactions in basic electrolytes, such as the oxidation of complex fuels: borohydride, boranes and hydrazine. All these molecules contain hydrogen in their structure and have been studied as promising fuels for DLFCs.

\subsection{Borohydride}

The borohydride $\left(\mathrm{BH}_{4}^{-}\right)$oxidation reaction (BOR, Equation 4.1) is thermodynamically possible 0.41 $\mathrm{V}$ negative of the equilibrium potential of the hydrogen electrode (Equation 4.2). This conveys large theoretical energy density and specific energy to direct borohydride fuel cells (DBFC), but requires 
complete valorization of the $\mathrm{BH}_{4}^{-}$fuel (recovering 8 electrons per $\mathrm{BH}_{4}{ }^{-}$species) at potentials close to its reversible potential. In practice, this requires electrocatalysts which are very active for the BOR (Equation 4.1), but at the same time are poorly active for the heterogeneous hydrolysis of $\mathrm{BH}_{4}^{-}$(Equation 4.3 and 4.4) and for the HER (Equation 4.2).

$$
\begin{array}{ll}
\mathrm{BH}_{4}^{-}+8 \mathrm{OH}^{-} \rightleftarrows \mathrm{BO}_{2}^{-}+6 \mathrm{H}_{2} \mathrm{O}+8 \mathrm{e}^{-} & E^{0}=-0.41 \mathrm{~V} v s \mathrm{RHE} \\
\mathrm{H}_{2}+2 \mathrm{OH}^{-} \rightleftarrows 2 \mathrm{H}_{2} \mathrm{O}+2 \mathrm{e}^{-} & E^{0}=0 \mathrm{~V} v s \mathrm{RHE} \\
\mathrm{BH}_{4}^{-}+\mathrm{H}_{2} \mathrm{O} \rightleftarrows \mathrm{BH}_{3} \mathrm{OH}^{-}+\mathrm{H}_{2} & \\
\mathrm{BH}_{3} \mathrm{OH}^{-}+\mathrm{H}_{2} \mathrm{O} \rightleftarrows \mathrm{BO}_{2}^{-}+3 \mathrm{H}_{2} &
\end{array}
$$

The first study dealing with the borohydride oxidation reaction at $\mathrm{Ni}$ electrodes was published by Elder in $1962 .{ }^{168}$ As for the two other complex fuels mentioned above (hydrazine and boranes), the practical interest of such studies was linked to electroplating reactions. ${ }^{169}$ Two decades later, the group of Suda published the first papers dealing with the BOR at Ni electrodes (based on commercial $\mu \mathrm{m}$-size Ni powders mixed with a PTFE binder pasted on a Ni foam) in the context of the DBFC development. ${ }^{170,171}$ They immediately spotted the main advantages and drawbacks of the BOR at Ni: "The open-circuit potential was found to be about 0.15-0.2 V more negative than the hydrogen potential, depending on the concentration of borohydride. The results of polarization measurements indicated that a high power density can be achieved for the borohydride/Ni system. However, the coulombic efficiency was found to be $50 \%$ or less due to hydrogen evolution (...) hydrogen gas was not only generated from the hydrolysis reaction, but also from the electrochemical reaction. The actual anodic reaction of borohydride on the $\mathrm{Ni}$ electrode was proved to be a four-electron process rather than an eight-electron one." ${ }^{170}$ Wang et al. 
later on confirmed these findings ${ }^{172}$ : Ni fails to completely valorize the $\mathrm{BH}_{4}^{-}$fuel and leads to nonnegligible hydrogen escape ${ }^{173}$ in the course of the BOR.

Based on this statement, there have been multiple studies exploring Ni-based (sometimes nanostructured) catalysts for the BOR. Many focused on alloying Ni with other metals, like lanthanum in hydrogen storage alloys, ${ }^{174,175}$ boron, ${ }^{176}$ cobalt, ${ }^{177,178}$ coper, ${ }^{179}$ cerium ${ }^{180}$ or other rare Earths, ${ }^{181}$ ruthenium, ${ }^{182,183}$ palladium, either in composites ${ }^{184,185}$ or alloys, ${ }^{186}$ gold, either in composites, ${ }^{21,187}$ coreshell ${ }^{188}$ or alloyed ${ }^{189}$ nanoparticles, and platinum in composite ${ }^{185,190}$ or alloyed ${ }^{191-196}$ nanoparticles. Most of these strategies have been reviewed in Refs. ${ }^{197,198}$, but none of them enabled to reach significant BOR currents at potentials below that of the reversible hydrogen electrode, and in many cases (except for $\mathrm{NiCo}$ alloys), the co-metal was governing the overall catalyst's behavior. Besides, the issue of $\mathrm{Ni}$ passivation upon incursion to positive ( $E>0.4 \mathrm{~V} v s \mathrm{RHE}$ ) potentials or contact with oxygen (either during the electrode storage/preparation or while in an electrolyte) was often ignored, even for pure $\mathrm{Ni}$ catalysts, ${ }^{199}$ which renders comparison between different materials inconclusive. In essence, the existing literature prior to 2019 did not really enable to state whether nanostructured Ni could be a viable catalyst for DBFC anode.

The picture recently changed, when Oshchepkov et al. demonstrated that the state of surface of electrodeposited nanostructured $\mathrm{Ni}$ electrodes $\left(\mathrm{Ni}_{\mathrm{ED}} / \mathrm{C}\right)$ had a tremendous influence on their $\mathrm{BOR}$ activity. ${ }^{200}$ The authors took benefit of the slow HER at a reduced Ni surface (see Section 3), to exploit electrocatalytic activity of carbon-supported electrodeposited $\mathrm{Ni}$ ED/C towards the BOR: in other words, the net BOR oxidation current at potentials below $E=0 \mathrm{~V} v s$ RHE is larger when the electrode is less HER active (Figure 6). In result, significant BOR currents are monitored below $E=-0.2 \mathrm{~V} v \mathrm{~s}$ RHE on a reduced metallic $\mathrm{Ni}_{\mathrm{ED}} / \mathrm{C}$ (curve 3 in Figure $6 \mathrm{~b}$ and $6 \mathrm{a}$ ), the limiting current being already reached at $E=$ $0 \mathrm{~V} v s$ RHE (a potential where most of the catalysts listed above as well as their PGM-based counterparts 
barely initiate the BOR). On the contrary, a partially-oxidized $\mathrm{NiED} / \mathrm{C}$ demonstrates significantly lower BOR activity, which goes along with its higher HER activity (curve 2 in Figure $6 \mathrm{~b}$ and $6 \mathrm{a}$ ). Finally, a strongly-oxidized $\mathrm{Ni}_{\mathrm{ED}} / \mathrm{C}$ is neither BOR nor HER active. This observation essentially explains the very contradictory results reported for Ni-based electrodes in the literature: in essence, most of these catalysts had an uncontrolled (likely strongly oxidized) state of the surface and could not lead to consequent BOR currents below $E=0 \mathrm{~V} v s$ RHE.

To better understand the origin of high BOR activity of metallic Ni, DFT calculations were used to determine binding of key BOR intermediates on $\mathrm{Ni}(111)$ and compare them with those of $\operatorname{Pt}(111)$, $\mathrm{Au}(111)$ and $\mathrm{Pd}(111){ }^{200}$ It was found that the binding of adsorbed $\mathrm{BH}_{4}$ with the metallic Ni surface is intermediate to that of $\mathrm{Pt}$ and $\mathrm{Au}$. It is strong enough to allow for the $\mathrm{B}-\mathrm{H}$ bond breaking at low overpotential but not too strong to result in surface poisoning by $\mathrm{BH}_{\mathrm{ad}}$ species as on the Pt surface. ${ }^{173}$

These promises of reduced $\mathrm{Ni}_{\mathrm{ED}} / \mathrm{C}$ catalysts were then confirmed in a DBFC configuration (Figure 7); Ni nanoparticles could be electrodeposited directly on a carbon-based commercial gas diffusion electrode (GDE), mounted as the anode in a membrane electrode assembly with a Nafion cation-exchange membrane and a commercial Pt-based cathode, and tested in a DBFC unit cell. ${ }^{200}$ In these tests, the $\mathrm{Ni}_{\mathrm{ED}} / \mathrm{GDE}$ outperformed a $\mathrm{Pt}_{\text {black }}$ anode in identical operating conditions: the Ni-based DBFC presented a higher open circuit voltage (OCV $=1.2 \mathrm{~V}$ against $1.0 \mathrm{~V}$ for the Pt-based DBFC), hereby confirming the possibility to catalyze BOR at potential below $E=0 \mathrm{~V} v s$ RHE, but also led to larger current densities at a given cell voltage. Overall, the power density of the Ni-based DBFC was ca. 2.5 times superior to that of the Pt-based DBFC, but larger hydrogen escape was monitored, owing to the inability of Ni to completely valorize produced $\mathrm{H}_{2}$. More recently Braesch et al. have further improved the DBFC performance by preparing Ni-based anodes with an open structure to facilitate mass-transfer of either borohydride or evolved hydrogen. ${ }^{201}$ For this purpose, the authors used electrochemically-assisted etching 
in order to depassivate the surface of an initially-oxidized (because of storage under air) Ni felt (NFT) support. The latter was further modified by electrodeposition of Ni nanoparticles providing high active surface area and ensuring its metallic state (Figure 8). The maximum power density of the DBFC achieved using NiED/eNFT (Ni nanoparticles electrodeposited on an etched NFT) anode was as high as $470 \mathrm{~mW}$ $\mathrm{cm}^{-2}$ at $c a .0 .58 \mathrm{~A} \mathrm{~cm}^{-2}$, while the current density at the cell voltage of $1.0 \mathrm{~V}$ was more than two times higher compared to $\mathrm{Ni}_{\mathrm{ED}} / \mathrm{GDE}$ anode $\left(23 \mathrm{~mA} \mathrm{~cm}{ }^{-2} v s 11 \mathrm{~mA} \mathrm{~cm}^{-2}\right.$ after 12 hours, respectively).

These results clearly demonstrate that Ni-based catalysts, provided that they are duly-prepared and employed, can outperform PGM-based ones for the oxidation of complex fuels in alkaline conditions, which is promising for the development of PGM-free DLFCs. 

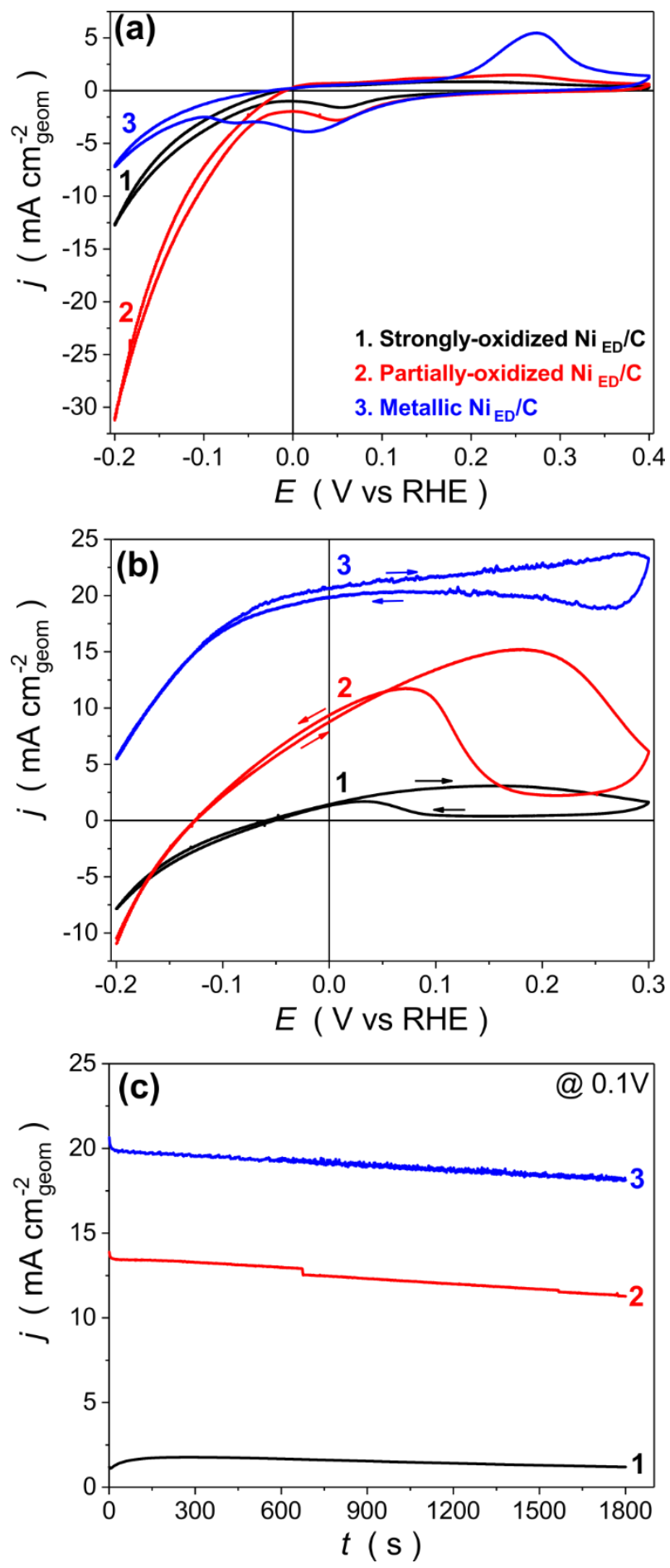

Figure 6. (a, b) CVs and (c) chronoamperommetry curves obtained for various $N i_{E D} / C$ catalysts with a similar loading on a rotating disc electrode but different surface state (as indicated in panel a) under $\mathrm{N}_{2}$ atmosphere at the following conditions: (a) $1.0 \mathrm{~mol} \mathrm{~L}^{-1} \mathrm{NaOH}, v=20 \mathrm{mV} \mathrm{s}^{-1}, \omega=0 \mathrm{rpm}$, (b) 
$1.0 \mathrm{~mol} \mathrm{~L}^{-1} \mathrm{NaOH}+5 \mathrm{mmol} \mathrm{L}^{-1} \mathrm{NaBH}_{4}, v=20 \mathrm{mV} \mathrm{s}^{-1}, \omega=1600 \mathrm{rpm}$, (c) $1.0 \mathrm{~mol} \mathrm{~L}^{-1} \mathrm{NaOH}+5 \mathrm{mmol}$ $L^{-1} \mathrm{NaBH}_{4}, \omega=1600 \mathrm{rpm}, \mathrm{E}=0.1 \mathrm{~V} v \mathrm{R}$ RE. Reproduced from ${ }^{200}$ with permission from the American Chemical Society.
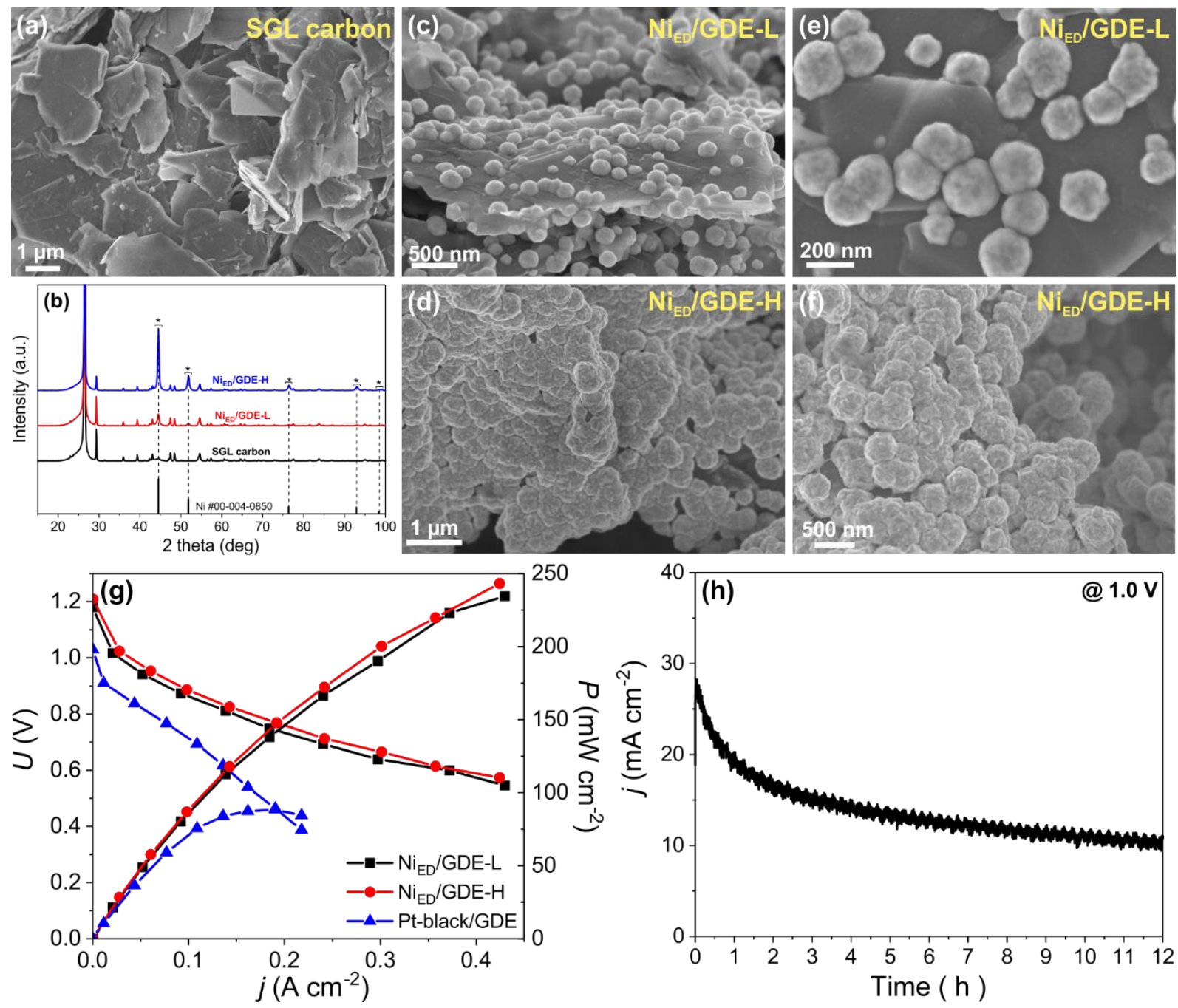

Figure 7. Characterization of $N i_{E D} / G D E$ samples. SEM images of pure carbon cloth (SGL carbon, SIGRATEX) (a) and after electrodeposition of Ni nanoparticles at low (NiED/GDE-L, $c$ and e) and high (Ni $i_{E D} / G D E-H, d$ and f) metal loading; (b) XRD patterns obtained for the corresponding samples; (g) Ohmic-drop corrected I-U and I-P curves registered in fuel cell configuration using either $N i_{E D} / G D E$ or Pt-black/GDE anodes and Pt-black/GDE cathode; (h) Durability study of $N i_{E D} / G D E-H$ anode at the 
potentiostatic hold at $U=1.0 \mathrm{~V}$. Reproduced from ${ }^{200}$ with permission from the American Chemical Society.
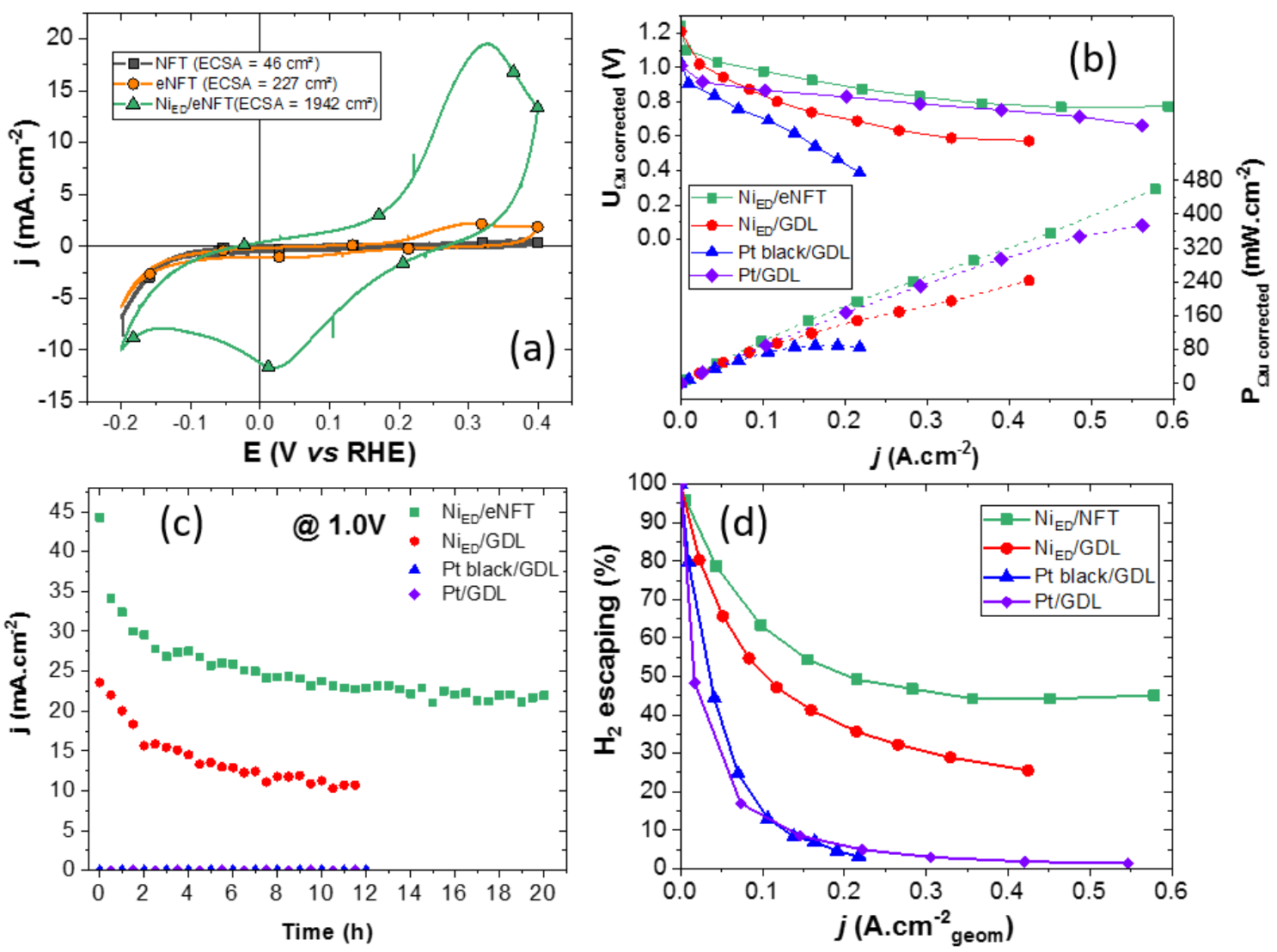

Figure 8. (a) CVS obtained for various Ni-based DBFC anodes at v $=20 \mathrm{mV} \mathrm{s}^{-1}$ in $1 \mathrm{~mol} \mathrm{~L}^{-1} \mathrm{NaOH}$, $T=25^{\circ} \mathrm{C}$ for (geometric surface area $8 \mathrm{~cm}^{2}$; ECSA values indicated in the plot): pristine Ni felt (NFT), etched Ni felt (eNFT), Ni nanoparticles electrodeposited on the etched Ni felt (NiED/eNFT). (b) DBFC performance of the electrodes of panel (a) compared to $N i_{E D} / G D L$ and Pt black/GDL from Ref. ${ }^{200}$ and Pt/GDL, $T=60^{\circ} \mathrm{C}$, flow rate $50 \mathrm{~mL} \mathrm{~min}{ }^{-1}$. (c) Stability measurements at $1 \mathrm{~V}$ for the four different electrodes. (d) Hydrogen escape (\%) during DBFC test measured using a $\mathrm{H}_{2}$ pump connected to the outlet of the cell. Reproduced from ${ }^{201}$ with permission from Willey. 


\subsection{Boranes}

Studies of borane electrooxidation on Ni electrodes were firstly motivated by the need to understand electroplating reactions. ${ }^{202}$ These works were pioneered by Burke et al., who studied the behavior of dimethylamine-borane (DMAB) at mechanically-polished $\mathrm{Ni} \cdot{ }^{203} \mathrm{Ni}$ was found to be very active for the reaction in its reduced state until the onset of $\beta-\mathrm{Ni}(\mathrm{OH})_{2}$ formation $(-0.3<E<0.4 \mathrm{~V} v s$ RHE), above which it gets passivated and hence inactive for the DMAB oxidation reaction (DMABOR). Such low (E $=-0.3 \mathrm{~V} v s \mathrm{RHE}$ ) potential for the reaction onset suggests that $\mathrm{BH}_{3} \mathrm{OH}^{-}$is the reactive species (eq. 4.5), as had been demonstrated for gold surfaces two decades earlier. ${ }^{204}$

$$
\mathrm{BH}_{3} \mathrm{OH}^{-}+6 \mathrm{OH}^{-} \rightleftarrows \mathrm{BO}_{2}^{-}+5 \mathrm{H}_{2} \mathrm{O}+6 \mathrm{e}^{-}
$$

Since then, to the authors' knowledge, only two papers have dealt with borane oxidation at Ni-based catalysts. Zadick et al. studied a series of $\mathrm{Ni}_{3} \mathrm{M} / \mathrm{Ketjenblack}$ catalysts $(\mathrm{M}=\mathrm{Pd}, \mathrm{Ag}$ and $\mathrm{Co})$ for the ammonia borane $(\mathrm{AB})$ oxidation reaction $(\mathrm{ABOR}){ }^{205}$ All the catalysts were active for either the direct $\mathrm{ABOR}$ or for the decomposition of $\mathrm{AB}$ to produce hydrogen, the latter being then oxidized in the HOR. The noblest catalyst $\left(\mathrm{Ni}_{3} \mathrm{Pd}\right)$ exhibited the most positive ABOR onset potential (a clear drawback), because it essentially promoted fast hydrogen generation (by decomposition of AB or by evolution from water through the HER) and oxidation reactions and not the ABOR. The lowest ABOR onset potential was reached for the non-noble material $\left(\mathrm{Ni}_{3} \mathrm{Co}\right)$, the least active for $\mathrm{AB}$ decomposition and $\mathrm{H}_{2}$ generation (an advantage). Unfortunately, this material was also the less easy to depassivate (Ni/Vulcan XC72 being completely inactive in similar conditions, owing to its strongly oxidized surface state upon the synthesis

method chosen then), but in the end, enabled the best compromise in terms of cost $v s$ activity/durability (this material leads to a low onset potential and reasonable ABOR activity at fuel cell anode-relevant 
potentials, Figure 9). Later on, Wang et al. ${ }^{206}$ studied $\mathrm{Ni}_{1-x} \mathrm{M}_{x} \mathrm{Se}_{2}(\mathrm{M}=\mathrm{Fe}, \mathrm{Co}, \mathrm{Cu})$ nanowires grown on carbon fibers (denoted as CFP) for the ABOR and observed near-similar catalytic activities for the ABOR to those of Zadick et al. ${ }^{205}$ : the most active of their catalysts, $\mathrm{Ni}_{1-x} \mathrm{Cu}_{x} \mathrm{Se}_{2} / \mathrm{CFP}$, exhibited a slightly lower ABOR onset potential ( $c a . E=-0.15 \mathrm{~V} v s$ RHE versus $E=-0.1 \mathrm{~V}$ vs $\mathrm{RHE}$ for the $\mathrm{Ni}_{3} \mathrm{Co} / \mathrm{KetjenBlack}$ of Zadick et al.) and equivalent kinetic current density to that of Zadick et al. An asset of these two catalysts $\left(\mathrm{Ni}_{1-x} \mathrm{Cu}_{x} \mathrm{Se}_{2} / \mathrm{CFP}\right.$ and $\left.\mathrm{Ni}_{3} \mathrm{Co} / \mathrm{Ketjenblack}\right)$ is that they are poor HOR/HER catalysts, which enables lowpotential oxidation of the $\mathrm{AB}$ fuel. In both cases, the activity in $\mathrm{ABOR}$ operation is rather stable, showing insignificant signs of poisoning of the catalyst surfaces by reaction intermediate species/products, which leaves hope to develop practical Ni-based catalysts for the ABOR in a direct borane fuel cell.

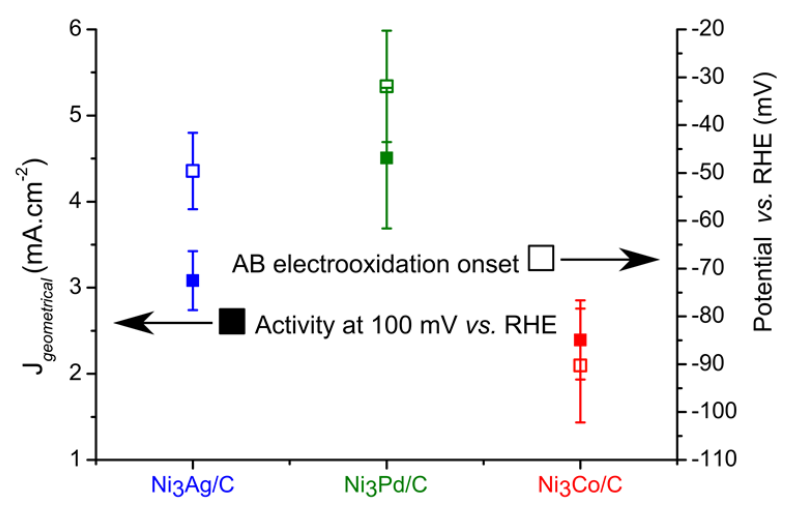

Figure 9. Comparison of the ABOR activity measured in $5 \mathrm{mmol} \mathrm{L}^{-1} \mathrm{AB}+0.1 \mathrm{~mol} \mathrm{~L}^{-1} \mathrm{NaOH}$ at $E=$ $100 \mathrm{mV}$ vs. RHE, $\mathrm{T}=25^{\circ} \mathrm{C}$ and $\omega=1600 \mathrm{rpm}$ for the $\mathrm{Ni} i_{3} \mathrm{Ag} / \mathrm{C}, \mathrm{Ni}{ }_{3} \mathrm{Pd} / \mathrm{C}$ and $\mathrm{Ni} i_{3} \mathrm{Co} / \mathrm{C}$ catalysts $(\mathrm{C}=$ Ketjenblack). Reproduced from ${ }^{205}$ with permission from Elsevier.

\subsection{Hydrazine}

The use of Ni-based electrocatalysts (namely Ni salts and Ni boride "impregnated on carbon") for hydrazine oxidation dates back to $1970 .{ }^{207}$ Note that as the oxidation of hydrazine for fuel cell applications 
is studied in aqueous electrolytes, this reactant is likely oxidized as hydrazine hydrate (hence the notation hydrazine hydrate oxidation reaction, HHOR, eq. 4.6).

$$
\mathrm{N}_{2} \mathrm{H}_{4}+4 \mathrm{OH}^{-} \rightleftarrows \mathrm{N}_{2}+4 \mathrm{H}_{2} \mathrm{O}+4 \mathrm{e}^{-} \quad E^{0}=-0.33 \mathrm{~V} v s \mathrm{RHE}
$$

In his seminal paper, Wiesener noted that the HHOR performance surpassed that of PGM catalysts, provided the $\mathrm{Ni}$ surface was "appropriately" activated (treatment with gaseous $\mathrm{NH}_{3}$ was the best solution according to the author). Many studies followed this initial report, aiming at optimizing the HHOR performance. Meibuhr et al. evaluated NiB/Ni electrodes for the HHOR 208 and found that surfaces reduced for 1 hour in a mixture of $6 \% \mathrm{H}_{2}$ in $\mathrm{Ar}$ at mild temperature $\left(93^{\circ} \mathrm{C}\right)$ were the most durable in operation, which was explained by their optimal retention of boron in such a reduced $\mathrm{NiB}$ layer. ${ }^{209}$ Considering the above-cited study of the BOR (see section 4.1.), strong dependence of the HHOR activity on the extent of oxidation of the Ni surface might represent an alternative explanation. Ni (studied as a mechanically-polished Ni rod) is itself active for the HHOR, and shows two domains of activity: the first at low potentials around the $\mathrm{Ni} / \alpha-\mathrm{Ni}(\mathrm{OH})_{2}$ transition $(0<E<0.4 \mathrm{~V} v s \mathrm{RHE})$, and the second one at higher potentials (above $E=1 \mathrm{~V} v$ s RHE) ${ }^{203}$. This suggests that reversible redox transitions of $\mathrm{Ni} / \mathrm{Ni}(\mathrm{II})$ and $\mathrm{Ni}(\mathrm{II}) / \mathrm{Ni}(\mathrm{III})$ are involved in the HHOR at low and high potentials, respectively (the second domain being useless for electricity generation in a direct hydrazine fuel cell).

Because practical fuel cell electrodes are necessarily porous, it soon became obvious that nanostructured Ni-based electrodes were mandatory. So, several studies evaluated carbon-supported Nibased electrodes for the HHOR in either neutral ${ }^{210}$ or alkaline ${ }^{211}$ conditions, and it became clear that the irreversible oxidation of $\mathrm{Ni}$ was a severe impediment for nanostructured materials. As such, many strategies have been employed to make Ni-based HHOR catalysts more robust. Amongst these strategies, forming composites (e.g. carbon-supported $\mathrm{Ni}+\mathrm{Pd}^{212}$ ) or alloys (e.g. unsupported $\mathrm{NiZn}{ }^{213}, \mathrm{NiCo}^{214}$, $\mathrm{NiLa}^{215}$ and NiMo ${ }^{216}$ alloys) could be promising solutions. Their success was explained by a retardation 
of the Ni passivation ${ }^{212}$; for example, in the case of the NiZn alloy, Ni alloying with Zn creates a Lewis base catalyst in which $\mathrm{Ni}$ acts as an electron-pair donor inducing the adsorption and partial dehydrogenation of hydrazine, which was proposed to prevent (or at least retard) its passivation ${ }^{213}$ (it could also be suggested that $\mathrm{Zn}$ provides anodic protection of $\mathrm{Ni}$ ). For the NiCo alloy, the authors noted that $\mathrm{Ni}$ was more reduced at a given potential than in a monometallic $\mathrm{Ni}$ electrode, here again pointing to the importance of the state of the Ni surface for electrocatalysis of oxidation reactions. The importance of initially metallic Ni for high-activity HHOR was confirmed by Jeon et al. ${ }^{217}$ and Finkelstein et al. ${ }^{218}$. In the case of NiLa "alloys", a positive influence of some $\mathrm{La}(\mathrm{OH})_{3}$ phase (the material is therefore a composite, at least in part) enhances the reaction kinetics by providing $\mathrm{OH}$-species at lower potential values. Finally, for the NiMo catalysts, the non-negligible $(<15$ at.\%) molybdenum content was proposed "to stabilize the hydrazine N-N bond, preventing the chemical decomposition of hydrazine into ammonia, and improving the catalyst selectivity towards the complete (and desired) hydrazine oxidation into $\mathrm{N}_{2}$ gas". ${ }^{216}$

This selected literature review demonstrates that there is some merit to combine $\mathrm{Ni}$ with other elements, notably to improve its capability to remain in "reduced" state of surface. The strategy was further followed by preparing binary or ternary Ni-based catalysts in a combinatorial chemistry approach, ${ }^{219}$ or oxide-based ${ }^{220,221}$ catalysts, but the latter materials showed more positive reaction onset potentials and did therefore not enable to surpass catalysts where $\mathrm{Ni}$ was in its reduced state.

Then, many other materials were developed for the HHOR, including strategies to enhance the bubble release ( $\mathrm{N}_{2}$ is the final product of the HHOR), via shape optimization (super-hydrophobicity was targeted) of the electrode material, ${ }^{222,223}$ or combination of $\mathrm{Ni}$ with Se, ${ }^{224,225}$ noble metal, ${ }^{226,227}$ phosphorus, ${ }^{228,229}$ or sulfur. ${ }^{224,230}$ As a matter of fact, none of these strategies resulted in catalysts which really outperform those prepared by the more conventional routes presented above. As such, real direct hydrazine fuel cell 
tests were performed in automotive conditions with the unsupported $\mathrm{Ni}-\mathrm{Zn}$ catalysts, moreover, a demonstration vehicle was launched with this catalyst ${ }^{231}$, clearly highlighting that Ni-based catalysts are practical and good candidates to replace PGM ones for automotive applications.

\section{Durability of Ni-based catalysts in alkaline environments}

Studies dealing with the degradation of Ni-based catalysts in alkaline environments are scarce. In the 1980s, Ross et al. performed systematic studies of corrosion of carbon black substrates to be used in oxygen evolution anodes in concentrated potassium hydroxide at a moderate temperature $\left(T=50^{\circ} \mathrm{C}\right)$. They noticed that while the presence of Co oxides (which were used as oxygen evolution catalysts) accelerated irreversible oxidation of an acetylene black support into $\mathrm{CO}$ and/or soluble organic compounds, ${ }^{232}$ the presence of $\mathrm{Ni}$ oxide nanoparticles led to little or no effect on the corrosion rate of a graphitized carbon black. ${ }^{233}$

More recently, Davydova et al. investigated chemical and electrochemical stability of tailored Vulcan (VXCMAX22) carbon-supported monometallic $\mathrm{Ni}$ and bimetallic $\mathrm{Ni}_{3} \mathrm{M}(\mathrm{M}=\mathrm{Co}, \mathrm{Fe}, \mathrm{Cu}, \mathrm{Mo})$ nanoparticles in supporting alkaline electrolytes, using a combination of in situ on-line ICP-MS (inductively coupled plasma mass spectrometry) with a flow cell and ex situ TEM (transmission electron microscopy), XPS (X-ray photoelectron spectroscopy) and XRD (X-ray diffraction). ${ }^{234}$ The authors noticed different behavior of the studied materials (Figure 10a). On the one hand, two catalysts have shown non-negligible instability in potentiodynamic conditions: Mo intensely dissolves from $\mathrm{Ni}_{3} \mathrm{Mo} / \mathrm{C}$, while $\mathrm{Cu}$ in $\mathrm{Ni}_{3} \mathrm{Cu} / \mathrm{C}$ is stable below $E=0.4 \mathrm{~V}$ vs $\mathrm{RHE}$ but undergoes noticeable electrochemical transient dissolution above this potential. On the other hand, pure $\mathrm{Ni} / \mathrm{C}, \mathrm{Ni} 3 \mathrm{Co} / \mathrm{C}$ and $\mathrm{Ni}_{3} \mathrm{Fe} / \mathrm{C}$ showed negligible dissolution up to $E=0.7 \mathrm{~V} v s$ RHE. This absence of dissolution does however not grant stability of their HOR performance, since all catalysts lose their HOR activity upon incursions to the potential interval 
above $E=0.5 \mathrm{~V}$ vs RHE (Figure $10 \mathrm{~b}$, for $\mathrm{Ni}_{3} \mathrm{Fe} / \mathrm{C}$ ), owing to the passivation of metal nanoparticles. The authors concluded that fuel starvation events in AEMFCs, which would result in high anodic potentials, require adapted cell activation and operation strategies to prevent any catalyst passivation and an ensuing depreciation of their HOR performance.

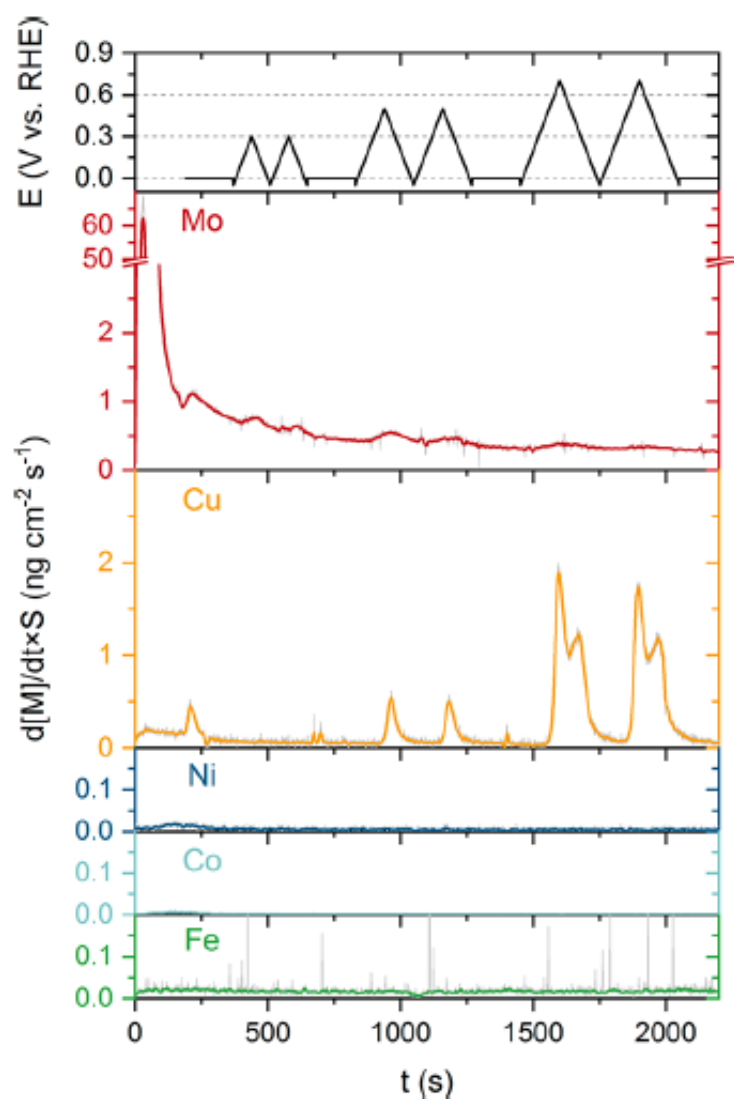

I
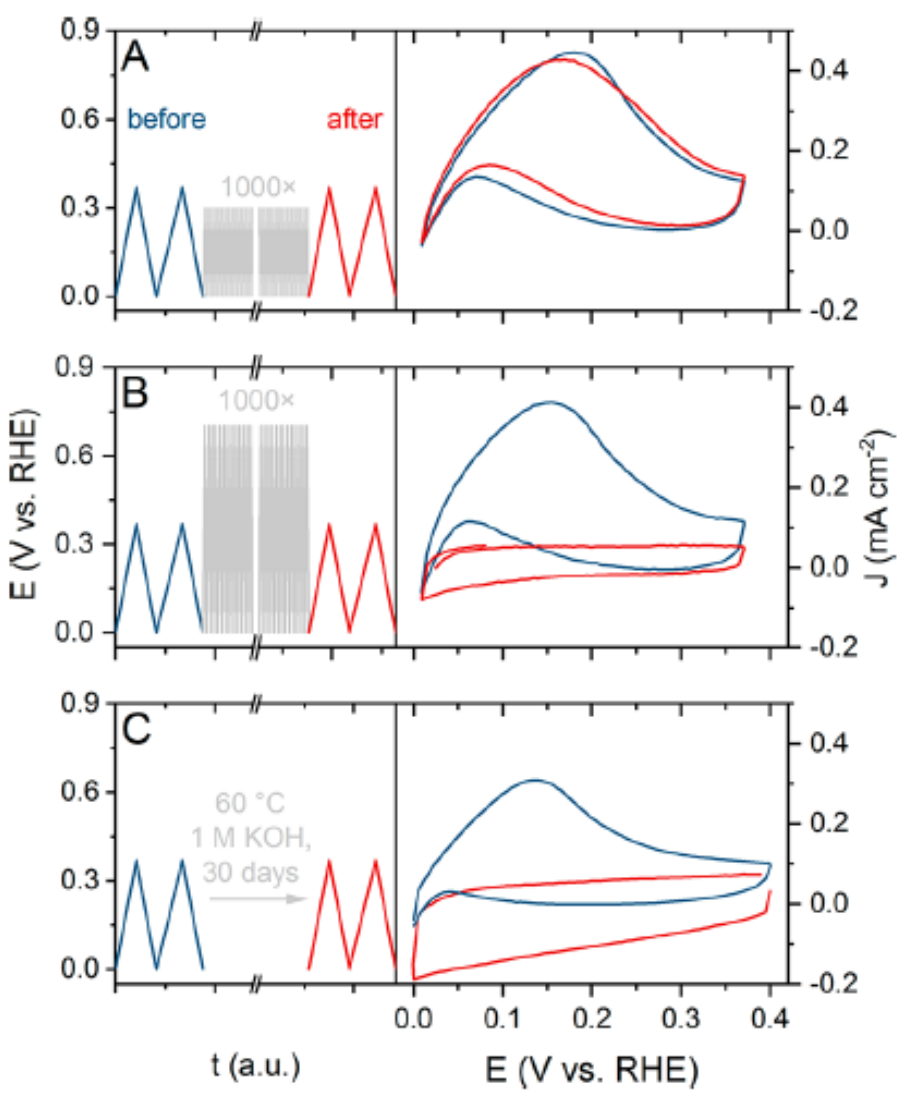

II

Figure 10. (I) Characterization of the dissolution of $\mathrm{Ni} / \mathrm{C}$ and of several $\mathrm{Ni}{ }_{3} \mathrm{M} / \mathrm{C}$ catalysts upon potentiodynamic cycling in the range $-0.05<E<0.7 \mathrm{~V}$ vs $\mathrm{RHE}$ in $0.05 \mathrm{~mol} \mathrm{~L}^{-1} \mathrm{KOH}$ supporting electrolyte for $M=F e$ (green), $M=$ Co (light blue), Ni (dark blue), $M=C u$ (orange), and $M=M o$ (red). The light gray traces represent the original dissolution data, and the colored components were smoothed for clarity. (II) HOR polarization curves (right panel) for $\mathrm{Ni} 3 \mathrm{Fe} / \mathrm{C}$ before (blue) and after (red) various degradation protocols shown in the left panel: 1000 cycles in the potential window of (a) $0<E<0.3 \mathrm{~V}$ vs RHE and (b) $0<E<0.7 \mathrm{~V} v \mathrm{RHE}$, as well as (c) before and after 30 days at open-circuit potential. 
$0.05 \mathrm{~mol} \mathrm{~L}^{-1} \mathrm{KOH}, T=25^{\circ} \mathrm{C}, v=1 \mathrm{mV} \mathrm{s}^{-1}, \omega=1600 \mathrm{rpm}$. Reproduced from ${ }^{234}$ with permission from the American Chemical Society.

These results confirmed those of Zadick et al., obtained on a similar class of materials $\left(\mathrm{Ni}_{3} \mathrm{M} /\right.$ Ketjenblack 600J nanoparticles, with $\mathrm{M}=\mathrm{Pd}, \mathrm{Co}$ and Ag). ${ }^{205}$ The Ni-based nanoparticles showed neither sign of consequent metal dissolution nor of severe modification of their shape or of detachment from the carbon support, as revealed by identical-location transmission electron microscopy after potentiostatic (at $E=100 \mathrm{mV}$ vs RHE in a $5 \mathrm{mmol} \mathrm{L}-1 \mathrm{AB}+0.1 \mathrm{~mol} \mathrm{~L}^{-1} \mathrm{NaOH}$ electrolyte) or potentiodynamic (between $0.1<E<1.23 \mathrm{~V} v s$ RHE in $0.1 \mathrm{~mol} \mathrm{~L}^{-1} \mathrm{NaOH}$ ) polarization at $T=25^{\circ} \mathrm{C}$ (Figure 11), for $\mathrm{Ni}_{3} \mathrm{Co} /$ Ketjenblack 600J nanoparticles). While the borane oxidation activity did decrease after incursion of the electrodes to high potential values, it could be restored provided a proper re-activation procedure (incursion to low potential values in presence of the strong borane reducer) was adopted. This shows that combining a suitable reducing-potential and the presence of strong reducer in the electrolyte can depassivate $\mathrm{Ni}_{3} \mathrm{Co}$ nanoparticles (and even more easily noble-based $\mathrm{Ni}_{3} \mathrm{Ag}$ and $\mathrm{Ni}_{3} \mathrm{Pd}$ catalysts); the comparison with the results of Davydova et al. ${ }^{234}$, shows that molecular hydrogen is not a sufficiently strong reducer to enable depassivation of this class of non-noble carbon-supported Ni-based catalysts (nanostructured $\mathrm{Ni}_{3} \mathrm{M}, \mathrm{M}=\mathrm{Co}, \mathrm{Fe}, \mathrm{Cu}$, etc.).

In any case, carbon-supported $\mathrm{Ni}$-based nanoparticles do not seem to suffer consequent nanoparticles detachment from their carbon support, owing to the rupture of their binding to the carbon substrate by nanoparticles-assisted local corrosion of the carbon into carbonate species. While this mechanism of degradation seriously hampers the long-term stability of PGM-based nanoparticles in alkaline electrolytes, ${ }^{235-238}$ it seems rather less operant in interface with an anion-exchange polymer electrolyte, ${ }^{239}$ but no such data exists for Ni-based catalysts, at least to the authors' knowledge. 


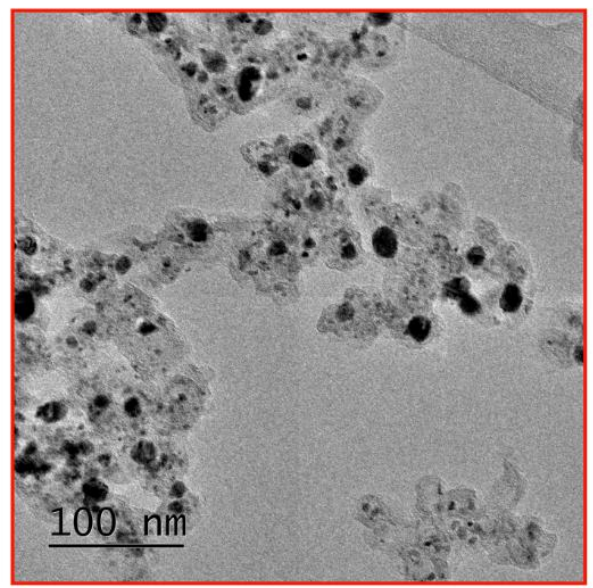

\section{Pristine}
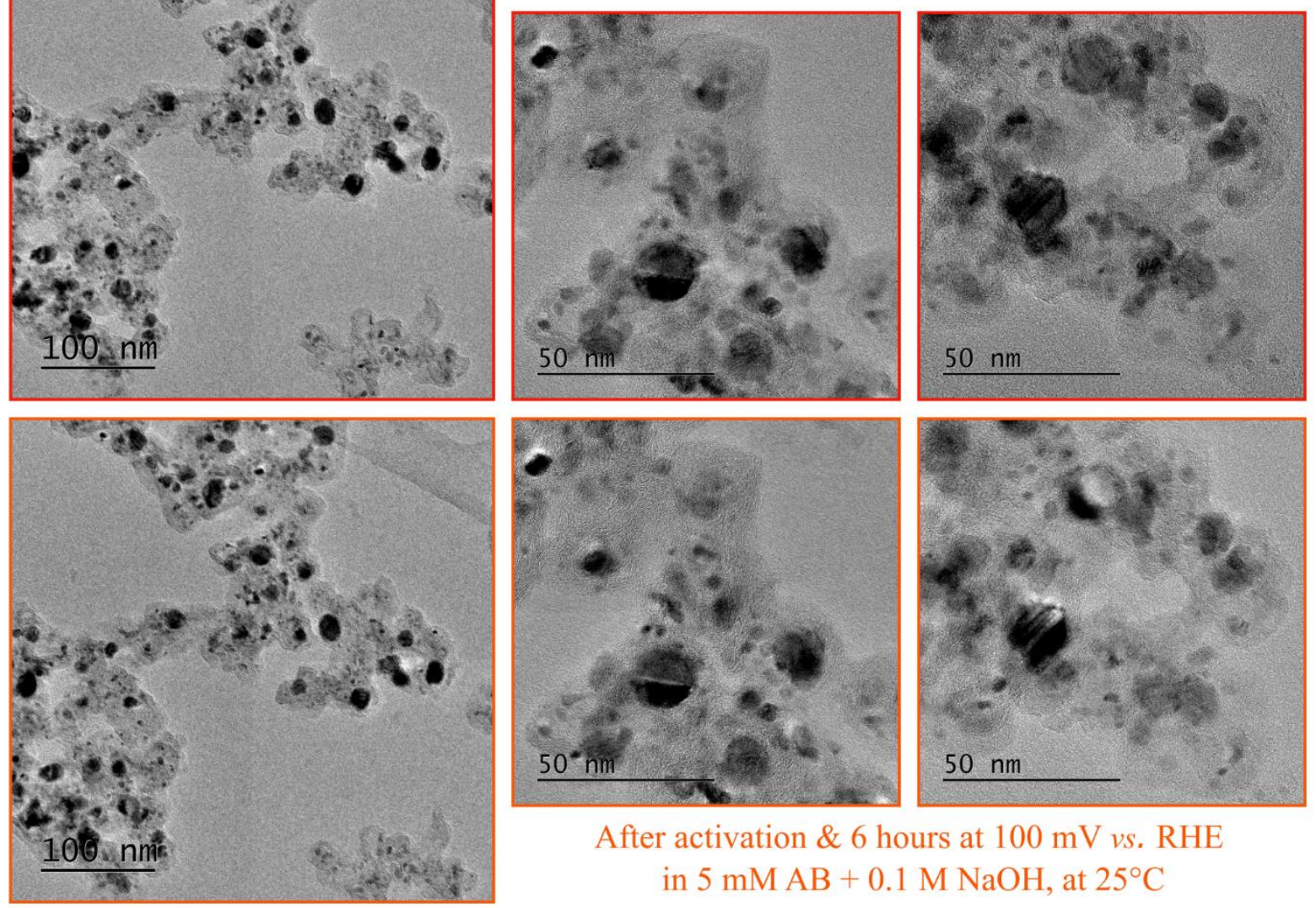

After activation \& 6 hours at $100 \mathrm{mV}$ vs. RHE in $5 \mathrm{mM} \mathrm{AB}+0.1 \mathrm{M} \mathrm{NaOH}$, at $25^{\circ} \mathrm{C}$
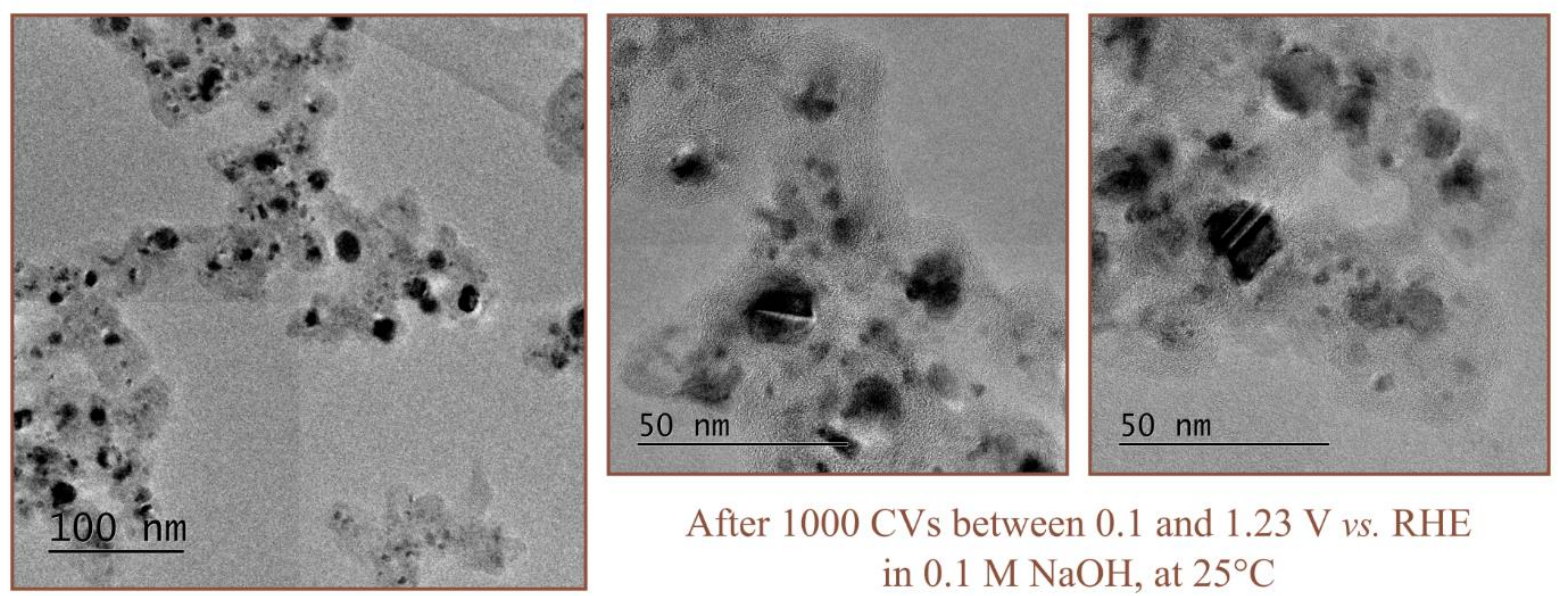

After $1000 \mathrm{CVs}$ between 0.1 and $1.23 \mathrm{~V}$ vs. RHE in $0.1 \mathrm{M} \mathrm{NaOH}$, at $25^{\circ} \mathrm{C}$

Figure 11: Representative ILTEM micrographs of a $\mathrm{Ni}_{3} \mathrm{Co} /$ Ketjenblack $600 \mathrm{~J}$ catalyst obtained before (top three micrographs) and after several electrochemical treatments, (i) activation + 6-h-long steadypolarization at $E=100 \mathrm{mV}$ vs. $\mathrm{RHE}$ in a $5 \mathrm{mMAB}+0.1 \mathrm{M} \mathrm{NaOH}$ electrolyte at $\mathrm{T}=25^{\circ} \mathrm{C}$ (middle three micrographs); (ii) 1000 CV cycles of AST (bottom three micrographs); the AST consisted of repeated 
cycling between $0.1<E<1.23 \mathrm{~V}$ vs. RHE in $0.1 \mathrm{M} \mathrm{NaOH}$ at $T=25^{\circ} \mathrm{C}$. Reproduced from ${ }^{205}$ with permission from Elsevier.

Extended and unsupported Ni surfaces, also show some degree of instability upon electrochemical operation in alkaline electrolytes. As detailed in Section 2, Ni surfaces are subjected to complementary adverse effects, which can affect their electrocatalytic properties ${ }^{43}$ : below $E=0 \mathrm{~V} v s \mathrm{RHE}$, they form $\mathrm{Ni}$ hydrides $\left(\alpha-\mathrm{NiH}_{\mathrm{x}}\right.$ and $\beta-\mathrm{NiH}_{\mathrm{x}}$ depending on the applied conditions) ${ }^{96,240}$; above $E=0 \mathrm{~V} v s \mathrm{RHE}$ (and in particular at open-circuit conditions), $\mathrm{Ni}$ (hydr)oxides are formed (e.g. reversible $\alpha-\mathrm{Ni}(\mathrm{OH})_{2}$, which mostly reduces back to $\mathrm{Ni}$ on subsequent cathodic polarization, but also $\beta-\mathrm{Ni}(\mathrm{OH})_{2}$, which cannot be electrochemically reduced back into metallic $\mathrm{Ni}$, and at higher potentials undergoes reversible oxidation into $\left.\beta / \gamma-\mathrm{NiOOH}{ }^{45-47,114}\right)$, which may deactivate the electrode if uncontrolled. Sections 3 and 4 presented the means to optimize the electrode activity for the $\mathrm{HOR}^{48,137}$ and the BOR ${ }^{200}$ by controlling the extent of Ni surface oxidation. Appropriately cycling a Ni electrode at high/low potential values could enable to prevent detrimental hydride or oxide formation, ${ }^{241}$ but repeated oxidation and reduction periods (e.g. experienced in transient or intermittent operation) may lead to strain in the Ni catalyst, which can induce mechanical failure. ${ }^{43}$

Such mechanical failure was observed by Schulze and Gülzow ${ }^{242}$ when using Raney Ni electrodes for the HOR in an alkaline fuel cell (pasted Raney Ni + PTFE binder electrodes were studied). On the one hand, hydrogen embrittlement caused disintegration of the crystallites/grains of the Ni electrodes, hence their destructuration (also owing to PTFE gradual decomposition). On the other hand, irreversible Ni oxide formation led to their progressive deactivation, overall gradually depreciating the HOR performance in operation. Raney Ni is particularly used for the HER in alkaline environments. ${ }^{243,244}$ This catalyst, obtained from dealloying NiAl or NiZn alloys, is known to deactivate owing to the formation of hydrides 
when maintained in prolonged hydrogen evolution regime ${ }^{245,246}$; the leaching of their residual impurities (e.g. $\mathrm{Al}$ and $\mathrm{Zn}$ ) when the electrode is maintained at open-circuit (i.e. in discontinuous HER operation) or positive (e.g. HOR) polarization also accounts for their gradual loss of activity over time. ${ }^{247}$ To counter these adverse effects, several doped Raney Ni alloys ${ }^{243,244,248,249}$ and composites between Raney Ni and metal hydride alloys ${ }^{250,251}$ have been tested, as well as addition of metal ions/complexes in the electrolyte (e.g. iron cations from the electrolyte deposit at the Ni surface and inhibit Ni hydrides formation, ${ }^{246,252}$ while vanadium salts in the electrolyte enhance Ni hydride decomposition, ${ }^{253}$ a positive effect in both cases). To date, these strategies were only partly successful, and there remains room for improving the durability and long-term activity of Ni-based electrodes in operation.

Finally, although Ni electrodes show some material's stability in operation in alkaline environments, their progressive deactivation (e.g. by surface oxide or hydride formation) may pose a problem. Future studies should therefore aim at stabilizing such $\mathrm{Ni}$ surfaces for real applications, i.e. in conditions where the materials could be subjected to oxygen contact, alternation between low and high potential values, open-circuit holds, etc.

\section{Conclusions}

In this paper, the electrochemical properties of $\mathrm{Ni}$ electrocatalysts have been reviewed. Since $\mathrm{Ni}$ and its (oxy)(hydr)oxides are stable at high $\mathrm{pH}$ (while being unstable at low $\mathrm{pH}$ ), the electrochemical behavior of $\mathrm{Ni}$ in alkaline media was particularly emphasized. As one moves from low to high potentials, the $\mathrm{Ni}$ surface is (i) covered by adsorbed hydrogen $\left(\mathrm{H}_{\mathrm{ad}}\right)$ in the hydrogen evolution and likely also in the hydrogen oxidation potential region, (ii) covered by surface $\alpha-\mathrm{Ni}(\mathrm{OH})_{2}$ and then (iii) $\beta-\mathrm{Ni}(\mathrm{OH})_{2}$, the latter being (iv) further oxidized into $\gamma / \beta-\mathrm{NiOOH}$ in the oxygen evolution region. The occurrence of $\mathrm{Ni} / \alpha-\mathrm{Ni}(\mathrm{OH})_{2}$ and $\alpha / \beta-\mathrm{Ni}(\mathrm{OH})_{2} / \gamma / \beta-\mathrm{NiOOH}$ transitions in the "low" and "high" potential regions provide practical tools to determine the active surface area of Ni. Besides, these different potential-dependent states of the surface 
largely determine the activity of Ni electrodes towards fuel oxidation reactions. This is the case for the HOR in alkaline media, which is strongly accelerated on partially-oxidized $\mathrm{Ni}$ surfaces (mixed $\mathrm{Ni} / \mathrm{NiO}_{x}$ surface). Alloying/combining Ni with other elements or supporting Ni on well-chosen substrates, can also lead to a better HOR performance, and both strategies have been practically demonstrated in AEMFCs. Oxidation of complex fuels (borohydride, boranes, hydrazine) is also possible on Ni-based electrocatalysts, paving the way to PGMs-free direct liquid alkaline fuel cells. In these cases, Ni is interesting because it is possible to tune its surface state so that it catalyzes the desired reaction (e.g. the borohydride oxidation reaction) without promoting possible competing reactions (e.g. the hydrogen evolution reaction or the hydrolysis of the fuel species). It should be noted however that much work still needs to be done by applying in situ spectroscopic tools (e.g. FTIR), ab initio calculations, and kinetic modeling in order to better understand the nature of adsorbed species on Ni surface depending on the applied potential and mechanisms of oxidation of these fuel molecules on $\mathrm{Ni}$ electrodes, and propose viable solutions for the development of more active catalysts.

Lastly, this selected review also addresses the durability of Ni-based catalysts in alkaline environments. It is notably shown that, unlike carbon-supported PGM-based electrocatalysts, $\mathrm{Ni} / \mathrm{C}$ and $\mathrm{NiM} / \mathrm{C}$ materials are rather robust against the detachment of the metal nanoparticles from the carbon support, and, depending on their composition, can be resistant to metal dissolution. Stability of Ni-based electrodes is however strongly dependent on the explored potential domain, and more work is necessary to clarify whether they are sufficiently stable under the AEMFCs and DLFCs operation conditions. In addition, it is clear that materials stability of Ni-based catalysts must not be confused with the performance stability of the corresponding electrodes. Indeed, passivation by $\mathrm{Ni}$ oxides or hydride formation is possible if the Ni-based electrode is brought to "inadequate" potential intervals during the operation. This means that, 
although $\mathrm{Ni}$ catalysts do really present strong assets for use in fuel oxidation reactions, their practical deployment in long-lasting real devices still requires research and development.

\section{Corresponding Authors}

*E-mail: Oshchepkov@,catalysis.ru

*E-mail: Marian.Chatenet@grenoble-inp.fr

\section{Author Contributions}

All authors contributed to the analysis of the referenced papers, writing and reviewing of the manuscript.

Notes

The authors declare no financial and non-financial competing interests.

\section{ACKNOWLEDGMENTS}

This work has been performed in the frame of the MobiDiC project, funded by the French National Research Agency (ANR, grant No. ANR-16-CE05-0009-01) and RSF project No. 18-73-00143, funded by the Russian Science Foundation. Some of the work presented herein has been performed within the framework of the Centre of Excellence of Multifunctional Architectured Materials "CEMAM" No. ANR10-LABX-44-01. 


\section{REFERENCES}

(1) Holdcroft, S.; Fan, J. Sterically-Encumbered Ionenes as Hydroxide Ion-Conducting Polymer Membranes. Curr. Opin. Electrochem. 2019, 18, 99-105.

(2) Ramaswamy, N.; Mukerjee, S. Alkaline Anion-Exchange Membrane Fuel Cells: Challenges in Electrocatalysis and Interfacial Charge Transfer. Chem. Rev. 2019, 119, 11945-11979.

(3) Campos-Roldán, C. A.; Alonso-Vante, N. The Hydrogen Oxidation Reaction in Alkaline Medium: An Overview. Electrochem. Energy Rev. 2019, 2, 312-331.

(4) Hu, C.; Zhang, L.; Gong, J. Recent Progress Made in the Mechanism Comprehension and Design of Electrocatalysts for Alkaline Water Splitting. Energy Environ. Sci. 2019, 12, 2620-2645.

(5) Vesborg, P. C. K.; Jaramillo, T. F. Addressing the Terawatt Challenge: Scalability in the Supply of Chemical Elements for Renewable Energy. RSC Adv. 2012, 2, 7933-7947.

(6) De, S.; Zhang, J.; Luque, R.; Yan, N. Ni-Based Bimetallic Heterogeneous Catalysts for Energy and Environmental Applications. Energy Environ. Sci. 2016, 9, 3314-3347.

(7) Ouyang, L.; Huang, J.; Wang, H.; Liu, J.; Zhu, M. Progress of Hydrogen Storage Alloys for NiMH Rechargeable Power Batteries in Electric Vehicles : A Review. Mater. Chem. Phys. 2017, 200, $164-178$.

(8) Salunkhe, R. R.; Lin, J.; Malgras, V.; Xue, S.; Ho, J.; Yamauchi, Y. Large-Scale Synthesis of Coaxial Carbon Nanotube/ $\mathrm{Ni}(\mathrm{OH})_{2}$ Composites for Asymmetric Supercapacitor Application. Nano Energy 2015, 11, 211-218.

(9) Zhang, M.; Huang, Z.; Shen, Z.; Gong, Y.; Chi, B.; Pu, J.; Li, J. High-Performance Aqueous Rechargeable Li-Ni Battery Based on $\mathrm{Ni}(\mathrm{OH})_{2} / \mathrm{NiOOH}$ Redox Couple with High Voltage. $A d v$. Energy Mater. 2017, 7, 1700155.

(10) Li, W.; Song, B.; Manthiram, A. High-Voltage Positive Electrode Materials for Lithium-Ion 
Batteries. Chem. Soc. Rev. 2017, 46, 3006-3059.

(11) Yuan, C.; Wu, H. Bin; Xie, Y.; Lou, X. W. D. Mixed Transition-Metal Oxides: Design, Synthesis, and Energy-Related Applications. Angew. Chemie Int. Ed. 2014, 53, 1488-1504.

(12) You, J.; Meng, L.; Song, T.; Guo, T.; Yang, Y. M.; Chang, W.; Hong, Z.; Chen, H.; Zhou, H.; Chen, Q.; Liu, Y.; De Marco, N.; Yang, Y. Improved Air Stability of Perovskite Solar Cells via Solution-Processed Metal Oxide Transport Layers. Nat. Nanotechnol. 2015, 11, 75-81.

(13) Kim, J.; Lee, H.; Cha, H.; Yoon, M.; Park, M.; Cho, J. Prospect and Reality of Ni-Rich Cathode for Commercialization. Adv. Energy Mater. 2018, 8, 1-25.

(14) Roger, I.; Shipman, M. A.; Symes, M. D. Earth-Abundant Catalysts for Electrochemical and Photoelectrochemical Water Splitting. Nat. Rev. Chem. 2017, 1, 0003.

(15) McCrory, C. C. L.; Jung, S.; Peters, J. C.; Jaramillo, T. F. Benchmarking Heterogeneous Electrocatalysts for the Oxygen Evolution Reaction. J. Am. Chem. Soc. 2013, 135, 16977-16987.

(16) Moureaux, F.; Stevens, P.; Toussaint, G.; Chatenet, M. Timely-Activated 316L Stainless Steel: A Low Cost, Durable and Active Electrode for Oxygen Evolution Reaction in Concentrated Alkaline Environments. Appl. Catal. B Environ. 2019, 258, 117963.

(17) Wang, T.; Xie, H.; Chen, M.; D’Aloia, A.; Cho, J.; Wu, G.; Li, Q. Precious Metal-Free Approach to Hydrogen Electrocatalysis for Energy Conversion: From Mechanism Understanding to Catalyst Design. Nano Energy 2017, 42, 69-89.

(18) Gong, M.; Wang, D.-Y. Y.; Chen, C.-C. C.; Hwang, B.-J. J.; Dai, H. A Mini Review on NickelBased Electrocatalysts for Alkaline Hydrogen Evolution Reaction. Nano Res. 2016, 9, $28-46$.

(19) Zeng, M.; Li, Y. Recent Advances in Heterogeneous Electrocatalysts for the Hydrogen Evolution Reaction. J. Mater. Chem. A 2015, 3, 14942-14962.

(20) Miliauskas, D.; Tarozaite, R.; Tamasauskaite Tamasiunaite, L. Investigation of Borohydride 
Oxidation at Ultrafine Gold Layer Supported on Nickel. Medziagotyra 2008, 14, 20-22.

(21) Cao, D.; Gao, Y.; Wang, G.; Miao, R.; Liu, Y. A Direct $\mathrm{NaBH}_{4}-\mathrm{H}_{2} \mathrm{O}_{2}$ Fuel Cell Using Ni Foam Supported Au Nanoparticles as Electrodes. Int. J. Hydrogen Energy 2010, 35, 807-813.

(22) Celik, C.; Boyaci San, F. G.; Sarac, H. I. Investigation of Ni Foam Effect for Direct Borohydride Fuel Cell. Fuel Cells 2012, 12, 1027-1031.

(23) Medway, S. L. L.; Lucas, C. A. A.; Kowal, A.; Nichols, R. J. J.; Johnson, D. In Situ Studies of the Oxidation of Nickel Electrodes in Alkaline Solution. J. Electroanal. Chem. 2006, 587, 172-181.

(24) Lambers, E. S.; Dykstal, C. N.; Seo, J. M.; Rowe, J. E.; Holloway, P. H. Room-Temerature Oxidation of Ni(110) at Low and Atmospheric Oxygen Pressures. Oxid. Met. 1996, 45, 301-321.

(25) Holloway, P. H. Chemisorption and Oxide Formation on Metals: Oxygen-Nickel Reaction. J. Vac. Sci. Technol. 1981, 18, 653-659.

(26) Lasia, A. Mechanism and Kinetics of the Hydrogen Evolution Reaction. Int. J. Hydrogen Energy 2019, 44, 19484-19518.

(27) Wang, J.; Xu, F.; Jin, H.; Chen, Y.; Wang, Y. Non-Noble Metal-Based Carbon Composites in Hydrogen Evolution Reaction: Fundamentals to Applications. Adv. Mater. 2017, 29, 1605838.

(28) Zhu, J.; Hu, L.; Zhao, P.; Lee, L. Y. S.; Wong, K.-Y. Recent Advances in Electrocatalytic Hydrogen Evolution Using Nanoparticles. Chem. Rev. 2020, 120, 851-918.

(29) Emelianova, N. V. Researches with the Dropping Mercury Cathode: Part VII. Nickel and Cobalt. Recl. des Trav. Chim. des Pays-Bas 1925, 44, 528-548.

(30) Lukovtsev, P.; Levina, S.; Frumkin, A. Hydrogen Overpotential on Nickel. Acta Physicochim. U.S.S.R. 1939, 11, 916-930.

(31) Frumkin, A. Hydrogen Overvoltage. Discuss. Faraday Soc. 1947, 1, 57-67.

(32) Conway, B. E.; Bourgault, P. L. The Electrochemical Behavior of the Nickel - Nickel Oxide 
Electrode: Part I. Kinetics of Self-Discharge. Can. J. Chem. 1959, 37, 292-307.

(33) Bourgault, P. L.; Conway, B. E. The Electrochemical Behavior of the Nickel Oxide Electrode: Part II. Quasi-Equilibrium Behavior. Can. J. Chem. 1960, 38, 1557-1575.

(34) Conway, B. E.; Bourgault, P. L. Electrochemistry of the Nickel Oxide Electrode: Part III. Anodic Polarization and Self-Discharge Behavior. Can. J. Chem. 1962, 40, 1690-1707.

(35) Conway, B. E.; Gileadi, E. Electrochemistry of the Nickel Oxide Electrode: Part IV. Electrochemical Kinetic Studies of Reversible Potentials as a Function of Degree of Oxidation. Can. J. Chem. 1962, 40, 1933-1942.

(36) Conway, B. E.; Sattar, M. A. Electrochemistry of the Nickel Oxide Electrode. J. Electroanal. Chem. Interfacial Electrochem. 1968, 19, 351-364.

(37) Conway, B. E.; Sattar, M. A.; Gilroy, D. Electrochemistry of the Nickel-Oxide Electrode—V. SelfPassivation Effects in Oxygen-Evolution Kinetics. Electrochim. Acta 1969, 14, 677-694.

(38) Sattar, M. A.; Conway, B. E. Electrochemistry of the Nickel-Oxide Electrode-VI. Surface Oxidation of Nickel Anodes in Alkaline Solution. Electrochim. Acta 1969, 14, 695-710.

(39) Conway, B. E.; Sattar, M. A.; Gilroy, D. Electrochemistry of the Nickel-Oxide Electrode-VII. Potentiostatic Step Method for Study of Adsorbed Intermediates. Electrochim. Acta 1969, 14, 711724.

(40) Weininger, J. L.; Breiter, M. W. Effect of Crystal Structure on the Anodic Oxidation of Nickel. J. Electrochem. Soc. 1963, 110, 484-490.

(41) Weininger, J. L.; Breiter, M. W. Hydrogen Evolution and Surface Oxidation of Nickel Electrodes in Alkaline Solution. J. Electrochem. Soc. 1964, 111, 707-712.

(42) Bockris, J. O. M. O.; Potter, E. C. The Mechanism of Hydrogen Evolution at Nickel Cathodes in Aqueous Solutions. J. Chem. Phys. 1952, 20, 614-628. 
(43) Hall, D. S.; Bock, C; MacDougall, B. R. The Electrochemistry of Metallic Nickel: Oxides, Hydroxides, Hydrides and Alkaline Hydrogen Evolution. J. Electrochem. Soc. 2013, 160, F235F243.

(44) Hall, D. S.; Lockwood, D. J.; Bock, C.; MacDougall, B. R. Nickel Hydroxides and Related Materials: A Review of Their Structures, Synthesis and Properties. Proc. R. Soc. A Math. Phys. Eng. Sci. 2014, 471, 20140792.

(45) Alsabet, M.; Grden, M.; Jerkiewicz, G. Electrochemical Growth of Surface Oxides on Nickel. Part 1: Formation of $\alpha-\mathrm{Ni}(\mathrm{OH})_{2}$ in Relation to the Polarization Potential, Polarization Time, and Temperature. Electrocatalysis 2011, 2, 317-330.

(46) Alsabet, M.; Grden, M.; Jerkiewicz, G. Electrochemical Growth of Surface Oxides on Nickel. Part 2: Formation of $\beta-\mathrm{Ni}(\mathrm{OH})_{2}$ and $\mathrm{NiO}$ in Relation to the Polarization Potential, Polarization Time, and Temperature. Electrocatalysis 2014, 5, 136-147.

(47) Alsabet, M.; Grdeń, M.; Jerkiewicz, G. Electrochemical Growth of Surface Oxides on Nickel. Part 3: Formation of $\beta-\mathrm{NiOOH}$ in Relation to the Polarization Potential, Polarization Time, and Temperature. Electrocatalysis 2015, 6, 60-71.

(48) Oshchepkov, A. G.; Bonnefont, A.; Saveleva, V. A.; Papaefthimiou, V.; Zafeiratos, S.; Pronkin, S. N.; Parmon, V. N.; Savinova, E. R. Exploring the Influence of the Nickel Oxide Species on the Kinetics of Hydrogen Electrode Reactions in Alkaline Media. Top. Catal. 2016, 59, 1319-1331.

(49) Oshchepkov, A. G.; Bonnefont, A.; Parmon, V. N.; Savinova, E. R. On the Effect of Temperature and Surface Oxidation on the Kinetics of Hydrogen Electrode Reactions on Nickel in Alkaline Media. Electrochim. Acta 2018, 269, 111-118.

(50) Oshchepkov, A. G.; Bonnefont, A.; Savinova, E. R. On the Influence of the Extent of Oxidation on the Kinetics of the Hydrogen Electrode Reactions on Polycrystalline Nickel. Electrocatalysis 2020, 
$11,133-142$.

(51) Salmazo, D.; Juarez, M. F.; Oshchepkov, A. G.; Cherstiouk, O. V.; Bonnefont, A.; Shermukhamedov, S. A.; Nazmutdinov, R. R.; Schmickler, W.; Savinova, E. R. On the Feasibility of Bifunctional Hydrogen Oxidation on Ni and NiCu Surfaces. Electrochim. Acta 2019, 305, 452458.

(52) Kuznetsov, A. N.; Oshchepkov, A. G.; Cherstiouk, O. V.; Simonov, P. A.; Nazmutdinov, R. R.; Savinova, E. R.; Bonnefont, A. Influence of the $\mathrm{NaOH}$ Concentration on the Hydrogen Electrode Reaction Kinetics of $\mathrm{Ni}$ and $\mathrm{NiCu}$ Electrodes. ChemElectroChem 2020, 7, 1438-1447.

(53) Grdeń, M.; Klimek, K.; Czerwiński, A. A Quartz Crystal Microbalance Study on a Metallic Nickel Electrode. J. Solid State Electrochem. 2004, 8, 390-397.

(54) Beden, B.; Floner, D.; Léger, J. M.; Lamy, C. A Voltammetric Study of the Formation on Hydroxides and Oxyhydroxides on Nickel Single Crystal Electrodes in Contact with an Alkaline Solution. Surf. Sci. 1985, 162, 822-829.

(55) Simpraga, R.; Conway, B. E. Realization of Monolayer Levels of Surface Oxidation of Nickel by Anodization at Low Temperatures. J. Electroanal. Chem. Interfacial Electrochem. 1990, 280, 341357.

(56) Diard, J.-P.; LeGorrec, B.; Maximovitch, S. Etude de l'activation Du Degagement d'hydrogene Sur Electrode d'oxyde de Nickel Par Spectroscopie d'impedance. Electrochim. Acta 1990, 35, 1099-1108.

(57) Melendres, C. A.; Pankuch, M. On the Composition of the Passive Film on Nickel: A SurfaceEnhanced Raman Spectroelectrochemical Study. J. Electroanal. Chem. 1992, 333, 103-113.

(58) Nakamura, M.; Ikemiya, N.; Iwasaki, A.; Suzuki, Y.; Ito, M. Surface Structures at the Initial Stages in Passive Film Formation on Ni(111) Electrodes in Acidic Electrolytes. J. Electroanal. Chem. 
2004, 566, 385-391.

(59) Seyeux, A.; Maurice, V.; Klein, L. H.; Marcus, P. In Situ Scanning Tunnelling Microscopic Study of the Initial Stages of Growth and of the Structure of the Passive Film on Ni(111) in $1 \mathrm{M}$ $\mathrm{NaOH}(\mathrm{Aq})$. J. Solid State Electrochem. 2005, 9, 337-346.

(60) Conway, B. E.; Barnett, B.; Angerstein-Kozlowska, H.; Tilak, B. V. A Surface-Electrochemical Basis for the Direct Logarithmic Growth Law for Initial Stages of Extension of Anodic Oxide Films Formed at Noble Metals. J. Chem. Phys. 1990, 93, 8361-8373.

(61) D’Alkaine, C. .; Santanna, M. . The Passivating Films on Nickel in Alkaline Solutions I. General Aspects of the Ni (II) Region. J. Electroanal. Chem. 1998, 457, 5-12.

(62) Keddam, M. Transpassive Dissolution of Ni in Acidic Sulfate Media: A Kinetic Model. $J$. Electrochem. Soc. 1985, 132, 2561-2566.

(63) Zoltowski, P. The Capacity of Monocrystalline Nickel Electrode in Potassium Hydroxide Solution at Low Hydrogen Overpotentials. Electrochim. Acta 1993, 38, 2129-2133.

(64) Floner, D.; Lamy, C.; Leger, J. M. Electrocatalytic Oxidation of Hydrogen on Polycrystal and Single-Crystal Nickel Electrodes. Surf. Sci. 1990, 234, 87-97.

(65) Esau, D.; Schuett, F. M.; Varvaris, K. L.; Björk, J.; Jacob, T.; Jerkiewicz, G. ControlledAtmosphere Flame Fusion Growth of Nickel Poly-Oriented Spherical Single Crystals_-Unraveling Decades of Impossibility. Electrocatalysis 2020, 11, 1-13.

(66) Mohsenzadeh, A.; Richards, T.; Bolton, K. DFT Study of the Water Gas Shift Reaction on Ni(111), Ni(100) and Ni(110) Surfaces. Surf. Sci. 2016, 644, 53-63.

(67) Kresse, G.; Hafner, J. First-Principles Study of the Adsorption of Atomic H on Ni (111), (100) and (110). Surf. Sci. 2000, 459, 287-302.

(68) Visscher, W.; Barendrecht, E. Anodic Oxide Films of Nickel in Alkaline Electrolyte. Surf. Sci. 
1983, 135, 436-452.

(69) Grdeń, M.; Klimek, K. EQCM Studies on Oxidation of Metallic Nickel Electrode in Basic Solutions. J. Electroanal. Chem. 2005, 581, 122-131.

(70) Beden, B.; Bewick, A. The Anodic Layer on Nickel in Alkaline Solution: An Investigation Using in Situ IR Spectroscopy. Electrochim. Acta 1988, 33, 1695-1698.

(71) Hoppe, H.-W.; Strehblow, H.-H. XPS and UPS Examinations of the Formation of Passive Layers on Ni in 1 M Sodium Hydroxide and 0.5 M Sulphuric Acid. Surf. Interface Anal. 1989, 14, 121131.

(72) Beverskog, B.; Puigdomenech, I. Revised Pourbaix Diagrams for Nickel at 25-300 ${ }^{\circ}$ C. Corros. Sci. 1997, 39, 969-980.

(73) Hu, C.-C.; Wen, T.-C. Effects of the Nickel Oxide on the Hydrogen Evolution and ParaNitroaniline Reduction at Ni-Deposited Graphite Electrodes in $\mathrm{NaOH}$. Electrochim. Acta 1998, 43, $1747-1756$.

(74) Pshenichnikov, A. G. Electrocatalytic Properties of Nickel and Nickel-Based Alloys. Mater. Chem. Phys. 1989, 22, 121-148.

(75) Machado, S. A. S.; Avaca, L. A. The Hydrogen Evolution Reaction on Nickel Surfaces Stabilized by H-Absorption. Electrochim. Acta 1994, 39, 1385-1391.

(76) Burke, L. D.; Twomey, T. A. M. Voltammetric Behaviour of Nickel in Base with Particular Reference to Thick Oxide Growth. J. Electroanal. Chem. Interfacial Electrochem. 1984, 162, 101119.

(77) Visscher, W.; Barendrecht, E. The Anodic Oxidation of Nickel in Alkaline Solution. Electrochim. Acta 1980, 25, 651-655.

(78) Visscher, W.; Barendrecht, E. Absorption of Hydrogen in Reduced Nickel Oxide. J. Appl. 
Electrochem. 1980, 10, 269-274.

(79) Shumilova, N. A.; Bagotzky, V. S. Oxygen Ionization on Nickel in Alkaline Solutions. Electrochim. Acta 1968, 13, 285-293.

(80) Karimi Shervedani, R.; Lasia, A. Evaluation of the Surface Roughness of Microporous Ni-Zn-P Electrodes by in Situ Methods. J. Appl. Electrochem. 1999, 29, 979-986.

(81) Jerkiewicz, G. Hydrogen Sorption at/in Electrodes. Prog. Surf. Sci. 1998, 57, 137-186.

(82) Markovic, N. M.; Ross Jr., P. N. Surface Science Studies of Model Fuel Cell Electrocatalysts. Surf. Sci. Rep. 2002, 45, 117-229.

(83) Quaino, P.; Juarez, F.; Santos, E.; Schmickler, W. Volcano Plots in Hydrogen Electrocatalysis Uses and Abuses. Beilstein J. Nanotechnol. 2014, 5, 846-854.

(84) Choquette, Y.; Brossard, L.; Lasia, A.; Ménard, H. Investigation of Hydrogen Evolution on RaneyNickel Composite-Coated Electrodes. Electrochim. Acta 1990, 35, 1251-1256.

(85) Kreysa, G.; Hakansson, B.; Ekdunge, P. Kinetic and Thermodynamic Analysis of Hydrogen Evolution at Nickel Electrodes. Electrochim. Acta 1988, 33, 1351-1357.

(86) Katić, J.; Metikoš-Huković, M.; Peter, R.; Petravić, M. The Electronic Structure of the $\alpha-\mathrm{Ni}(\mathrm{OH})_{2}$ Films: Influence on the Production of the High-Performance Ni-Catalyst Surface. J. Power Sources 2015, 282, 421-428.

(87) Juarez, F.; Salmazo, D.; Savinova, E. R.; Quaino, P.; Belletti, G.; Santos, E.; Schmickler, W. The Initial Stage of OH Adsorption on Ni(111). J. Electroanal. Chem. 2019, 832, 137-141.

(88) Bai, Y.; Kirvassilis, D.; Xu, L.; Mavrikakis, M. Atomic and Molecular Adsorption on Ni(111). Surf. Sci. 2019, 679, 240-253.

(89) Taylor, C.; Kelly, R. G.; Neurock, M. Theoretical Analysis of the Nature of Hydrogen at the Electrochemical Interface Between Water and a Ni(111) Single-Crystal Electrode. J. Electrochem. 
Soc. 2007, 154, F55-F64.

(90) Greeley, J.; Mavrikakis, M. A First-Principles Study of Surface and Subsurface H on and in Ni(111): Diffusional Properties and Coverage-Dependent Behavior. Surf. Sci. 2003, 540, 215-229.

(91) Dong, Y.; Dang, J.; Wang, W.; Yin, S.; Wang, Y. First-Principles Determination of Active Sites of Ni Metal-Based Electrocatalysts for Hydrogen Evolution Reaction. ACS Appl. Mater. Interfaces 2018, 10, 39624-39630.

(92) Liu, S.; Ishimoto, T.; Koyama, M. First-Principles Study of Oxygen Coverage Effect on Hydrogen Oxidation on Ni(1 11 1) Surface. Appl. Surf. Sci. 2015, 333, 86-91.

(93) Janik, M. J.; McCrum, I. T.; Koper, M. T. M. On the Presence of Surface Bound Hydroxyl Species on Polycrystalline Pt Electrodes in the "Hydrogen Potential Region" (0-0.4 V-RHE). J. Catal. 2018, 367, 332-337.

(94) Szklarska-Smialowska, Z.; Smialowski, M. Electrochemical Study of the Nickel-Hydrogen System. J. Electrochem. Soc. 1963, 110, 444-448.

(95) Soares, D. M.; Teschke, O.; Torriani, I. Hydride Effect on the Kinetics of the Hydrogen Evolution Reaction on Nickel Cathodes in Alkaline Media. J. Electrochem. Soc. 1992, 139, 98-105.

(96) Bernardini, M.; Comisso, N.; Mengoli, G.; Sinico, L. Formation of Nickel Hydrides by Hydrogen Evolution in Alkaline Media: Effect of Temperature. J. Electroanal. Chem. 1998, 457, 205-219.

(97) Cheng, C.; Grant, P. S.; Lührs, L. Electrochemical Mechanics of Metal Thin Films: Charge-Induced Reversible Surface Stress for Actuation. Adv. Electron. Mater. 2020, 6, 1-7.

(98) Comsa, G.; David, R.; Schumacher, B.-J. The Angular Dependence of Flux, Mean Energy and Speed Ratio for D2 Molecules Desorbing from a Ni(111) Surface. Surf. Sci. 1979, 85, 45-68.

(99) Haug, K. L.; Bürgi, T.; Trautman, T. R.; Ceyer, S. T. Distinctive Reactivities of Surface-Bound H and Bulk H for the Catalytic Hydrogenation of Acetylene. J. Am. Chem. Soc. 1998, 120, 8885- 
8886.

(100) Ceyer, S. T. The Unique Chemistry of Hydrogen beneath the Surface: Catalytic Hydrogenation of Hydrocarbons. Acc. Chem. Res. 2001, 34, 737-744.

(101) Desilvestro, J. Characterization of Redox States of Nickel Hydroxide Film Electrodes by In Situ Surface Raman Spectroscopy. J. Electrochem. Soc. 1988, 135, 885.

(102) Bagotzky, V. S.; Shumilova, N. A.; Samoilov, G. P.; Khrushcheva, E. I. Electrochemical Oxygen Reduction on Nickel Electrodes in Alkaline Solutions-II. Electrochim. Acta 1972, 17, 1625-1635.

(103) Kim, M.-S.; Kim, K.-B. A Study on the Phase Transformation of Electrochemically Precipitated Nickel Hydroxides Using an Electrochemical Quartz Crystal Microbalance. J. Electrochem. Soc. 1998, $145,507$.

(104) Guzmán, R. S. S.; Vilche, J. R.; Arvía, A. J. Non-Equilibrium Effects in the Nickel Hydroxide Electrode. J. Appl. Electrochem. 1979, 9, 183-189.

(105) Doyle, R. L.; Godwin, I. J.; Brandon, M. P.; Lyons, M. E. G. Redox and Electrochemical Water Splitting Catalytic Properties of Hydrated Metal Oxide Modified Electrodes. Phys. Chem. Chem. Phys. 2013, 15, 13737-13783.

(106) Trzesniewski, B. J.; Diaz-Morales, O.; Vermaas, D. A.; Longo, A.; Bras, W.; Koper, M. T. M.; Smith, W. A. In Situ Observation of Active Oxygen Species in Fe-Containing Ni-Based Oxygen Evolution Catalysts: The Effect of $\mathrm{pH}$ on Electrochemical Activity. J. Am. Chem. Soc. 2015, 137, $15112-15121$.

(107) Johnston, C.; Graves, P. R. In Situ Raman Spectroscopy Study of the Nickel Oxyhydroxide Electrode (NOE) System. Appl. Spectrosc. 1990, 44, 105-115.

(108) Oblonsky, L. J. Surface Enhanced Raman Spectra from the Films Formed on Nickel in the Passive and Transpassive Regions. J. Electrochem. Soc. 1995, 142, 3677-3682. 
(109) Yeo, B. S.; Bell, A. T. In Situ Raman Study of Nickel Oxide and Gold-Supported Nickel Oxide Catalysts for the Electrochemical Evolution of Oxygen. J. Phys. Chem. C 2012, 116, 8394-8400.

(110) El Gabaly, F.; McCarty, K. F.; Bluhm, H.; McDaniel, A. H. Oxidation Stages of Ni Electrodes in Solid Oxide Fuel Cell Environments. Phys. Chem. Chem. Phys. 2013, 15, 8334-8341.

(111) Ali-Löytty, H.; Louie, M. W.; Singh, M. R.; Li, L.; Sanchez Casalongue, H. G.; Ogasawara, H.; Crumlin, E. J.; Liu, Z.; Bell, A. T.; Nilsson, A.; Friebel, D. Ambient-Pressure XPS Study of a NiFe Electrocatalyst for the Oxygen Evolution Reaction. J. Phys. Chem. C 2016, 120, 2247-2253.

(112) van Drunen, J.; Barbosa, A. F. B.; Tremiliosi-Filho, G. The Formation of Surface Oxides on Nickel in Oxalate-Containing Alkaline Media. Electrocatalysis 2015, 6, 481-491.

(113) Zhuang, Z.; Giles, S. A.; Zheng, J.; Jenness, G. R.; Caratzoulas, S.; Vlachos, D. G.; Yan, Y. Nickel Supported on Nitrogen-Doped Carbon Nanotubes as Hydrogen Oxidation Reaction Catalyst in Alkaline Electrolyte. Nat. Commun. 2016, 7, 10141.

(114) Grdeń, M.; Alsabet, M.; Jerkiewicz, G. Surface Science and Electrochemical Analysis of Nickel Foams. ACS Appl. Mater. Interfaces 2012, 4, 3012-3021.

(115) Yang, F.; Bao, X.; Li, P.; Wang, X.; Cheng, G.; Chen, S.; Luo, W. Boosting Hydrogen Oxidation Activity of $\mathrm{Ni}$ in Alkaline Media through Oxygen-Vacancy-Rich $\mathrm{CeO}_{2} / \mathrm{Ni}$ Heterostructures. Angew. Chemie - Int. Ed. 2019, 58, 14179-14183.

(116) Chen, L.; Lasia, A. Study of the Kinetics of Hydrogen Evolution Reaction on Nickel-Zinc Alloy Electrodes. J. Electrochem. Soc. 1991, 138, 3321-3328.

(117) Shervedani, R. K.; Lasia, A. Studies of the Hydrogen Evolution Reaction on Ni-P Electrodes. $J$. Electrochem. Soc. 1997, 144, 511-519.

(118) Lasia, A.; Rami, A. Kinetics of Hydrogen Evolution on Nickel Electrodes. J. Electroanal. Chem. 1990, 294, 123-141. 
(119) Lyons, M. E. G.; Brandon, M. P. The Oxygen Evolution Reaction on Passive Oxide Covered Transition Metal Electrodes in Aqueous Alkaline Solution. Part 1-Nickel. Int. J. Electrochem. Sci. 2008, 3, 1386-1424.

(120) Ho, J. C. K.; Piron, D. L. Active Surface Area in Oxide Electrodes by Overpotential Deposited Oxygen Species for the Oxygen Evolution Reaction. J. Appl. Electrochem. 1996, 26, 515-521.

(121) Faid, A. Y.; Barnett, A. O.; Seland, F.; Sunde, S. Optimized Nickel-Cobalt and Nickel-Iron Oxide Catalysts for the Hydrogen Evolution Reaction in Alkaline Water Electrolysis. J. Electrochem. Soc. 2019, 166, F519-F533.

(122) Jung, S.; McCrory, C. C. L.; Ferrer, I. M.; Peters, J. C.; Jaramillo, T. F. Benchmarking Nanoparticulate Metal Oxide Electrocatalysts for the Alkaline Water Oxidation Reaction. J. Mater. Chem. A 2016, 4, 3068-3076.

(123) Hall, D. S.; Bock, C.; MacDougall, B. R. An Oxalate Method for Measuring the Surface Area of Nickel Electrodes. J. Electrochem. Soc. 2014, 161, H787-H795.

(124) Oliva, P.; Leonardi, J.; Laurent, J. F.; Delmas, C.; Braconnier, J. J.; Figlarz, M.; Fievet, F.; Guibert, A. d. Review of the Structure and the Electrochemistry of Nickel Hydroxides and Oxy-Hydroxides. J. Power Sources 1982, 8, 229-255.

(125) Watzele, S.; Hauenstein, P.; Liang, Y.; Xue, S.; Fichtner, J.; Garlyyev, B.; Scieszka, D.; Claudel, F.; Maillard, F.; Bandarenka, A. S. Determination of Electroactive Surface Area of Ni-, Co-, Fe-, and Ir-Based Oxide Electrocatalysts. ACS Catal. 2019, 9, 9222-9230.

(126) Trasatti, S.; Petrii, O. A. Real Surface Area Measurements in Electrochemistry. J. Electroanal. Chem. 1992, 327, 353-376.

(127) Oshchepkov, A. G.; Simonov, P. A.; Cherstiouk, O. V.; Nazmutdinov, R. R.; Glukhov, D. V.; Zaikovskii, V. I.; Kardash, T. Y.; Kvon, R. I.; Bonnefont, A.; Simonov, A. N.; Parmon, V. N.; 
Savinova, E. R. On the Effect of $\mathrm{Cu}$ on the Activity of Carbon Supported Ni Nanoparticles for Hydrogen Electrode Reactions in Alkaline Medium. Top. Catal. 2015, 58, 1181-1192.

(128) Simonov, P. A.; Cherstiouk, O. V.; Kuznetsov, A. N.; Zaikovskii, V. I.; Kardash, T. Y.; Oshchepkov, A. G.; Bonnefont, A.; Savinova, E. R. Highly Active Carbon-Supported Ni Catalyst Prepared by Nitrate Decomposition with a Sacrificial Agent for the Hydrogen Oxidation Reaction in Alkaline Medium. J. Electroanal. Chem. 2019, 852, 113551.

(129) Gao, L.; Wang, Y.; Li, H.; Li, Q.; Ta, N.; Zhuang, L.; Fu, Q.; Bao, X. A Nickel Nanocatalyst within a h-BN Shell for Enhanced Hydrogen Oxidation Reactions. Chem. Sci. 2017, 8, 5728-5734.

(130) Kucernak, A. R.; Zalitis, C. General Models for the Electrochemical Hydrogen Oxidation and Hydrogen Evolution Reactions: Theoretical Derivation and Experimental Results under Near Mass-Transport Free Conditions. J. Phys. Chem. C 2016, 120, 10721-10745.

(131) Sheng, W.; Myint, M.; Chen, J. G.; Yan, Y. Correlating the Hydrogen Evolution Reaction Activity in Alkaline Electrolytes with the Hydrogen Binding Energy on Monometallic Surfaces. Energy Environ. Sci. 2013, 6, 1509-1512.

(132) Greeley, J.; Jaramillo, T. F.; Bonde, J.; Chorkendorff, I.; Nørskov, J. K. Computational HighThroughput Screening of Electrocatalytic Materials for Hydrogen Evolution. Nat. Mater. 2006, 5, 909-913.

(133) Santos, E.; Hindelang, P.; Quaino, P.; Schulz, E. N.; Soldano, G.; Schmickler, W. Hydrogen Electrocatalysis on Single Crystals and on Nanostructured Electrodes. ChemPhysChem 2011, 12, 2274-2279.

(134) Lu, S.; Zhuang, Z. Investigating the Influences of the Adsorbed Species on Catalytic Activity for Hydrogen Oxidation Reaction in Alkaline Electrolyte. J. Am. Chem. Soc. 2017, 139, 5156-5163.

(135) Nørskov, J. K.; Bligaard, T.; Logadottir, A.; Kitchin, J. R.; Chen, J. G.; Pandelov, S.; Stimming, U. 
Trends in the Exchange Current for Hydrogen Evolution. J. Electrochem. Soc. 2005, 152, J23-J26.

(136) Skúlason, E.; Tripkovic, V.; Björketun, M. E.; Gudmundsdóttir, S.; Karlberg, G.; Rossmeisl, J.; Bligaard, T.; Jónsson, H.; Nørskov, J. K. Modeling the Electrochemical Hydrogen Oxidation and Evolution Reactions on the Basis of Density Functional Theory Calculations. J. Phys. Chem. C 2010, 114, 18182-18197.

(137) Oshchepkov, A. G.; Bonnefont, A.; Pronkin, S. N.; Cherstiouk, O. V.; Ulhaq-Bouillet, C.; Papaefthimiou, V.; Parmon, V. N.; Savinova, E. R. Nanostructured Nickel Nanoparticles Supported on Vulcan Carbon as a Highly Active Catalyst for the Hydrogen Oxidation Reaction in Alkaline Media. J. Power Sources 2018, 402, 447-452.

(138) Yang, F.; Bao, X.; Zhao, Y.; Wang, X.; Cheng, G.; Luo, W. Enhanced HOR Catalytic Activity of PGM-Free Catalysts in Alkaline Media: The Electronic Effect Induced by Different Heteroatom Doped Carbon Supports. J. Mater. Chem. A 2019, 7, 10936-10941.

(139) Wang, T.; Wang, M.; Yang, H.; Xu, M.; Zuo, C.; Feng, K.; Xie, M.; Deng, J.; Zhong, J.; Zhou, W.; Cheng, T.; Li, Y. Weakening Hydrogen Adsorption on Nickel via Interstitial Nitrogen Doping Promotes Bifunctional Hydrogen Electrocatalysis in Alkaline Solution. Energy Environ. Sci. 2019, $12,3522-3529$.

(140) Ni, W.; Krammer, A.; Hsu, C. S.; Chen, H. M.; Schüler, A.; Hu, X. Ni3N as an Active Hydrogen Oxidation Reaction Catalyst in Alkaline Medium. Angew. Chemie - Int. Ed. 2019, 58, 7445-7449.

(141) Yang, Y.; Sun, X.; Han, G.; Liu, X.; Zhang, X.; Sun, Y.; Zhang, M.; Cao, Z.; Sun, Y. Enhanced Electrocatalytic Hydrogen Oxidation on $\mathrm{Ni} / \mathrm{NiO} / \mathrm{C}$ Derived from a Nickel-Based Metal-Organic Framework. Angew. Chemie - Int. Ed. 2019, 58, 10644-10649.

(142) Song, F.; Li, W.; Yang, J.; Han, G.; Liao, P.; Sun, Y. Interfacing Nickel Nitride and Nickel Boosts Both Electrocatalytic Hydrogen Evolution and Oxidation Reactions. Nat. Commun. 2018, 9, 4531. 
(143) Shinagawa, T.; Takanabe, K. Towards Versatile and Sustainable Hydrogen Production through Electrocatalytic Water Splitting: Electrolyte Engineering. ChemSusChem 2017, 10, 1318-1336.

(144) Zheng, Y.; Jiao, Y.; Vasileff, A.; Qiao, S. Z. The Hydrogen Evolution Reaction in Alkaline Solution: From Theory, Single Crystal Models, to Practical Electrocatalysts. Angew. Chemie - Int. Ed. 2018, 57, 7568-7579.

(145) Durst, J.; Siebel, A.; Simon, C.; Hasché, F.; Herranz, J.; Gasteiger, H. A. New Insights into the Electrochemical Hydrogen Oxidation and Evolution Reaction Mechanism. Energy Environ. Sci. 2014, 7, 2255-2260.

(146) Danilovic, N.; Subbaraman, R.; Strmcnik, D.; Chang, K. C.; Paulikas, A. P.; Stamenkovic, V. R.; Markovic, N. M. Enhancing the Alkaline Hydrogen Evolution Reaction Activity through the Bifunctionality of $\mathrm{Ni}(\mathrm{OH})_{2} /$ Metal Catalysts. Angew. Chemie - Int. Ed. 2012, 51, 12495-12498.

(147) Makrides, A. C. Hydrogen Overpotential on Nickel in Alkaline Solution. J. Electrochem. Soc. 1962, 109, 977-984.

(148) Devanathan, M. A. V. V.; Selvaratnam, M. Mechanism of the Hydrogen-Evolution Reaction on Nickel in Alkaline Solutions by the Determination of the Degree of Coverage. Trans. Faraday Soc. 1960, 56, 1820.

(149) Ahn, S. H.; Hwang, S. J.; Yoo, S. J.; Choi, I.; Kim, H.-J.; Jang, J. H.; Nam, S. W.; Lim, T.-H.; Lim, T.; Kim, S.-K.; Kim, J.-J. Electrodeposited Ni Dendrites with High Activity and Durability for Hydrogen Evolution Reaction in Alkaline Water Electrolysis. J. Mater. Chem. 2012, 22, 1515315159.

(150) Huot, J.-Y. Hydrogen Evolution and Interface Phenomena on a Nickel Cathode in 30 w/o KOH. $J$. Electrochem. Soc. 1989, 136, 1933.

(151) McArthur, M. A.; Jorge, L.; Coulombe, S.; Omanovic, S. Synthesis and Characterization of 3D Ni 
Nanoparticle/Carbon Nanotube Cathodes for Hydrogen Evolution in Alkaline Electrolyte. J. Power Sources 2014, 266, 365-373.

(152) Gong, M.; Wang, D. Y.; Chen, C. C.; Hwang, B. J.; Dai, H. A Mini Review on Nickel-Based Electrocatalysts for Alkaline Hydrogen Evolution Reaction. Nano Res. 2016, 9, 28-46.

(153) Pan, Y.; Hu, G.; Lu, J.; Xiao, L.; Zhuang, L. Ni(OH)2-Ni/C for Hydrogen Oxidation Reaction in Alkaline Media. J. Energy Chem. 2019, 29, 111-115.

(154) Davydova, E.; Zaffran, J.; Dhaka, K.; Toroker, M.; Dekel, D. Hydrogen Oxidation on Ni-Based Electrocatalysts: The Effect of Metal Doping. Catalysts 2018, 8, 454.

(155) Shviro, M.; Polani, S.; Dunin-Borkowski, R. E.; Zitoun, D. Bifunctional Electrocatalysis on Pd-Ni Core-Shell Nanoparticles for Hydrogen Oxidation Reaction in Alkaline Medium. Adv. Mater. Interfaces 2018, 5, 1701666.

(156) Alesker, M.; Page, M.; Shviro, M.; Paska, Y.; Gershinsky, G.; Dekel, D. R.; Zitoun, D. Palladium/Nickel Bifunctional Electrocatalyst for Hydrogen Oxidation Reaction in Alkaline Membrane Fuel Cell. J. Power Sources 2016, 304, 332-339.

(157) Shi, G.; Yano, H.; Tryk, D. A.; Iiyama, A.; Uchida, H. Highly Active, CO-Tolerant, and Robust Hydrogen Anode Catalysts: Pt-M ( $\mathrm{M}=\mathrm{Fe}, \mathrm{Co}, \mathrm{Ni})$ Alloys with Stabilized Pt-Skin Layers. ACS Catal. 2017, 7, 267-274.

(158) Cherstiouk, O. V.; Simonov, P. A.; Oshchepkov, A. G.; Zaikovskii, V. I.; Kardash, T. Y.; Bonnefont, A.; Parmon, V. N.; Savinova, E. R. Electrocatalysis of the Hydrogen Oxidation Reaction on Carbon-Supported Bimetallic NiCu Particles Prepared by an Improved Wet Chemical Synthesis. J. Electroanal. Chem. 2016, 783, 146-151.

(159) Roy, A.; Talarposhti, M. R.; Normile, S. J.; Zenyuk, I. V.; De Andrade, V.; Artyushkova, K.; Serov, A.; Atanassov, P. Nickel-Copper Supported on a Carbon Black Hydrogen Oxidation Catalyst 
Integrated into an Anion-Exchange Membrane Fuel Cell. Sustain. Energy Fuels 2018, 2, 22682275.

(160) Wang, G.; Li, W.; Huang, B.; Xiao, L.; Lu, J.; Zhuang, L. Exploring the Composition-Activity Relation of $\mathrm{Ni}-\mathrm{Cu}$ Binary Alloy Electrocatalysts for Hydrogen Oxidation Reaction in Alkaline Media. ACS Appl. Energy Mater. 2019, 2, 3160-3165.

(161) Kelley, M. J.; Ponec, V. Surface Composition of Alloys. Prog. Surf. Sci. 1981, 11, 139-244.

(162) Kabir, S. A.; Lemire, K.; Artyushkova, K.; Roy, A.; Odgaard, M.; Schlueter, D.; Oshchepkov, A.; Bonnefont, A.; Savinova, E.; Sabarirajan, D.; Mandal, P.; Crumlin, E. J.; Zenyuk, I. V.; Atanassov, P.; Serov, A. Platinum Group Metal-Free NiMo Hydrogen Oxidation Catalysts: High Performance and Durability in Alkaline Exchange Membrane Fuel Cells. J. Mater. Chem. A 2017, 5, 2443324443.

(163) Schalenbach, M.; Speck, F. D.; Ledendecker, M.; Kasian, O.; Goehl, D.; Mingers, A. M.; Breitbach, B.; Springer, H.; Cherevko, S.; Mayrhofer, K. J. J. Nickel-Molybdenum Alloy Catalysts for the Hydrogen Evolution Reaction: Activity and Stability Revised. Electrochim. Acta 2018, 259, 11541161.

(164) Sheng, W.; Bivens, A. P.; Myint, M.; Zhuang, Z.; Forest, R. V.; Fang, Q.; Chen, J. G.; Yan, Y. Non-Precious Metal Electrocatalysts with High Activity for Hydrogen Oxidation Reaction in Alkaline Electrolytes. Energy Environ. Sci. 2014, 7, 1719-1724.

(165) Deng, S.; Liu, X.; Huang, T.; Zhao, T.; Lu, Y.; Cheng, J.; Shen, T.; Liang, J.; Wang, D. MoO 2 Modulated Electrocatalytic Properties of $\mathrm{Ni}$ : Investigate from Hydrogen Oxidation Reaction to Hydrogen Evolution Reaction. Electrochim. Acta 2019, 324, 134892.

(166) Tang, M. H.; Hahn, C.; Klobuchar, A. J.; Ng, J. W. D.; Wellendorff, J.; Bligaard, T.; Jaramillo, T. F. Nickel-Silver Alloy Electrocatalysts for Hydrogen Evolution and Oxidation in an Alkaline 
Electrolyte. Phys. Chem. Chem. Phys. 2014, 16, 19250.

(167) Yang, F.; Bao, X.; Zhao, Y.; Wang, X.; Cheng, G.; Luo, W. Enhanced HOR Catalytic Activity of PGM-Free Catalysts in Alkaline Media: The Electronic Effect Induced by Different Heteroatom Doped Carbon Supports. J. Mater. Chem. A 2019, 7, 10936-10941.

(168) Elder, J. P.; Hickling, A. Anodic Behaviour of the Borohydride Ion. Trans. Faraday Soc. 1962, 58, $1852-1864$.

(169) Duncan, R. N.; Arney, T. L. Sodium Borohydride Reduced Electroless Nickel - Its Operation and Uses. In AES Second Electroless Plating Symposium; Orlando, 1983, Code 4874.

(170) Liu, B. H.; Li, Z. P.; Suda, S. Anodic Oxidation of Alkali Borohydrides Catalyzed by Nickel. J. Electrochem. Soc. 2003, 150, 398-402.

(171) Liu, B. H.; Li, Z. P.; Suda, S. Electrocatalysts for the Anodic Oxidation of Borohydrides. Electrochim. Acta 2004, 49, 3097-3105.

(172) Wang, K.; Juntao Lu, L. Z. A Current-Decomposition Study of the Borohydride Oxidation Reaction at Ni Electrodes. J. Phys. Chem. C 2007, 111, 7456-7462.

(173) Olu, P. Y.; Bonnefont, A.; Braesch, G.; Martin, V.; Savinova, E. R.; Chatenet, M. Influence of the Concentration of Borohydride towards Hydrogen Production and Escape for Borohydride Oxidation Reaction on Pt and Au Electrodes - Experimental and Modelling Insights. J. Power Sources 2018, 375, 300-309.

(174) Liu, B. H.; Suda, S. Hydrogen Storage Alloys as the Anode Materials of the Direct Borohydride Fuel Cell. J. Alloys Compd. 2008, 454, 280-285.

(175) Paschoalino, W. J.; Ticianelli, E. A. An Investigation of the Borohydride Oxidation Reaction on La-Ni-Based Hydrogen Storage Alloys. Int. J. Hydrogen Energy 2013, 38, 7344-7352.

(176) Li, S.; Shu, C.; Chen, Y.; Wang, L. A New Application of Nickel-Boron Amorphous Alloy 
Nanoparticles: Anode-Catalyzed Direct Borohydride Fuel Cell. Ionics (Kiel). 2018, 24, 201-209.

(177) Saha, S.; Ganguly, S.; Banerjee, D.; Kargupta, K. Novel Bimetallic Graphene-Cobalt-Nickel (GCo-Ni) Nano-Ensemble Electrocatalyst for Enhanced Borohydride Oxidation. Int. J. Hydrogen Energy 2015, 40, 1760-1773.

(178) Guo, M.; Cheng, Y.; Yu, Y.; Hu, J. Ni-Co Nanoparticles Immobilized on a 3D Ni Foam Template as a Highly Efficient Catalyst for Borohydride Electrooxidation in Alkaline Medium. Appl. Surf. Sci. 2017, 416, 439-445.

(179) Santos, D. M. F.; Eugénio, S.; Cardoso, D. S. P.; Šljukić, B.; Montemor, M. F. Three-Dimensional Nanostructured Ni-Cu Foams for Borohydride Oxidation. Russ. J. Phys. Chem. A 2015, 89, 2449 2454.

(180) Santos, D. M. F.; Šljukić, B.; Amaral, L.; Macciò, D.; Saccone, A.; Sequeira, C. A. C. Nickel and Nickel-Cerium Alloy Anodes for Direct Borohydride Fuel Cells. J. Electrochem. Soc. 2014, 161, F594-F599.

(181) Santos, D. M. F.; Šljukić, B.; Amaral, L.; Milikić, J.; Sequeira, C. A. C.; Macciò, D.; Saccone, A. Nickel-Rare Earth Electrodes for Sodium Borohydride Electrooxidation. Electrochim. Acta 2016, $190,1050-1056$.

(182) Grinberg, V. A.; Mayorova, N. A.; Korlyukov, A. A.; Pasynskii, A. A. Direct Borohydride Oxidation Electrocatalysts Based on Ni-Ru/C and Ni-Ru-F/C Alloys. Russ. J. Electrochem. 2010, 46, 1289-1296.

(183) Tsivadze, A. Y.; Tarasevich, M. R.; Titova, V. N.; Yavich, A. A.; Petrova, N. V. New Electrocatalysts for Direct Borohydride Fuel Cells. Dokl. Phys. Chem. 2007, 414, 107-109.

(184) Liu, B. H.; Li, Z. P.; Suda, S. Development of High-Performance Planar Borohydride Fuel Cell Modules for Portable Applications. J. Power Sources 2008, 175, 226-231. 
(185) Ma, J.; Sahai, Y.; Buchheit, R. G. Direct Borohydride Fuel Cell Using Ni-Based Composite Anodes. J. Power Sources 2010, 195, 4709-4713.

(186) Šljukić, B.; Martins, M.; Kayhan, E.; Balčiūnaite, A.; Şener, T.; Sequeira, C. A. C.; Santos, D. M. F. SnO2-C Supported PdNi Nanoparticles for Oxygen Reduction and Borohydride Oxidation. $J$. Electroanal. Chem. 2017, 797, 23-30.

(187) Ma, X.; Ye, K.; Wang, G.; Duan, M.; Cheng, K.; Wang, G.; Cao, D. Facile Fabrication of Gold Coated Nickel Nanoarrays and Its Excellent Catalytic Performance towards Sodium Borohydride Electro-Oxidation. Appl. Surf. Sci. 2017, 414, 353-360.

(188) Duan, D.; Liang, J.; Liu, H.; You, X.; Wei, H.; Wei, G.; Liu, S. The Effective Carbon Supported Core-Shell Structure of Ni@Au Catalysts for Electro-Oxidation of Borohydride. Int. J. Hydrogen Energy 2015, 40, 488-500.

(189) Tamašauskaitė-Tamašiūnaitė, L.; Balčiūnaitè, A.; Šimkūnaitė, D.; Selskis, A. Self-Ordered Titania Nanotubes and Flat Surfaces as a Support for the Deposition of Nanostructured Au-Ni Catalyst: Enhanced Electrocatalytic Oxidation of Borohydride. J. Power Sources 2012, 202, 85-91.

(190) Hasan, M.; Newcomb, S. B.; Razeeb, K. M. Novel Core/Shell Ni@NiO/Pt as High Efficient Electrocatalyst for Alkaline Direct Ethanol Fuel Cells. ECS Trans. 2013, 45, 111-126.

(191) Martins, M.; Šljukić, B.; Sequeira, C. A. C.; Soylu, G. S. P.; Yurtcan, A. B.; Bozkurt, G.; Sener, T.; Santos, D. M. F. PtNi Supported on Binary Metal Oxides: Potential Bifunctional Electrocatalysts for Low-Temperature Fuel Cells? Appl. Surf. Sci. 2018, 428, 31-40.

(192) Šljukić, B.; Milikić, J.; Santos, D. M. F.; Sequeira, C. A. C. Carbon-Supported Pt0.75M0.25 (M = Ni or Co) Electrocatalysts for Borohydride Oxidation. Electrochim. Acta 2013, 107, 577-583.

(193) Gyenge, E.; Atwan, M.; Northwood, D. Electrocatalysis of Borohydride Oxidation on Colloidal Pt and Pt-Alloys (Pt-Ir, Pt-Ni, and Pt-Au) and Application for Direct Borohydride Fuel Cell Anodes. 
J. Electrochem. Soc. 2006, 153, 150-158.

(194) Tamašauskaite-Tamašiunaite, L.; Čekaviciute, R.; Šimkunaite, D.; Selskis, A. NANO-Pt(Ni)/TiO $2^{-}$ NTs Catalysts for Borohydride Oxidation. In International Conference on Power and Energy Systems, EuroPES; 2011; pp 467-472.

(195) Tamasauskaite-Tamasiunaite, L.; Balčiunaite, A.; Zabielaite, A.; Vaičiuniene, J.; Selskis, A.; Pakštas, V.; Norkus, E. Electrocatalytic Activity of Nanostructured Pt-Ni Catalysts Deposited on the Titania Nanotube Arrays towards Borohydride Oxidation. J. Electroanal. Chem. 2013, 707, 31 37.

(196) Martins, M.; Milikić, J.; Šljukić, B.; Soylu, G. S. P.; Yurtcan, A. B.; Bozkurt, G.; Santos, D. M. F. $\mathrm{Mn}_{2} \mathrm{O}_{3}-\mathrm{MO}\left(\mathrm{MO}=\mathrm{ZrO}_{2}, \mathrm{~V}_{2} \mathrm{O}_{5}, \mathrm{WO}_{3}\right)$ Supported PtNi Nanoparticles: Designing Stable and Efficient Electrocatalysts for Oxygen Reduction and Borohydride Oxidation. Microporous Mesoporous Mater. 2019, 273, 286-293.

(197) Ma, J.; Choudhury, N. A.; Sahai, Y. A Comprehensive Review of Direct Borohydride Fuel Cells. Renew. Sustain. Energy Rev. 2010, 14, 183-199.

(198) Olu, P. Y.; Job, N.; Chatenet, M. Evaluation of Anode (Electro)Catalytic Materials for the Direct Borohydride Fuel Cell: Methods and Benchmarks. J. Power Sources 2016, 327, 235-257.

(199) Aytaç, A.; Gürbüz, M.; Sanli, A. E. Electrooxidation of Hydrogen Peroxide and Sodium Borohydride on Ni Deposited Carbon Fiber Electrode for Alkaline Fuel Cells. Int. J. Hydrogen Energy 2011, 36, 10013-10021.

(200) Oshchepkov, A. G.; Braesch, G.; Ould-Amara, S.; Rostamikia, G.; Maranzana, G.; Bonnefont, A.; Papaefthimiou, V.; Janik, M. J.; Chatenet, M.; Savinova, E. R. Nickel Metal Nanoparticles as Anode Electrocatalysts for Highly Efficient Direct Borohydride Fuel Cells. ACS Catal. 2019, 9, 8520-8528. 
(201) Braesch, G.; Oshchepkov, A. G.; Bonnefont, A.; Asonkeng, F.; Maurer, T.; Maranzana, G.; Savinova, E. R.; Chatenet, M. Nickel 3D Structures Enhanced by Electrodeposition of Nickel Nanoparticles as High Performance Anodes for Direct Borohydride Fuel Cells. ChemElectroChem 2020, 7, 1789-1799.

(202) Paunovic, M. Electrochemical Aspects of Electroless Nickel Deposition. Plat. Surf. Finish. 1983, $70,62-66$.

(203) Burke, L. D.; Lee, B. H. An Investigation of Some Electrocatalytic Processes Occurring at Low Potentials at a Nickel Electrode in Base. J. Electrochem. Soc. 1991, 138, 2496-2504.

(204) Okinaka, Y. Electrochemical Study of Electroless Gold-Deposition Reaction. J. Electrochem. Soc. 1973, 120, 739-744.

(205) Zadick, A.; Dubau, L.; Artyushkova, K.; Serov, A.; Atanassov, P.; Chatenet, M. Nickel-Based Electrocatalysts for Ammonia Borane Oxidation: Enabling Materials for Carbon-Free-Fuel Direct Liquid Alkaline Fuel Cell Technology. Nano Energy 2017, 37, 248-259.

(206) Wang, G.; Wang, H.; Chen, T.; Tan, Y. $\mathrm{Ni}_{1-\mathrm{x}} \mathrm{M}_{\mathrm{x}} \mathrm{Se}_{2}(\mathrm{M}=\mathrm{Fe}, \mathrm{Co}, \mathrm{Cu})$ Nanowires as Anodes for Ammonia-Borane Electrooxidation and the Derived $\mathrm{Ni}_{1-\mathrm{x}} \mathrm{M}_{\mathrm{x}} \mathrm{Se}_{2-\mathrm{y}}-\mathrm{OOH}$ Ultrathin Nanosheets as Efficient Electrocatalysts for Oxygen Evolution. J. Mater. Chem. A 2019, 7, 16372-16386.

(207) Wiesener, W. Untersuchung Zur Anodischen Hydrazin-Oxidation an Porösen Kohleelektroden Unter Verwendung von Nickel- Und Nickelboridkatalysatoren. Electrochim. Acta 1970, 15, 1065 1077.

(208) Meibuhr, S. G. Surface-Catalyzed Anodes for Hydrazine Fuel Cells: I. Preparation of the Substrate. J. Electrochem. Soc. 1974, 121, 1264-1270.

(209) Meibuhr, S. G.; Paluch, R. F. Surface-Catalyzed Anodes for Hydrazine Fuel Cells II. Lifetime Studies of Heat-Treated Nickel Boride Catalyzed Anodes. J. Electrochem. Soc. 1975, 122, 164- 
171.

(210) Adekunle, A. S.; Ozoemena, K. I. Insights into the Electro-Oxidation of Hydrazine at SingleWalled Carbon-Nanotube-Modified Edge-Plane Pyrolytic Graphite Electrodes Electro-Decorated with Metal and Metal Oxide Films. J. Solid State Electrochem. 2008, 12, 1325-1336.

(211) Qin, H. Y.; Liu, Z. X.; Yin, W. X.; Zhu, J. K.; Li, Z. P. Effects of Hydrazine Addition on Gas Evolution and Performance of the Direct Borohydride Fuel Cell. J. Power Sources 2008, 185, 895898.

(212) Ye, L. Q.; Li, Z. P.; Qin, H. Y.; Zhu, J. K.; Liu, B. H. Hydrazine Electrooxidation on a Composite Catalyst Consisting of Nickel and Palladium. J. Power Sources 2011, 196, 956-961.

(213) Martinez, U.; Asazawa, K.; Halevi, B.; Falase, A.; Kiefer, B.; Serov, A.; Padilla, M.; Olson, T.; Datye, A.; Tanaka, H.; Atanassov, P. Aerosol-Derived $\mathrm{Ni}_{1-\mathrm{x}} \mathrm{Zn}_{\mathrm{x}}$ Electrocatalysts for Direct Hydrazine Fuel Cells. Phys. Chem. Chem. Phys. 2012, 14, 5512-5517.

(214) Sakamoto, T.; Asazawa, K.; Yamada, K.; Tanaka, H. Study of Pt-Free Anode Catalysts for Anion Exchange Membrane Fuel Cells. Catal. Today 2011, 164, 181-185.

(215) Sakamoto, T.; Asazawa, K.; Martinez, U.; Halevi, B.; Suzuki, T.; Arai, S.; Matsumura, D.; Nishihata, Y.; Atanassov, P.; Tanaka, H. Electrooxidation of Hydrazine Hydrate Using Ni-La Catalyst for Anion Exchange Membrane Fuel Cells. J. Power Sources 2013, 234, 252-259.

(216) Asset, T.; Roy, A.; Sakamoto, T.; Padilla, M.; Matanovic, I.; Artyushkova, K.; Serov, A.; Maillard, F.; Chatenet, M.; Asazawa, K.; Tanaka, H.; Atanassov, P. Highly Active and Selective Nickel Molybdenum Catalysts for Direct Hydrazine Fuel Cell. Electrochim. Acta 2016, 215, 420-426.

(217) Jeon, T. Y.; Watanabe, M.; Miyatake, K. Carbon Segregation-Induced Highly Metallic Ni Nanoparticles for Electrocatalytic Oxidation of Hydrazine in Alkaline Media. ACS Appl. Mater. Interfaces 2014, 6, 18445-18449. 
(218) Finkelstein, D. A.; Imbeault, R.; Garbarino, S.; Roué, L.; Guay, D. Trends in Catalysis and Catalyst Cost Effectiveness for $\mathrm{N}_{2} \mathrm{H}_{4}$ Fuel Cells and Sensors: A Rotating Disk Electrode (RDE) Study. $J$. Phys. Chem. C 2016, 120, 4717-4738.

(219) Sakamoto, T.; Asazawa, K.; Sanabria-Chinchilla, J.; Martinez, U.; Halevi, B.; Atanassov, P.; Strasser, P.; Tanaka, H. Combinatorial Discovery of Ni-Based Binary and Ternary Catalysts for Hydrazine Electrooxidation for Use in Anion Exchange Membrane Fuel Cells. J. Power Sources 2014, 247, 605-611.

(220) Sakamoto, T.; Masuda, T.; Yoshimoto, K.; Kishi, H.; Yamaguchi, S.; Matsumura, D.; Tamura, K.; Hori, A.; Horiuchi, Y.; Serov, A.; Artyushkova, K.; Atanassov, P.; Tanaka, H. NiO/ $/ \mathrm{Nb}_{2} \mathrm{O}_{5} / \mathrm{C}$ Hydrazine Electrooxidation Catalysts for Anion Exchange Membrane Fuel Cells. J. Electrochem. Soc. 2017, 164, F229-F234.

(221) Anu Prathap, M. U.; Anuraj, V.; Satpati, B.; Srivastava, R. Facile Preparation of Ni(OH)$)_{2}-\mathrm{MnO}_{2}$ Hybrid Material and Its Application in the Electrocatalytic Oxidation of Hydrazine. J. Hazard. Mater. 2013, 262, 766-774.

(222) Feng, G.; Kuang, Y.; Li, Y.; Sun, X. Three-Dimensional Porous Superaerophobic Nickel Nanoflower Electrodes for High-Performance Hydrazine Oxidation. Nano Res. 2015, 8, 33653371.

(223) Kuang, Y.; Feng, G.; Li, P.; Bi, Y.; Li, Y.; Sun, X. Single-Crystalline Ultrathin Nickel Nanosheets Array from in Situ Topotactic Reduction for Active and Stable Electrocatalysis. Angew. Chemie Int. Ed. 2016, 55, 693-697.

(224) Li, X.; Hu, W. H.; Liu, Y. R.; Dong, B.; Han, G. Q.; Shang, X.; Chai, Y. M.; Liu, Y. Q.; Liu, C. G. Facile Synthesis of Novel NiSe-NixSy Nanocubes Supported on Nickel Foam with Enhanced Activity for Hydrazine Electroxidation. Mater. Lett. 2016, 175, 118-121. 
(225) Dong, B.; Li, X.; Shang, X.; Chai, Y. M.; Liu, C. G. In-Situ Grown Interwoven NiSe on Ni Foam as a Catalyst for Hydrazine Oxidation. Int. J. Mater. Res. 2016, 107, 586-589.

(226) de Oliveira, D. C.; Silva, W. O.; Chatenet, M.; Lima, F. H. B. NiOx-Pt/C Nanocomposites: Highly Active Electrocatalysts for the Electrochemical Oxidation of Hydrazine. Appl. Catal. B Environ. 2017, 201, 22-28.

(227) Wu, L. S.; Wen, X. P.; Wen, H.; Dai, H. Bin; Wang, P. Palladium Decorated Porous Nickel Having Enhanced Electrocatalytic Performance for Hydrazine Oxidation. J. Power Sources 2019, 412, 71 77.

(228) Zhang, J.; Cao, X.; Guo, M.; Wang, H.; Saunders, M.; Xiang, Y.; Jiang, S. P.; Lu, S. Unique Ni Crystalline Core/Ni Phosphide Amorphous Shell Heterostructured Electrocatalyst for Hydrazine Oxidation Reaction of Fuel Cells. ACS Appl. Mater. Interfaces 2019, 11, 19048-19055.

(229) Wang, X. L.; Zheng, Y. X.; Jia, M. L.; Yuan, L. S.; Peng, C.; Yang, W. H. Formation of Nanoporous NiCuP Amorphous Alloy Electrode by Potentiostatic Etching and Its Application for Hydrazine Oxidation. Int. J. Hydrogen Energy 2016, 41, 8449-8458.

(230) Liu, X.; Li, Y.; Chen, N.; Deng, D.; Xing, X.; Wang, Y. Ni3S2@Ni Foam 3D Electrode Prepared via Chemical Corrosion by Sodium Sulfide and Using in Hydrazine Electro-Oxidation. Electrochim. Acta 2016, 213, 730-739.

(231) Serov, A.; Padilla, M.; Roy, A. J.; Atanassov, P.; Sakamoto, T.; Asazawa, K.; Tanaka, H. Anode Catalysts for Direct Hydrazine Fuel Cells: From Laboratory Test to an Electric Vehicle. Angew. Chemie Int. Ed. 2014, 53, 10336-10339.

(232) Ross, P. N.; Sokol, H. Corrosion of Carbon Black Anodes in Alkaline Electrolyte: I. Acetylene Black and the Effect of Cobalt Catalyzation. Proc. - Electrochem. Soc. 1984, 84-5, 313-343.

(233) Staud, N.; Sokol, H.; Ross, P. N. The Corrosion of Carbon Black Anodes in Alkaline Electrolyte 
IV . Current Efficiencies for Oxygen Evolution from Metal Oxide-Impregnated Graphitized Furnace Blacks. J. Electrochem. Soc. 1989, 136, 3570-3576.

(234) Davydova, E. S.; Speck, F. D.; Paul, M. T. Y.; Dekel, D. R.; Cherevko, S. Stability Limits of NiBased Hydrogen Oxidation Electrocatalysts for Anion Exchange Membrane Fuel Cells. ACS Catal. 2019, 9, 6837-6845.

(235) Zadick, A.; Dubau, L.; Sergent, N.; Berthomé, G.; Chatenet, M. Huge Instability of Pt/C Catalysts in Alkaline Medium. ACS Catal. 2015, 5, 4819-4824.

(236) Zadick, A.; Dubau, L.; Demirci, U. B.; Chatenet, M. Effects of Pd Nanoparticle Size and Solution Reducer Strength on Pd/C Electrocatalyst Stability in Alkaline Electrolyte. J. Electrochem. Soc. 2016, 163, F781-F787.

(237) Lafforgue, C.; Zadick, A.; Dubau, L.; Maillard, F.; Chatenet, M. Selected Review of the Degradation of Pt and Pd-Based Carbon-Supported Electrocatalysts for Alkaline Fuel Cells: Towards Mechanisms of Degradation. Fuel Cells 2018, 18, 229-238.

(238) Lafforgue, C.; Maillard, F.; Martin, V.; Dubau, L.; Chatenet, M. Degradation of Carbon-Supported Platinum-Group-Metal Electrocatalysts in Alkaline Media Studied by in Situ Fourier Transform Infrared Spectroscopy and Identical-Location Transmission Electron Microscopy. ACS Catal. 2019, 9, 5613-5622.

(239) Lafforgue, C.; Chatenet, M.; Dubau, L.; Dekel, D. R. Accelerated Stress Test of Pt/C Nanoparticles in an Interface with an Anion-Exchange Membrane - An Identical-Location Transmission Electron Microscopy Study. ACS Catal. 2018, 8, 1278-1286.

(240) Soared, D.; Kleinke, M.; Torriani, I.; Teschke, O. Deactivation Mechanism of Nickel Cathodes in Alkaline Media. Int. J. Hydrogen Energy 1994, 19, 573-578.

(241) Chade, D.; Berlouis, L.; Infield, D.; Nielsen, P. T.; Mathiesen, T. Deactivation Mechanisms of 
Atmospheric Plasma Spraying Raney Nickel Electrodes. J. Electrochem. Soc. 2016, 163, F308F317.

(242) Schulze, M.; Gülzow, E. Degradation of Nickel Anodes in Alkaline Fuel Cells. J. Power Sources 2004, 127, 252-263.

(243) Endoh, E.; Otouma, H.; Morimoto, T.; Oda, Y. New Raney Nickel Composite-Coated Electrode for Hydrogen Evolution. Int. J. Hydrogen Energy 1987, 12, 473-479.

(244) Kiros, Y.; Majari, M.; Nissinen, T. A. Effect and Characterization of Dopants to Raney Nickel for Hydrogen Oxidation. J. Alloys Compd. 2003, 360, 279-285.

(245) Korovin, N. V.; Kumenko, M. V.; Kozlova, N. I. Changes in the Properties of Raney Nickel Surface Catalysts during Continuous, Long-Term Cathodic Polarization. Sov. Electrochem. (Engl. Transl.) 1987, 23, 376-379.

(246) Kirk, D. W.; Thorpe, S. J. Nickel Cathode Passivation in Alkaline Water Electrolysis. ECS Trans. 2007, 2, 71-76.

(247) Divisek, J.; Mergel, J.; Schmitz, H. Advanced Water Electrolysis and Catalyst Stability under Discontinuous Operation. Int. J. Hydrogen Energy 1990, 15, 105-114.

(248) Endoh, E.; Otouma, H.; Morimoto, T. Advanced Low Hydrogen Overvoltage Cathode for ChlorAlkali Electrolysis Cells. Int. J. Hydrogen Energy 1988, 13, 207-213.

(249) Marini, S.; Salvi, P.; Nelli, P.; Pesenti, R.; Villa, M.; Kiros, Y. Stable and Inexpensive Electrodes for the Hydrogen Evolution Reaction. Int. J. Hydrogen Energy 2013, 38, 11484-11495.

(250) Yoshida, N.; Yoshitake, M.; Endoh, E.; Morimoto, T. Development of Highly Durable Low Hydrogen Overvoltage Cathode in Chlor-Alkali Cells. Int. J. Hydrogen Energy 1989, 14, 137-140.

(251) Yoshida, N.; Morimoto, T. A New Low Hydrogen Overvoltage Cathode for Chlor-Alkali Electrolysis Cell. Electrochim. Acta 1994, 39, 1733-1737. 
(252) Mauer, A. E.; Kirk, D. W.; Thorpe, S. J. The Role of Iron in the Prevention of Nickel Electrode Deactivation in Alkaline Electrolysis. Electrochim. Acta 2007, 52, 3505-3509.

(253) Abouatallah, R. M.; Kirk, D. W.; Graydon, J. W. Long-Term Electrolytic Hydrogen Permeation in Nickel and the Effect of v Anadium Species Addition. 2002, 47, 2483-2494. 